RICARDO AUGUSTO DIAS

\title{
EMPREGO DE SISTEMAS DE INFORMAÇÃO GEOGRÁFICA (SIG) NO CONTROLE DA RAIVA CANINA
}

Dissertação apresentada para obtenção do título de Mestre, junto à Faculdade de Medicina Veterinária e Zootecnia da Universidade de São Paulo

\section{Departamento:}

Medicina Veterinária Preventiva e Saúde Animal

Área de Concentração:

Epidemiologia Experimental e Aplicada às Zoonoses

Orientador:

Prof. Dr. Fernando Ferreira

São Paulo

2001 
Aos meus pais

e à Natália, fontes de inspiração e alegria. 


\section{AGRADECIMENTOS}

Agradeço à Divisão Técnica de Controle de Zoonoses, da Secretaria Municipal de Saúde da Prefeitura Municipal de Guarulhos pela disponibilidade em auxiliar-nos em trabalhos de pesquisa do nosso Departamento.

Agradeço especialmente às Médicas Veterinárias Adriana Maria Lopes Vieira e Cristina Magnabosco por prestarem auxílio imprescindível ao trabalho.

Agradeço aos funcionários da Divisão Técnica de Controle de Zoonoses (DTCZ), especialmente ao Roberto Cavalheiro, por realizarem as entrevistas domiciliares.

Agradeço à Divisão Técnica do SIGeo, ligado ao Departamento de Planejamento da Secretaria Municipal de Economia e Planejamento da Prefeitura Municipal de Guarulhos, por fornecerem a base cartográfica necessária ao trabalho.

Agradeço aos alunos da Universidade de Guarulhos por auxiliar na aplicação de questionários durante a Campanha de Vacinação Anti-rábica do ano 2000.

Agradeço aos amigos do Curso de Pós-graduação em Epidemiologia Experimental e Aplicada às Zoonoses por sua disposição em ajudar, sempre que necessário.

Agradeço ao Professor Doutor Sílvio Arruda Vasconcellos por orientar-me na fase inicial do trabalho.

Agradeço ao meu irmão, Wagner Dias, por realizar a correção gramatical do trabalho, e por suas idéias e contribuições, sempre tão pertinentes. 


\section{LISTA DE QUADROS}

Quadro 1 - Variáveis do Censo Populacional de 1991 excluídas na primeira abordagem, Guarulhos - 2000

Quadro 2 - Variáveis do Censo Populacional de 1991 selecionadas para a análise de correlações,

Guarulhos - 2000

Quadro 3 - Variáveis do Censo Populacional de 1991 selecionadas para a análise de clusters, Guarulhos

$-2000$ 


\section{LISTA DE TABELAS}

Tabela 1 - Setores censitários típicos, para cada área sócioeconomicamente homogênea, definidas pela análise de clusters, Guarulhos - 2000

Tabela 2 - Definição do tamanho das amostras para cada área homogênea, segundo a população humana presente em 1991, Guarulhos - 2000

Tabela 3 - Quadro-resumo do cálculo do número de setores censitários a ser sorteado em cada área homogênea, Guarulhos - 2000

Tabela 4 - Somatórias dos números de habitantes, cães e gatos por setor censitário amostrado, baseadas nos questionários domiciliares, Guarulhos - 2000

Tabela 5 - Valores médios das populações humana, canina e felina e suas respectivas incertezas, por domicílio, nos setores censitários amostrados, Guarulhos 2000

Tabela 6 - Razões entre a população humana e animal (canina e felina) e suas respectivas incertezas, por setor censitário amostrado, Guarulhos - 2000

Tabela 7 - Razões entre a população humana e a população animal (canina e felina) e suas respectivas incertezas, por área sócio-economicamente homogênea, Guarulhos - 2000 


\section{LISTA DE GRÁFICOS}

Gráfico 1 - Gráfico de dispersão das variáveis selecionadas para a análise de correlações, Guarulhos - 2000

Gráfico 2 - Representação da regressão linear baseada nas razões entre a população humana e população canina, por área sócio-economicamente

homogênea, Guarulhos - 2000 


\section{LISTA DE MAPAS}

Mapa 1 - Mapa georreferenciado do Município de Guarulhos, Guarulhos - 2001

Mapa 2 - Delimitação da Zona Rural do Município de Guarulhos, Guarulhos - 2001

Mapa 3 - Setores censitários do Município de Guarulhos, Guarulhos - 1996 .50

Mapa 4 - Delimitação das áreas homogêneas, Município de Guarulhos, Guarulhos - 2000

Mapa 5 - Setores censitários sorteados para inquérito domiciliar, Guarulhos - 2000 .60

Mapa 6 - Densidade populacional canina no ano de 1991, Guarulhos - 2000

Mapa 7 - Localização dos postos da Campanha de Vacinação Anti-rábica, Guarulhos - 2000

Mapa 8 - Mapa das áreas de influência dos postos da Campanha de Vacinação Anti-rábica, Guarulhos 2000

Mapa 9 - Sobreposição da mancha constituída pelas áreas de influência dos postos da Campanha de Vacinação Anti-rábica ao mapa de densidade populacional canina, Guarulhos - 2000 


\section{LISTA DE SÍMBOLOS E ABREVIATURAS}

CDA: Coordenadoria de Defesa Animal

DIR: Direção Regional de Saúde

DTCZ: Divisão Técnica de Controle de Zoonoses

IBGE: Instituto Brasileiro de Geografia e Estatística

PMG: Prefeitura Municipal de Guarulhos

RMSP: Região Metropolitana de São Paulo

RNA: Ácido Ribonucléico

SIG: Sistema de Informação Geográfica

SPG: Sistema de Posicionamento Global por Satélites 


\section{RESUMO}

DIAS, R. A. Emprego de sistemas de informação geográfica (SIG) no controle da raiva canina. [Use of a geographic information system (GIS) in canine rabies control.]. 2001. 84 f. Dissertação (Mestrado em Epidemiologia Experimental e Aplicada às Zoonoses) - Faculdade de Medicina Veterinária e Zootecnia, Universidade de São Paulo, São Paulo.

Estimou-se o tamanho e a distribuição espacial da população canina domiciliada no Município de Guarulhos, Estado de São Paulo, correlacionando-os com a população humana e composição sócio-econômica. Um Sistema de Informação Geográfica (SIG) foi elaborado para avaliar a localização espacial dos postos da Campanha de Vacinação Anti-rábica Canina em Guarulhos, no ano 2000. A população total de cães, no ano 2000 , foi estimada com base em uma razão entre a população humana e a população canina, de acordo com uma amostra que considerou critérios sócio-econômicos. Observou-se que esta razão não está correlacionada com nível sócio-econômico, podendose considerar um valor único, ou seja, 5,30 (erro padrão de 0,27), para a Zona Urbana do município. Na Zona Rural, estimou-se a razão em 8,16 (erro padrão de 1,13$)$. Foi determinada a densidade populacional canina para os setores censitários, com base na razão entre a população humana e a população canina. Baseado em uma lista de endereços, a localização geográfica dos 160 postos fixos de vacinação foi levantada, pelo uso de um aparelho de localização global por satélite (SPG). Estes pontos foram então plotados em um mapa georreferenciado do município de Guarulhos e suas 'áreas de influência' foram estabelecidas com base em uma distância média de desloca- 
mento dos proprietários até os postos de vacinação. A população canina foi estimada em 193886 no ano 2000. A população felina foi estimada em 44070 no mesmo ano. Confrontando-se estes números com o total de animais vacinados na Campanha de Vacinação Anti-rábica do ano 2000, estimou-se que $61,77 \%$ dos cães domiciliados e $38,31 \%$ dos gatos domiciliados foram atendidos. Observou-se, através de mapas temáticos, que a cobertura espacial dos postos de vacinação é adequada, pois atende as áreas de maior densidade populacional animal. A proporção entre os gêneros da população canina foi estimada em 1,70, ou seja, 1,70 machos para cada fêmea. A mesma proporção, para a população felina, foi estimada em 1,44.

Unitermos: Estimativa de população, Vacina anti-rábica, Sistemas de informação geográfica, Raiva 


\section{SUMMARY}

\section{DIAS, R. A. Use of a geographic information system (GIS) in canine} rabies control. [Emprego de sistemas de informação geográfica (SIG) no controle da raiva canina.]. 2001. 84 f. Dissertação (Mestrado em Epidemiologia Experimental e Aplicada às Zoonoses) - Faculdade de Medicina Veterinária e Zootecnia, Universidade de São Paulo, São Paulo.

The size of supervised dog population and its distribution was estimated in Guarulhos, State of Sao Paulo, and correlated with human population and its socio-economic composition. A Geographic Information System (GIS) was built to evaluate spatial location of posts of anti-rabic vaccination campaign in Guarulhos, in the year 2,000. The total canine population in the year 2,000 was estimated by a human population:dog population ratio, obtained by a socio-economic criteria sampling. This ratio is not correlated with socioeconomic levels, so that it may be considered a single value, or 5.30 (standard error in 0.27), to Guarulhos Urban Area. In Rural Area, this ratio is 8.16 (standard error in 1.13). Canine population density in censitary sectors was determinated based on human population:dog population ratio. Geographic location of 160 vaccination posts was found, based on an address list, by using a global positioning system (GPS) device. Those points were plotted in a map of Guarulhos, and its 'influence areas' were established by a mean walking distance, or the distance that a dog owner was prone to reach a vaccination post. Canine population was estimated in 193,886 for the year of 2,000. Feline population was estimated in 44,070 in the same year. Comparing these numbers with total vaccinated animals (dogs and cats) in Anti-rabic 
Vaccination Campaign of $2000,61.77 \%$ of supervised dogs and $38.31 \%$ of cats were estimated to be attended. Through thematic maps, spatial coverage of vaccination posts was found to be adequate for Guarulhos, because it covers areas of high animal density. The proportion between genders of canine supervised population was estimated in 1.70 , or 1.70 male for each female. The same proportion for feline supervised population, was estimated in 1.44 .

Uniterms: Population estimate, Anti-rabic vaccine, Geographic information systems, Rabies 


\section{SUMÁRIO}

1 INTRODUÇÃO

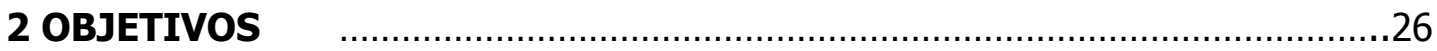

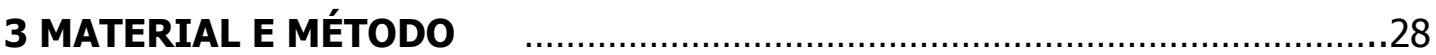

3.1 OBTENÇÃO E SELEÇÃO DAS VARIÁVEIS DE ESTUDO _...............................28

3.2 CONSTRUÇÃO DE MAPAS GEORREFERENCIADOS DO

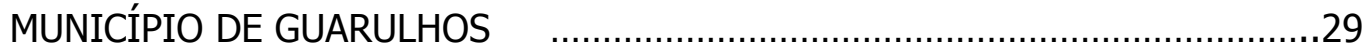

3.3 CATEGORIZAÇÃO SÓCIO-ECONÔMICA DOS SETORES

CENSITÁRIOS DO MUNICÍPIO DE GUARULHOS _.....................................30

3.4 AMOSTRAGEM PROBABILÍSTICA DOS SETORES

CENSITÁRIOS

3.5 DETERMINAÇÃO DA RAZÃO ENTRE A POPULAÇÃO

HUMANA E A POPULAÇÃO ANIMAL (CANINA E FELINA) ……....................35

3.6 DETERMINAÇÃO DA DENSIDADE POPULACIONAL

CANINA NO MUNICÍPIO DE GUARULHOS, EM 1991

3.7 LOCALIZAÇÃO ESPACIAL DOS POSTOS DE VACINAÇÃO

E SUAS RESPECTIVAS ÁREAS DE INFLUÊNCIA 38

3.8 DETERMINAÇÃO DA COBERTURA VACINAL DA CAMPA-

NHA DE VACINAÇÃO ANTI-RÁBICA NO

MUNICÍPIO DE GUARULHOS, NO ANO 2000

3.9 DETERMINAÇÃO DA RAZÃO ENTRE OS GÊNEROS NA

POPULAÇÃO ANIMAL (CANINA E FELINA)

DOMICILIADA

4 RESULTADOS

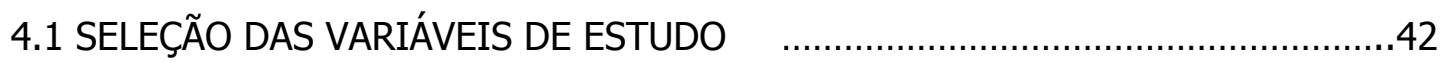

4.2 CONSTRUÇÃO DE MAPAS GEORREFERENCIADOS ……………….............49

4.3 CATEGORIZAÇÃO SÓCIO-ECONÔMICA DOS SETORES

CENSITÁRIOS ATRAVÉS DA ANÁLISE DE CLUSTERS _.................................51

4.4 AMOSTRAGEM PROBABILÍSTICA DOS SETORES

CENSITÁRIOS 
4.5 DETERMINAÇÃO DA RAZÃO ENTRE A POPULAÇÃO

HUMANA E A POPULAÇÃO ANIMAL (CANINA E FELINA)

4.6 CONSTRUÇÃO DO MAPA DE DENSIDADE

POPULACIONAL CANINA

4.7 LOCALIZAÇÃO ESPACIAL DOS POSTOS DE VACINAÇÃO

E DEFINIÇÃO DAS SUAS ÁREAS DE INFLUÊNCIA

4.8 DETERMINAÇÃO DA COBERTURA VACINAL DA CAMPA-

NHA DE VACINAÇÃO ANTI-RÁBICA NO

MUNICÍPIO DE GUARULHOS, NO ANO 2000

4.9 DETERMINAÇÃO DA RAZÃO ENTRE OS GÊNEROS NA POPULAÇÃO ANIMAL (CANINA E FELINA) DOMICILIADA _...........................76

5 DISCUSSÃO . .77

6 CONCLUSÕES .81

7 REFERÊNCIAS 83

ANEXO 1 - Variáveis do Censo Populacional de 1991 85

ANEXO 2 - Matriz de correlação de 38 variáveis selecionadas 90

ANEXO 3 - Área sócio-econômica a que cada setor pertence . .91

ANEXO 4 - Lista de endereços dos postos de vacinação 95 


\section{INTRODUÇÃO}

O vírus rábico é a causa de uma das mais antigas e temidas doenças de humanos e animais, a Raiva-observada no Egito antes de 2300 a. C. e na Antiga Grécia, onde foi bem descrita por Aristóteles (FANG, 1997). A Raiva tem distinção dúbia: é considerada a mais letal de todas as doenças infecciosas; também foi importante por ser a doença que estimulou uma das maiores descobertas biomédicas recentes. Em 1885, antes da natureza do vírus estar totalmente esclarecida, Louis Pasteur desenvolveu, testou e aplicou uma vacina anti-rábica, abrindo assim a era moderna da prevenção de doenças virais pela vacinação.

A Raiva é uma zoonose causada por um vírus RNA, do gênero Lyssavirus (família Rhabdoviridae), que ataca o sistema nervoso de todos os mamíferos, principalmente bovinos, eqüinos, suínos, cães, gatos e morcegos. Os rabdovírus têm aproximadamente 75 X $180 \mathrm{~nm}$ e consistem de um envelope lipídico (bicamada) com glicoproteínas envolvendo um nucleocapsídeo. Este último dá a forma característica de bala ao vírus e contém uma molécula linear única de ácido ribonucléico (RNA) (FENNER, 1993). Em humanos, assim que os sintomas da Raiva se instalam, a doença é $100 \%$ fatal (ACHA e SZYFRES, 1986).

Na América Latina, os cães e os gatos são as principais fontes de infecção para os humanos, devido ao seu convívio próximo ao homem (FANG, 1997). Também é na América Latina onde ocorre a maioria dos casos de rai- 
va humana (FANG, 1997). No Brasil, ocorreram 26 casos de raiva humana no ano 2000. Na região Nordeste, ocorreram 11 casos (ou 42,31\% do total nacional). Na região Sudeste, ocorreram quatro casos no Estado de Minas Gerais. O Estado de São Paulo não registrou nenhum caso da doença em humanos, no ano 2000 (BOLETIM ELETRÔNICO EPIDEMIOLÓGICO, 2001).

A doença possui dois ciclos distintos: um ciclo rural e um ciclo urbano. $\mathrm{Na}$ zona rural, carnívoros silvestres e quirópteros (inclusive os nãohematófagos) são os principais transmissores do vírus da Raiva para os animais domésticos (principalmente bovinos) e para os humanos (ACHA e SZYFRES, 1986).

A doença mantém-se no meio urbano graças à elevada concentração de animais susceptíveis, resultado da densidade e taxa de reprodução dos cães e gatos (GUIDELINES FOR DOG POPULATION MANAGEMENT, 1990).

Em áreas onde se erradicou a Raiva canina, esta pode ser reintroduzida por animais silvestres se a população de cães não é imunizada adequadamente (ACHA e SZYFRES, 1986).

O vírus da Raiva é eliminado na saliva do animal doente, sendo a mordida a principal via de transmissão. Há a possibilidade de arranhões transmitirem o vírus, devido ao fato da limpeza das garras ser realizada pela lambedura (FENNER, 1993). Ao penetrar no organismo, o vírus da Raiva multiplicase nos nervos periféricos e migra em direção ao sistema nervoso central. Com a infecção estabelecida no cérebro, o vírus realiza outra migração em 
direção aos nervos periféricos e multiplica-se em diversos órgãos (FENNER, 1993).

Nos cães, o período de incubação (desde a infecção até o início dos sintomas) é de dez dias a dois meses (ACHA e SZYFRES, 1986). Os cães raivosos manifestam mudança de conduta com aumento da agressividade, excitabilidade reflexa, anorexia, aumento da micção, salivação e hipertermia. Após um a três dias, acentuam-se os sintomas de excitação e agitação. Na fase terminal da doença, pode-se observar convulsões incoordenação muscular e paralisia. Pode também ocorrer o curso paralítico da doença, no qual não se evidencia comportamento agressivo, mas que também é fatal. $\mathrm{O}$ óbito ocorre num período de um a onze dias após o início dos sintomas (ACHA e SZYFRES, 1986).

Em gatos, a maioria dos casos é furioso, com sintomatologia semelhante à dos cães (ACHA e SZYFRES, 1986).

O período de incubação em humanos varia de cinco dias a um ano, com um período médio de dois meses (ACHA e SZYFRES, 1986). Inicialmente, há um período de sintomas inespecíficos que dura dois a dez dias, podendo haver hipertermia, dor de cabeça, indisposição, diminuição de apetite, vômitos, além de dor, coceira e torpor no local da ferida. No próximo estágio, ocorre dificuldade de deglutição por paralisia dos músculos da deglutição. Alguns pacientes tornam-se agitados e desorientados, enquanto outros ficam paralisados. Os doentes podem morrer durante este estágio ou entrar em coma, morrendo de complicações diversas. Durante o curso da doença, as respos- 
tas inflamatória e imune específica são apenas minimamente estimuladas (ACHA e SZYFRES, 1986).

O diagnóstico pós-mortem envolve imunofluorescência direta de impressões de tecido cerebral (medula, cerebelo e hipocampo) do animal suspeito. Não existem técnicas confiáveis de diagnóstico ante-mortem para utilização em animais suspeitos (ACHA e SZYFRES, 1986).

Uma vez iniciada a sintomatologia, não há tratamento efetivo conhecido. Preconiza-se que, ao ser comprovado que o animal agressor é raivoso, inicie-se um tratamento de soro-vacinação para evitar o desenvolvimento da doença (BENENSON, 1987). Entretanto, tanto o soro quanto a vacina não são inócuos e podem produzir acidentes vacinais que eventualmente levam o indivíduo à morte. Sendo assim, a prevenção da Raiva animal é o instrumento mais importante no controle da Raiva humana (FENNER, 1993).

O controle da Raiva animal baseia-se principalmente na vacinação dos animais domésticos sendo esta uma atribuição dos Estados e prefeituras. Anualmente são vacinados cerca de 9.000 .000 de animais no país (SCHNEIDER et al., 1996).

No Brasil, tanto a Raiva humana quanto a canina apresentaram uma queda acentuada entre 1980 e 1990, devido basicamente à implantação do Programa Nacional de Controle da Raiva. Porém a doença começou a ressurgir no início desta década, principalmente na região Nordeste do Brasil (SCHNEIDER et al., 1996). 
O controle da Raiva animal na zona urbana difere do controle da Raiva animal na zona rural. Nesta última, a ação fundamental é o controle da Raiva bovina, que tem os morcegos como fonte de infecção primária. Assim, é preconizada a vacinação do gado e controle da população de morcegos (FENNER, 1993). No Estado de São Paulo, o controle da Raiva na zona rural é atribuído à Coordenadoria de Defesa Animal (CDA).

Na zona urbana, o controle da Raiva humana é feito através do controle da Raiva canina e felina principalmente por meio de vacinação de cães e gatos (na forma de campanhas de vacinação) e controle da população de cães errantes (por meio de apreensão, esterilização e eutanásia), realizados pelas prefeituras municipais.

O município de Guarulhos dispõe de um Serviço de Controle de Zoonoses que, há 12 anos realiza vacinação de cães e gatos, além da apreensão e eutanásia de animais errantes, como forma de controle da Raiva. Há três anos foi associado o controle da natalidade (na forma de campanha). Deste modo, o último caso de Raiva humana ocorreu em 1977 e o de Raiva felina em 1992, sendo que o felino era proveniente de região de periferia, próximo a área de mata, o que destaca a importância de uma ação continuada de vigilância e controle de Raiva animal (PREFEITURA MUNICIPAL DE GUARULHOS, 2000). O Município de Guarulhos pertence à Região Metropolitana de São Paulo, possuindo, no entanto, uma extensa zona rural. Guarulhos é a segunda maior cidade do Estado de São Paulo, com 1071299 habitantes no ano 2000 (IBGE, 2001). 
O risco permanente de reintrodução do vírus no Município de Guarulhos fica demonstrado com a apreensão de morcegos albergando o vírus da Raiva, tanto na zona rural quanto na urbana (PREFEITURA MUNICIPAL DE GUARULHOS, 2000). No ano 2000, diagnosticou-se o virus rábico em equinos, em propriedades da Zona Rural do Município de Guarulhos. Além disso, o Município de Guarulhos faz fronteira com municípios que estão enfrentando uma epidemia de raiva de herbívoros, tais como Santa Isabel, Arujá e Itaquaquecetuba (PREFEITURA MUNICIPAL DE GUARULHOS, 2000).

Até o ano de 2000, o Serviço de Controle de Zoonoses do Município de Guarulhos dimensionava as campanhas de vacinação anti-rábica com base em uma população canina estimada segundo uma recomendação do Instituto Pasteur de São Paulo, que sugere como primeira aproximação, uma proporção entre a população canina e humana de 1:7 (ou seja, 1 cão para 7 humanos), nos municípios da Direção Regional de Saúde III (DIR-III), da qual Guarulhos faz parte (INSTITUTO PASTEUR, 1999).

Entretanto, o cálculo da cobertura vacinal realizado com base no número de animais vacinados e nessa estimativa de população resultava em coberturas maiores que $100 \%$, indicando a imprecisão da estimativa do denominador. A imprecisão compromete a avaliação dos resultados da campanha de vacinação e do programa de controle da Raiva animal.

Essa situação evidencia a necessidade de se produzir novos indicadores para a população animal, que devem ser produzidos de modo a considerar- 
se a estrutura sócio-econômica das regiões o que permitiria a sua aplicação a regiões semelhantes de maneira mais segura.

Conhecer as condições de vida e saúde dos diversos grupos populacionais é uma etapa indispensável do processo de planejamento da oferta de serviços e da avaliação do impacto das ações de saúde. Além disso, o enfoque epidemiológico atende o compromisso de integralidade da atenção, ao incorporar, como objeto das ações, a pessoa, o ambiente e os comportamentos interpessoais. Entretanto, Saúde Pública e ambiente são influenciados pelos padrões de ocupação do espaço: não basta descrever as características da população, mas é necessário localizar o mais precisamente possível onde estão os agravos, que serviços a população necessita e os locais de risco potencial. Planejamento, monitoramento e avaliação de programas, estudos sócio-econômicos, vigilância em saúde e todas as ações essenciais à reorientação de intervenções do setor saúde são beneficiadas por uma visão que incorpore a distribuição espacial.

\section{Sistemas de Informação Geográfica}

A avaliação das campanhas de vacinação precisa considerar a heterogeneidade espacial que se traduz em concentrações animais variáveis nas diferentes regiões do município. Assim há necessidade de se empregar uma tecnologia que permita incluir variáveis espaciais. 
A distribuição das doenças pode ser mapeada e analisada usando-se Sistemas de Informação Geográfica (SIG). Estes sistemas computadorizados podem ser usados para coleta, estocagem, administração, interrogação e exibição de dados espaciais. Eles possuem mais funções que o simples mapeamento; incluem análises gráficas baseadas em localização espacial, análises estatísticas e modelagem (DEMERS, 1997).

Os dados a serem incluídos nesses sistemas devem ser cartográficos, possuindo a localização dos componentes, além de seus atributos textuais, descrevendo suas características.

O Sistema de Informação Geográfica estoca estes dados geograficamente referenciados em banco de dados, de forma que possam ser graficamente consultados e sumarizados.

A habilidade dos SIG em ligar dados gráficos e não-gráficos facilita análises de distribuição espacial de doenças e fatores relacionados.

O Sistema de Informação Geográfica (SIG) é um sistema que emprega informações referenciadas a coordenadas espaciais ou geográficas, ou seja, trata-se de um banco de dados com capacidades específicas para referenciar informações espaciais (DEMERS, 1997).

O Mapa 1 mostra os 47 bairros do Município de Guarulhos, de forma georreferenciada. 
Mapa 1 - Mapa georreferenciado do Município de Guarulhos, GuaruIhos - 2001

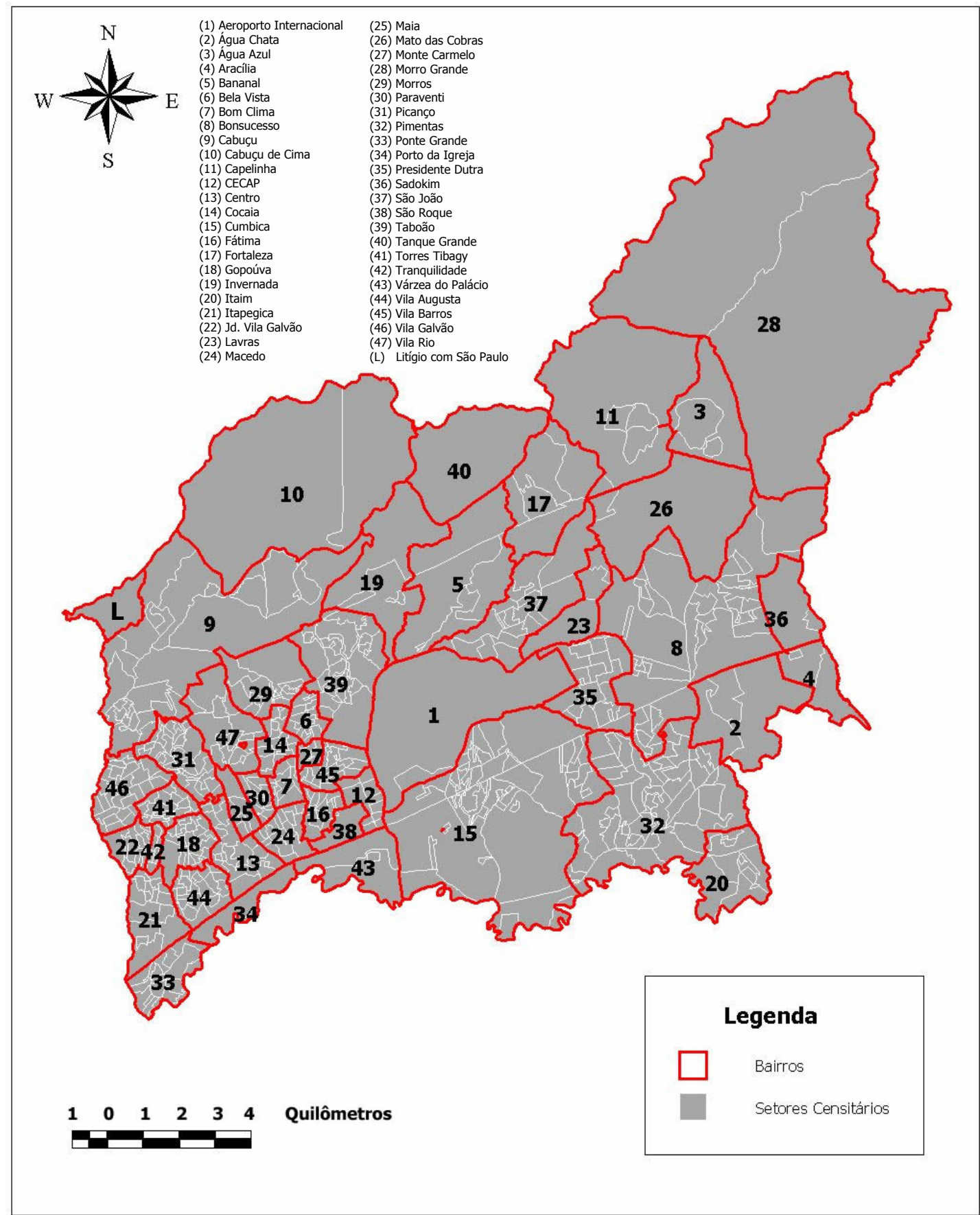

O Município de Guarulhos 
O Município de Guarulhos localiza-se no norte da Região Metropolitana de São Paulo (RMSP), fazendo divisa com os municípios de Mairiporã, Nazaré Paulista e Santa Isabel ao norte, Arujá e Itaquaquecetuba a leste e São Paulo ao sul e a oeste. O Município possui uma área de $341 \mathrm{~km}^{2}$, sendo $174 \mathrm{~km}^{2}$ correspondentes à Zona Urbana e $146 \mathrm{~km}^{2}$ correspondentes à Zona Rural (IBGE, 2001) (Mapa 2). Os restantes $21 \mathrm{~km}^{2}$ correspondem à área ocupada pelo Aeroporto Internacional de Cumbica. Guarulhos encontra-se a uma altitude média de 759 metros acima do nível do mar (IBGE, 2001).

A sede do município localiza-se à latitude de -23,46278 graus e longitude de $-46,53333$ (IBGE, 2001).

A população humana cresceu rapidamente na última década, passando de 778028 habitantes em 1991 para 1071029 em 2000 (IBGE,2001). A densidade demográfica é 3141,64 habitantes por $\mathrm{km}^{2}$. Isto é fruto da privilegiada localização do município, próximo à capital, sendo cortado por importantes rodovias federais e estaduais (Dutra, Fernão Dias e Ayrton Senna) e por sediar o Aeroporto Internacional. Apesar deste forte desenvolvimento econômico, foram agravados os problemas sociais, principalmente pela constante imigração de pessoas atraídas pelas oportunidades de trabalho.

Face a este panorama, visa-se estimar a população animal domiciliada e avaliar o serviço de controle de zoonoses no Município de Guarulhos, baseando-se em critérios científicos.

\footnotetext{
Mapa 2 - Delimitação da Zona Rural do Município de Guarulhos, Guarulhos - 2001
} 


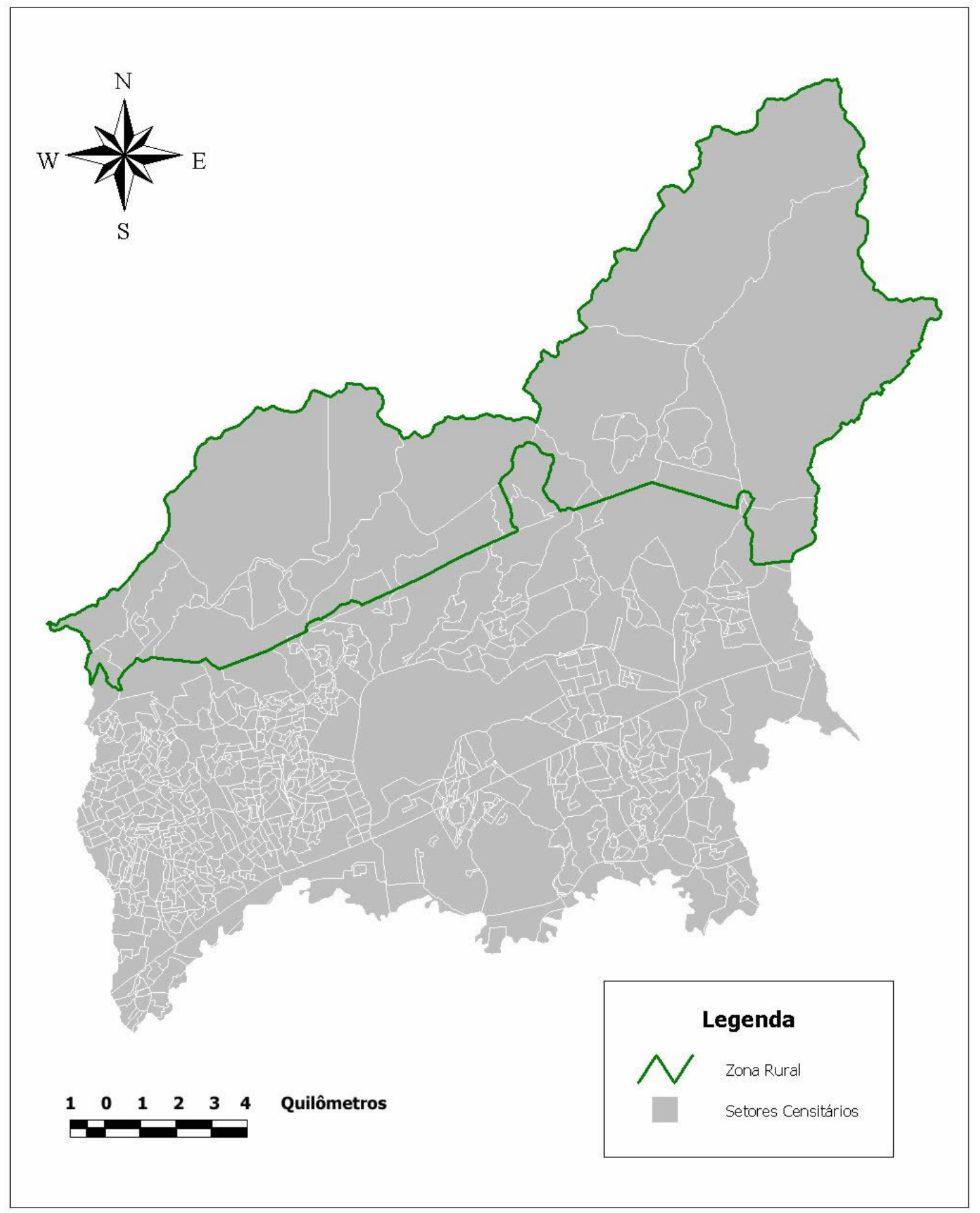




\section{OBJETIVOS}

(a) Objetivo geral:

Estimar o tamanho e a distribuição espacial da população canina domiciliada no Município de Guarulhos, correlacionando-a com o tamanho da população humana e sua composição sócio-econômica.

(b) Objetivos específicos:

Construir mapas georreferenciados do Município de Guarulhos, incluindo divisão por setor censitário.

Selecionar variáveis sócio-econômicas importantes para o trabalho.

Categorizar os setores censitários do Município de Guarulhos através de análise de clusters, com base nas variáveis de estudo selecionadas.

Determinar a razão entre a população humana e a população animal domiciliada (canina e felina).

Estimar o tamanho da população canina domiciliada no Município de Guarulhos, no ano 2000.

Correlacionar nível sócio-econômico com a razão entre a população humana e a população animal domiciliada (canina e felina).

Determinar a razão entre os gêneros na população animal (canina e felina) domiciliada. 
Estimar a cobertura vacinal e avaliar a distribuição espacial dos postos de vacinação anti-rábica durante a Campanha de Vacinação Anti-rábica, no ano 2000. 


\section{MATERIAL E MÉTODO}

\subsection{Obtenção e seleção das variáveis de estudo}

As variáveis sócio-econômicas do Município de Guarulhos, SP, foram obtidas junto ao Instituto Brasileiro de Geografia e Estatística (IBGE). Esta base de dados, referente ao Censo Populacional de 1991, é disponibilizada por setores censitários, que são as unidades mínimas de georreferenciamento. O Município de Guarulhos possuía, em 1991, 662 setores censitários. Foram utilizados os dados censitários de 1991, pois, o IBGE estima que os dados censitários de 2000 só estarão totalmente disponibilizados em março de 2003 (IBGE, 2001).

Buscou-se reduzir o número de variáveis existentes no Censo Populacional de 1991. Derivações de variáveis-chave foram descartadas. Assim, por exemplo, as seguintes variáveis: 'abastecimento de água com canalização interna - rede geral', 'abastecimento de água com canalização interna - poço/nascente', 'abastecimento de água com canalização interna - outra forma', derivadas da variável-chave 'abastecimento de água com canalização interna', foram excluídas do estudo.

Todas estas derivações foram excluídas do estudo, de modo a diminuir o tamanho do banco de dados original e por não serem essenciais ao estudo.

Foi realizada a recategorização dos estratos das variáveis quantitativas contínuas, a fim de diminuir o número de categorias das mesmas. 
Além disso, foi construída uma matriz de correlação com as variáveis remanescentes. Se um par de variáveis foi altamente correlacionado, uma delas foi eliminada.

Esta análise foi realizada com o auxílio do programa de computador SPSS 9.0 (SPSS Inc., 1999).

Esse tratamento inicial teve por objetivo reduzir o número de variáveis a serem incluídas na análise de clusters.

\subsection{Construção de mapas georreferenciados do Município de Guarulhos}

Os Sistemas de Informação Geográfica são programas de computador especializados que utilizam uma base cartográfica digitalizada e georreferenciada, sobre a qual é adicionada uma base textual (não-cartográfica), que descreve os componentes da primeira (DEMERS, 1997).

Foram construídos mapas digitalizados, com base em mapas fornecidos pelo Instituto Brasileiro de Geografia e Estatística (IBGE) e pela Prefeitura Municipal de Guarulhos. A Prefeitura de Guarulhos dispõe de uma base de mapas digitalizados, em plataforma $C A D$, que foram convertidos no programas de computador ArcView GIS versão 3.1 (ESRI Inc., 1996). 
Inicialmente foram localizados os setores censitários do Município de Guarulhos nos mapas digitalizados. Estes mapas foram utilizados como base para a construção de novos mapas temáticos, nos quais foram incluídos:

(a) a classificação dos setores censitários, segundo a área sócioeconomicamente homogênea a que pertencem;

(b) a estimativa da densidade populacional canina, por setor censitário, no ano de 1991;

(c) a estimativa da área geográfica coberta pela Campanha de Vacinação Anti-rábica do Município de Guarulhos, no ano 2000.

\subsection{Categorização sócio-econômica dos setores censitários do Município de Guarulhos}

As variáveis selecionadas na etapa anterior foram submetidas à análise de clusters, com o objetivo de agrupar os setores censitários do Município de Guarulhos em cinco categorias sócio-econômicas diferentes.

O objetivo principal desta análise é descobrir os 'agrupamentos naturais', se houver, dos elementos amostrais com base em um subconjunto de seus atributos. Assim, o pacote estatístico pôde, com base nas variáveis préselecionadas, criar subconjuntos de setores censitários disjuntos, mutuamente exclusivos, os quais são, internamente, o mais homogêneos possível, maximizando a diferença entre os subconjuntos. Cada subconjunto de setores 
(área sócio-economicamente homogênea) é chamado de partição ou cluster (CHATFIELD e COLLINS, 1980).

No entanto, devido às suas características, a análise de clusters não tem a capacidade de identificar a melhor ou a pior área sócio-econômica. Porém, como resultado da análise, foi fornecido um setor censitário típico (médio) para cada área homogênea, o que possibilitou a comparação individual das variáveis utilizadas na análise. Assim, foi possível obter elementos para inferir sobre a classificação das áreas homogêneas.

Para a realização da análise de clusters, utilizou-se o pacote estatístico SPSS versão 9.0 (SPSS Inc., 1999). O algoritmo utilizado na análise de clusters foi a média $K$, uma vez que esta é a escolha desejável quando se trabaIha com numerosas ocorrências (setores censitários), a fim de definir $k$ grupos homogêneos baseados em suas características (SPSS 9.0 USER'S GUIDE, 1999).

Os parâmetros fornecidos ao programa foram: algoritmo da análise de clusters pela média $k$ e o número de cluster desejado, que foi estabelecido em cinco, ou seja, cinco áreas sócio-economicamente homogêneas. Foi utilizado um banco de dados contendo somente as variáveis escolhidas após a análise de correlações.

O objetivo da categorização dos setores censitários em cinco áreas homogêneas foi verificar a existência de correlação entre nível sócio-econômico e densidade populacional animal (canina e felina), como será descrito adiante. 


\subsection{Amostragem probabilística dos setores censitários}

Foi realizada uma amostragem dos setores censitários a fim de estimar a razão entre a população animal (canina e felina) e a população humana.

Desse modo, para cada área homogênea, foi construída uma amostra de setores censitários, para a aplicação de um questionário domiciliar, contendo as seguintes questões:

(a) número de habitantes;

(b) número de cães domiciliados (e respectivos gêneros);

(c) número de gatos domiciliados (e respectivos gêneros).

O número de entrevistas domiciliares foi fixado, por questão operacional e de custos, em 3000, e foram realizadas pela Divisão Técnica de Controle de Zoonoses (DTCZ) da Prefeitura Municipal de Guarulhos (PMG).

Estas 3000 entrevistas foram divididas entre as áreas homogêneas (clusters) de acordo com a proporção da população humana existente em cada uma delas, no ano de 1991. Assim, com o número total da amostra fixado, foi realizada a amostragem de setores censitários em dois estágios ( $\mathrm{T}$ HRUSFIELD, 1995).

Este tipo de amostragem indicou o número de setores censitários e o número de domicílios que foram entrevistados nestes setores, de acordo com o nível de confiança escolhido e o tamanho da amostra.

A fórmula utilizada para o cálculo do número de setores censitários amostrados, com confiança de 95\%, definida por THRUSFIELD (1995), foi: 


$$
g=\frac{1,96^{2} T_{a} V_{c}}{d^{2} T_{a}-1,96^{2} R_{\text {esp }}\left(1-R_{\text {esp }}\right)}
$$

onde:

$g$ = número de setores censitários amostrados;

$R_{\text {esp }}=$ razão esperada;

$d=$ precisão absoluta desejada;

$T_{a}=$ número total de domicílios a serem amostrados;

$V_{c}=$ variância entre setores.

A Equação 1 é utilizada para uma população grande de setores censitários, quando comparada ao tamanho da amostra. Assim, esta foi ajustada, para população pequena de setores censitários, se comparada ao tamanho da amostra, como mostra a Equação 2, definida por THRUSFIELD (1995):

$$
g_{\text {ajust }}=\frac{G g}{(G+g)}
$$

onde:

$g_{a j u s t}=$ número de setores censitários amostrado para população de setores pequena, se comparada ao número de amostras;

$G=$ total de setores na área homogênea;

$g=$ número de setores inicialmente amostrados. 
Os parâmetros utilizados na Equação 1 foram:

(a) Razão esperada $\left(R_{\text {esp }}\right)$ fixada em 0,1428571 , correspondente à relação entre a população canina e a população humana de 1:7, estabelecida pelo Instituto Pasteur, para o Município de Guarulhos (INSTITUTO PASTEUR, 1999);

(b) Precisão absoluta (d) fixada em 7\%;

(c) Variância entre os setores censitários (clusters) $\left(V_{c}\right)$ fixada em $5 \%$, pois não foi possível realizar um projeto-piloto.

Após a definição do número de setores a serem amostrados em cada área homogênea, foi realizado um sorteio aleatório dos mesmos.

A escolha dos domicílios a serem amostrados, em cada setor censitário, foi feita de forma sistemática, de modo a determinar em que intervalo os domicílios seriam entrevistados. Por exemplo, em um setor censitário com 50 domicílios, onde deveriam ser entrevistados 10, foi entrevistado um domicílio a cada cinco. 


\subsection{Determinação da razão entre a população humana e a po- pulação animal (canina e felina)}

A aplicação dos questionários a campo contou com o apoio operacional da Prefeitura Municipal de Guarulhos. Esta atividade forneceu dados para a determinação das razões homem:cão e homem:gato. A partir dos resultados da aplicação dos questionários domiciliares, determinou-se a média de humanos, cães e gatos por domicílio, nos setores censitários amostrados. Foi calculada a razão entre as médias de humanos e animais (cães e gatos), para cada setor censitário. Posteriormente, estes valores foram utilizados no cálculo das razões para as áreas homogêneas e, finalmente, para o Município de Guarulhos.

Em cada etapa do cálculo da razão entre a população humana e a população animal (canina e felina), foi calculada sua respectiva incerteza (erro padrão) (BEVINGTON, 1969).

Essas incertezas foram propagadas desde o cálculo da média de humanos, cães e gatos, por domicílios, até o cálculo da razão entre a população humana e animal (canina e felina) para o município de Guarulhos.

As fórmulas de propagação de erros utilizadas foram:

(a) Erro padrão associado à razão entre a população humana e animal por setor censitário: 


$$
\sigma=\sqrt{R^{2}\left[\left(\frac{\sigma_{x c}}{x_{c}}\right)^{2}+\left(\frac{\sigma_{x h}}{x_{h}}\right)^{2}\right]}
$$

onde:

$$
\begin{aligned}
& \sigma=\text { erro padrão associado à razão } R ; \\
& R=\text { razão entre a população humana e animal por setor censitário; } \\
& \sigma_{X C}=\text { erro padrão da média de cães por domicílio, por setor censitário; } \\
& x_{C}=\text { média de cães por domicílio, por setor censitário; } \\
& \sigma_{x h}=\text { erro padrão da média de pessoas por domicílio, por setor censitá- }
\end{aligned}
$$

rio;

$x_{h}=$ média de pessoas por domicílio, por setor censitário.

(b) Erro padrão associado à razão entre a população humana e animal por área homogênea:

$$
\sigma=\frac{\sqrt{\sum \sigma_{i}^{2}}}{n}
$$

onde:

$\sigma=$ erro padrão associado à razão entre a população humana e animal por área homogênea;

$\sigma_{i}=$ erro padrão associado à razão entre a população humana e animal por setor censitário sorteado na área homogênea.

$n=$ número de setores censitários sorteados na área homogênea. 
Após esta fase, foi feita uma análise de regressão linear ajustada para incertezas diferentes, para verificar se existia correlação entre nível sócio econômico com a razão entre a população humana e a população canina domiciliada (variável dependente ou de interesse), com base nos valores definidos por área homogênea (BEVINGTON, 1969).

O objetivo desta etapa foi definir elementos para a adequação mais precisa dos serviços de controle de zoonoses dentro do município, de acordo com metodologias científicas, através da melhoria da estimativa da população animal domiciliada, possibilitando ainda a avaliação destes serviços.

\subsection{Determinação da densidade populacional canina no Muni- cípio de Guarulhos, em 1991}

Com base no mapa georreferenciado dos setores censitários do Município de Guarulhos,.foi construído um mapa temático mostrando a densidade populacional canina. Utilizou-se dados da população humana de 1991, pois os dados do Censo Populacional de 2000, por setor censitário, só estarão disponíveis em 2003 (IBGE, 2001). Para isso, definiu-se a população canina por setor censitário, dividindo-se a população humana de 1991 pela razão entre a população humana e a população canina definida anteriormente. Este valor foi dividido pela área de cada setor censitário, com o auxílio do programa de computador ArcView GIS versão 3.1 (ESRI Inc., 1996). 


\subsection{Localização espacial dos postos de vacinação e suas res- pectivas áreas de influência}

A localização espacial dos 160 postos de vacinação da Campanha de Vacinação Anti-rábica do ano 2000 foi feita através do levantamento das suas coordenadas geográficas através de aparelho de Sistema de Posicionamento Global (GPS).

Posteriormente, estas coordenadas foram plotadas nos mapas georreferenciados digitalizados. Para cada posto, foi estabelecida uma área em torno do mesmo, definida como área de influência (buffer), com base na determinação da distância média de deslocamento dos proprietários de animais até um posto de vacinação.

Esta distância foi definida a partir da aplicação de um segundo questionário, onde foi perguntado o endereço dos proprietários de cães que levaram seus animais aos postos de vacinação, durante a Campanha de Vacinação Anti-rábica de 2000.

O número de proprietários entrevistados por posto de vacinação foi definido pela fórmula, segundo COCHRAN (1977):

$$
n_{0}=\left[\frac{t S}{r \bar{y}}\right]^{2}
$$

onde: 
$n_{0}=$ número de proprietários entrevistados por posto de vacinação;

$t=$ probabilidade de $5 \%$, com graus de liberdade infinitos;

$S=$ desvio-padrão;

$r=$ erro relativo, estabelecido em $10 \%$;

$y=$ média de animais vacinados por posto, no ano de 1999.

Como $\mathrm{n}_{0} / \mathrm{N}$ é considerável, o valor ajustado para $\mathrm{n}_{0}$, definido por COCHRAN (1977), é:

$$
n_{\text {ajust }}=\frac{n_{0}}{\left[1+\left(\frac{n_{0}}{N}\right)\right]}
$$

onde:

$n_{\text {ajust }}=$ número de proprietários entrevistados por posto de vacinação (ajustado);

$N=$ animais vacinados por posto, no ano de 1999.

Os endereços foram plotados em mapas georreferenciados e foi calculada a distância média percorrida pelos proprietários, por posto de vacinação, definindo uma área de influência para cada um deles.

Posteriormente, as áreas de influência (buffers) de cada posto de vacinação foram plotadas nos mapas georreferenciados, de acordo com a definição da distância média de deslocamento. 
Nesta etapa do trabalho foi utilizado o programa de computador ArcView GIS versão 3.1 (ESRI Inc., 1996), na plotagem das coordenadas dos postos de vacinação e definição das áreas de influência (buffers) dos mesmos, nos mapas georreferenciados previamente elaborados. Nesta fase, não foi incluída a população felina.

\subsection{Determinação da cobertura vacinal da Campanha de Vaci- nação Anti-rábica no Município de Guarulhos, no ano 2000}

Dentre os resultados preliminares do Censo Populacional de 2000, o IBGE disponibilizou o total da população humana para o Município de GuaruIhos. Com base neste valor, 10712999 habitantes, foi possível estimar a população animal (canina e felina) com base nas razões entre a população humana e a população animal (canina e felina).

Estes valores foram confrontados com os totais de animais vacinados na Campanha de Vacinação do ano 2000, obtendo-se a cobertura vacinal.

Buscou-se também verificar a cobertura espacial dos postos de vacinação, sobrepondo-se o mapa da mancha constituída pelas 'áreas de influência' dos postos ao mapa de densidade populacional canina. 
3.9 Determinação da razão entre os gêneros na população animal (canina e felina) domiciliada

Durante a fase de aplicação dos 3000 questionários domiciliares, foi perguntado o gênero (macho ou fêmea) dos animais.

Isso permitiu estabelecer uma razão entre a população de machos e a população de fêmeas. O objetivo desta fase é fornecer subsídios para planejamento de medidas de controle populacional. 


\section{RESULTADOS}

\subsection{Seleção das variáveis de estudo}

Dentre as 292 variáveis constituintes do Censo Populacional de 1991, no Município de Guarulhos, 202 (69,18\%) foram excluídas do estudo numa primeira abordagem das variáveis. Outras 60 (20,55\%) variáveis tiveram o número de estratos reduzido; destas, foram criadas oito novas variáveis. Um total de 30 variáveis $(12,33 \%)$ foi utilizado na próxima fase do trabalho.

A principal característica que motivou a exclusão das variáveis em uma primeira abordagem, foi a existência de derivações de algumas variáveischave, em variáveis descritivas das primeiras, o que causou o aumento do número de variáveis no banco de dados original. Assim, por exemplo, a variável 'abastecimento de água com canalização interna' derivou as seguintes variáveis: 'abastecimento de água com canalização interna - rede geral', 'abastecimento de água com canalização interna - poço/nascente', 'abastecimento de água com canalização interna - outra forma'. Derivações como estas foram excluídas do estudo. A lista das variáveis do Censo Populacional de 1991 é apresentada no Anexo 1.

Ainda na primeira abordagem das variáveis, constatou-se que algumas variáveis eram complementares a outras, sendo uma delas excluída antes da próxima fase do trabalho, a análise de correlações. 
Assim, por exemplo, com relação às variáveis 'abastecimento de água com canalização interna' e 'abastecimento de água sem canalização interna', optou-se em excluir a segunda variável.

Também, as variáveis quantitativas que possuíam diversos estratos foram reagrupadas, de modo a apresentarem um número reduzido de estratos.

Por exemplo, os 17 estratos de faixas etárias (divididos de cinco em cinco anos) foram reagrupados em, somente, três novos estratos: 0 a 14 anos, 15 a 49 anos e mais de 50 anos.

O Quadro 1 lista as variáveis excluídas na primeira abordagem e as variáveis criadas pelos reagrupamentos.

O banco de dados com as variáveis do Censo Populacional de 1991 foi adquirido junto ao Instituto Brasileiro de Geografia e Estatística, na forma de tabelas (arquivos no formato .dbf), gravadas em discos flexíveis. Estes arquivos foram processados no pacote estatístico SPSS versão 9.0 (SPSS Inc., 1999). 


\section{Quadro 1 - Variáveis do Censo Populacional de 1991 excluídas na primeira abordagem, Guarulhos - 2000}

\begin{tabular}{|c|c|}
\hline $\begin{array}{l}\text { CÓDIGO DA } \\
\text { VARIÁVEL }^{1}\end{array}$ & NOME DA VARIÁVEL \\
\hline 1 a 7 & Códigos da UF, Município, Distrito, Subdistrito, Setor, Situação e Tipo \\
\hline 8 & Total de Domicílios \\
\hline 11 & Total de Casas Isoladas/Condomínio \\
\hline 12 & Total de Casas em Conjunto Residencial Popular \\
\hline 13 & Total de Casas em Aglomerado Subnormal \\
\hline 15 & Total de Apartamentos Isolados/Condomínio \\
\hline 16 & Total de Apartamentos em Conjunto Residencial Popular \\
\hline 17 & Total de Apartamentos em Aglomerado Subnormal \\
\hline 20 a 22 & Estratos da Variável Abastecimento de Água com Canalização Interna \\
\hline 23 a 26 & Abastecimento de Água sem Canalização Interna e seus Estratos \\
\hline 28 a 35 & Estratos da Variável Instalação Sanitária só Domicílio \\
\hline 37 e 44 & Estratos da Variável Instalação Sanitária Comum \\
\hline 47 e 48 & Estratos da Variável Condição de Ocupação - Próprio \\
\hline 51 e 52 & Estratos da Variável Condição de Ocupação - Cedido \\
\hline 53 & Condição de Ocupação - Outra \\
\hline 55 e 56 & Estratos da Variável Lixo Coletado \\
\hline 57 a 59 & Lixo Queimado, Enterrado e Jogado \\
\hline 60 e 61 & Estratos da Variável Lixo Jogado \\
\hline 62 & Lixo - Outro Destino \\
\hline 63 a 66 & $\begin{array}{l}\text { Números Médios de Cômodos, Dormitórios, Banheiros e Pessoas por Domi- } \\
\text { cílio }\end{array}$ \\
\hline 70 & Mulheres em Domicílios Particulares Permanentes \\
\hline 73 & Mulheres em Domicílios Particulares Improvisados \\
\hline 74 & Total de Chefes em Domicílios Particulares Permanentes \\
\hline 77 a 80 & Estratos da Variável Anos de Estudo² \\
\hline 81 a 89 & Estratos da Variável Rendimento (em salários mínimos)² \\
\hline 91 & Sem Declaração de Renda \\
\hline 92 e 93 & $\begin{array}{l}\text { Rendas Médias Nominais dos Chefes e por Unidade Habitacional em Domi- } \\
\text { ćlio Coletivo }\end{array}$ \\
\hline 94 & População Total \\
\hline 96 a 129 & Faixas Etárias e Totais de Alfabetizados ${ }^{3}$ \\
\hline 130 e 131 & População Residente Homens - Total e Alfabetizados \\
\hline 132 a 165 & Faixas Etárias e Totais de Alfabetizados (Homens) \\
\hline 166 e 167 & População Residente Mulheres - Total e Alfabetizadas \\
\hline 168 a 201 & Faixas Etárias e Totais de Alfabetizados (Mulheres) \\
\hline 202 e 203 & População no Domicílio - Total e Alfabetizada \\
\hline
\end{tabular}




\section{Quadro 1 - Variáveis do Censo Populacional de 1991 excluídas na primeira abordagem, Guarulhos, 2000}

\begin{tabular}{|c|c|}
\hline $\begin{array}{l}\text { CÓDIGO DA } \\
\text { VARIÁVEL }^{1}\end{array}$ & NOME DA VARIÁVEL \\
\hline 205,207 e 209 & $\begin{array}{l}\text { Total de Chefes Alfabetizados, Cônjuges Alfabetizados e Filhos Alfabetiza- } \\
\text { dos }\end{array}$ \\
\hline 211 a 215 & $\begin{array}{l}\text { Total de Agregados Alfabetizados, Outros Parentes, Outros Parentes Alfabe- } \\
\text { tizados, Pensionistas e Pensionistas Alfabetizados }\end{array}$ \\
\hline 217 a 221 & $\begin{array}{l}\text { Total de Empregados Domésticos Alfabetizados, Parentes do Empregado } \\
\text { Doméstico, Parentes do Empregado Doméstico Alfabetizados, Homens no } \\
\text { Domicílio, Homens no Domićlio Alfabetizados }\end{array}$ \\
\hline 224 a 240 & $\begin{array}{l}\text { Total de Homens Cônjuges, Homens Cônjuges Alfabetizados, Homens Fi- } \\
\text { Ihos, Homens Filhos Alfabetizados, Homens Agregados, Homens Agregados } \\
\text { Alfabetizados, Homens Outros Parentes, Homens Outros Parentes Alfabeti- } \\
\text { zados, Homens Pensionistas, Homens Pensionistas Alfabetizados, Homens } \\
\text { Empregados Domésticos, Homens Empregados Domésticos Alfabetizados, } \\
\text { Homens Parentes do Empregado Doméstico, Homens Parentes do Empre- } \\
\text { gado Doméstico Alfabetizados, Mulheres no Domicílio, Mulheres no Domicí- } \\
\text { lio Alfabetizadas }\end{array}$ \\
\hline 242 a 255 & $\begin{array}{l}\text { Total de Mulheres Cônjuges, Mulheres Cônjuges Alfabetizadas, Mulheres } \\
\text { Filhas, Mulheres Filhas Alfabetizadas, Mulheres Agregadas, Mulheres Agre- } \\
\text { gadas Alfabetizadas, Mulheres Outras Parentes, Mulheres Outras Parentes } \\
\text { Alfabetizadas, Mulheres Pensionistas, Mulheres Pensionistas Alfabetizadas, } \\
\text { Mulheres Empregadas Domésticas, Mulheres Empregadas Domésticas Alfa- } \\
\text { betizadas, Mulheres Parentes do Empregado Doméstico, Mulheres Parentes } \\
\text { do Empregado Doméstico Alfabetizadas }\end{array}$ \\
\hline 256 & Número de Domicílios \\
\hline 257 a 266 & Estratos do Número de Moradores por Domicílio ${ }^{2}$ \\
\hline 267 & Número de Domicílios Particulares \\
\hline 268 a 277 & Estratos do Número de Moradores por Domicílio Particular ${ }^{2}$ \\
\hline 279 a 288 & Estratos do Número de Moradores por Domicílio Coletivo \\
\hline 289 a 292 & Nomes do Município, Distrito, Sub-distrito e Fim do Registro \\
\hline
\end{tabular}

${ }^{1}$ Código do IBGE.

${ }^{2}$ Variáveis reagrupadas.

${ }^{3}$ Faixas Etárias foram reagrupadas e Totais de Alfabetizados, excluídos. 
A fase seguinte da seleção das variáveis foi a construção de uma matriz de correlação com as 30 variáveis remanescentes da primeira abordagem (Quadro 2), além de oito variáveis originadas pelos reagrupamentos dos estratos das variáveis contínuas, totalizando 38 variáveis.

Alguns setores censitários (35, 36, 37, 78, 79, 183, 198, 299, 308, 362, 380, 406, 407, 425, 434, 442, 447, 454, 458, 459, 466 e 475 no Distrito de Guarulhos; 105, 108, 129, 130, 131 e 139 no Distrito Jardim Presidente Dutra) não apresentavam população fixa, e não foram incluídos no trabalho.

Foi construído um novo banco de dados, contendo somente as 30 variáveis do Censo Populacional de 1991, remanescentes da primeira abordagem, além das oito variáveis originadas dos reagrupamentos, referentes a 634 dos 662 setores censitários do Município de Guarulhos, em 1991. Através do pacote estatístico SPSS versão 9.0 (SPSS Inc., 1999), foi construída uma matriz de correlação com as variáveis do novo banco de dados.

A matriz de ordem $38 \times 38$ possibilitou, através do coeficiente de correlação de Pearson, verificar quais as variáveis que possuíam correlação elevada. Através da observação do gráfico de dispersão (Gráfico 1), foram excluídas as variáveis correlacionadas. O Anexo 2 mostra a matriz de correlação das 38 variáveis selecionadas. 


\section{Quadro 2 - Variáveis do Censo Populacional de 1991 selecionadas para a análise de correlações, Guarulhos - 2000}

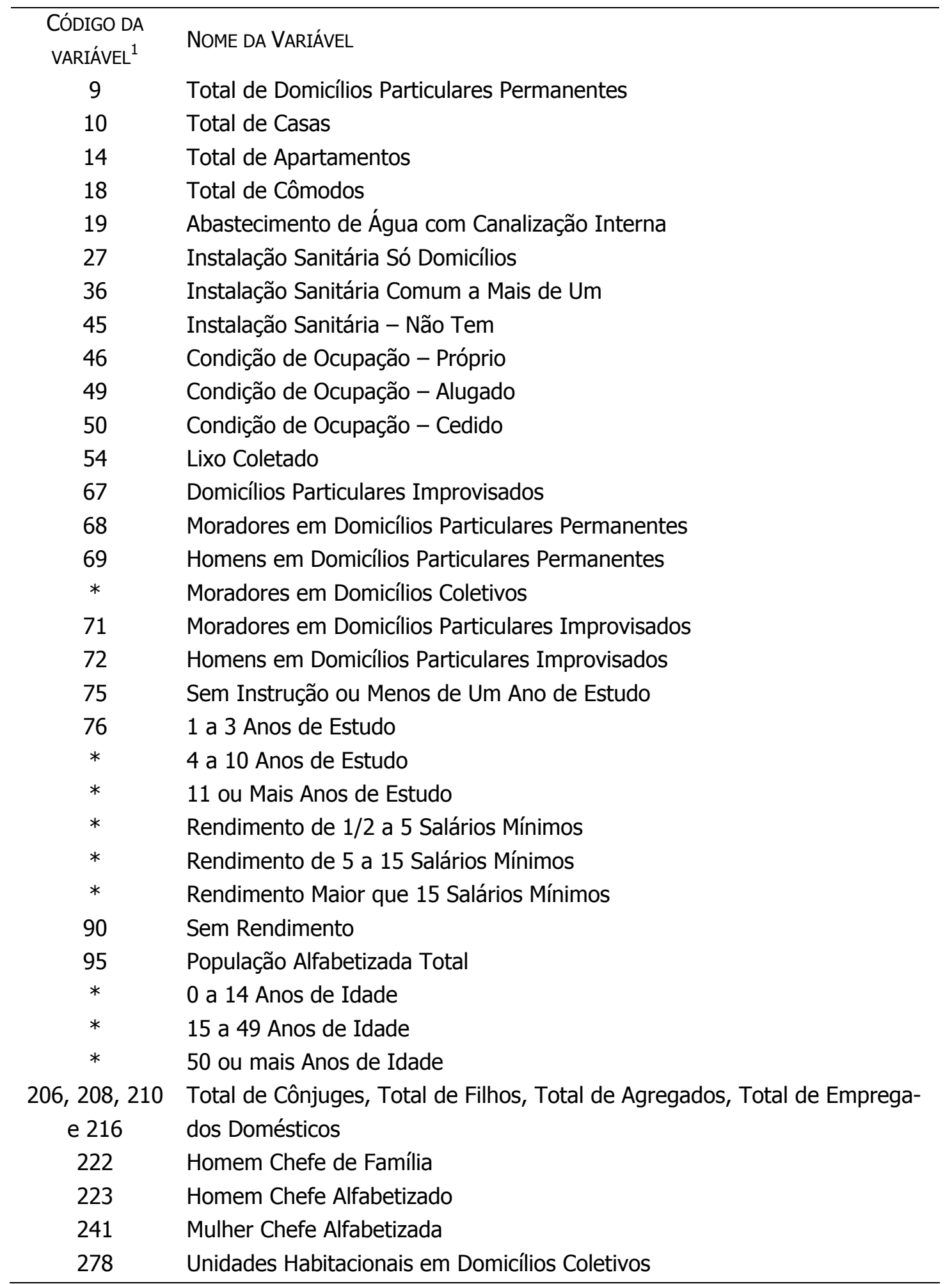

*Variáveis reagrupadas. 


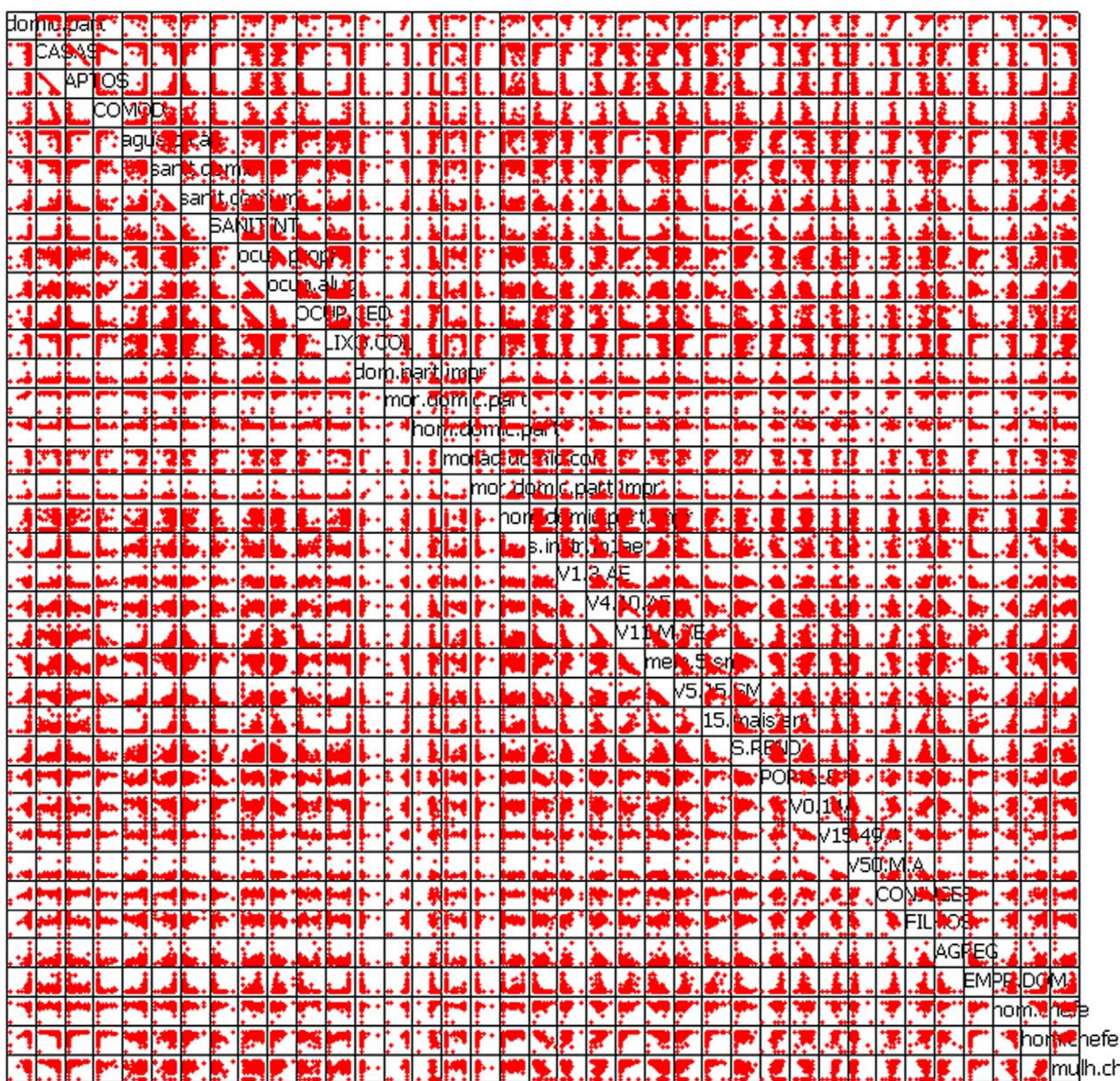


As variáveis 'total de domicílios particulares permanentes', 'instalação sanitária só domicílios', 'instalação sanitária comum a mais de um', 'moradores em domicílios particulares permanentes', 'moradores em domicílios coletivos', 'moradores em domicílios particulares improvisados' e 'sem instrução ou menos de um ano de estudo' apresentaram correlação elevada e foram excluídas do estudo.

Apesar de não apresentarem correlação elevada, as variáveis 'condição de ocupação - próprio', 'condição de ocupação - alugado', 'condição de ocupação - cedido', 'homens em domicílios particulares permanentes', 'homens em domicílios particulares improvisados', 'total de cônjuges', 'total de filhos', 'total de agregados', 'total de empregados domésticos', 'homem chefe de família', 'homem chefe alfabetizado' e mulher chefe alfabetizada' não foram consideradas importantes para o estudo e foram excluídas.

Na análise de clusters, foram utilizadas somente 19, de um total de 292 variáveis sócio-econômicas do Censo Populacional de 1991.

\subsection{Construção de mapas georreferenciados}

A Prefeitura Municipal de Guarulhos disponibilizou um mapa com a divisão dos setores censitários de 1996, em formato CAD, que foi convertido no programa de computador ArcView GIS versão 3.1 (ESRI Inc., 1996). Este mapa (Mapa 3) foi utilizado para a construção de mapas temáticos. 
Mapa 3 - Setores censitários do município de Guarulhos, Guarulhos - 1996

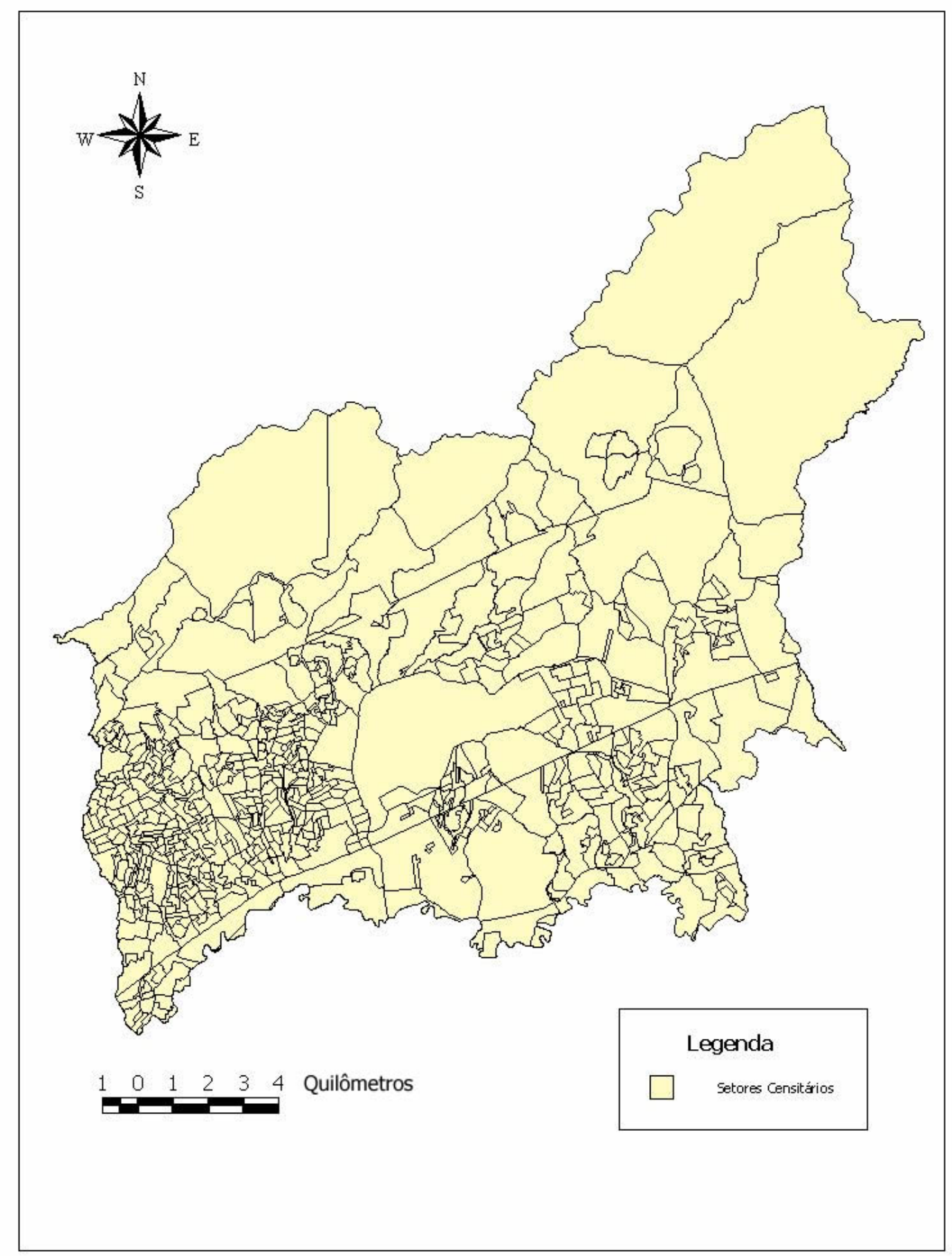




\subsection{Categorização sócio-econômica dos setores censitários a- través da análise de clusters}

Após a fase de seleção das variáveis, realizou-se a análise de clusters com o objetivo de categorizar dos setores censitários do Município de GuaruIhos em áreas sócio-econômicamente homogêneas, a partir de informações relevantes do Censo Populacional de 1991.

Somente 19 variáveis (Quadro 3), de um total de 292 pertencentes ao banco de dados original do Censo Populacional de 1991, foram utilizadas na análise de clusters.

Para a realização da análise, utilizou-se o pacote estatístico SPSS versão 9.0 (SPSS Inc., 1999). O algoritmo utilizado foi a média $K$, uma vez que esta é a escolha desejável quando se trabalha com numerosas ocorrências (setores censitários), a fim de definir $k$ grupos homogêneos baseados em suas características (SPSS 9.0 USER'S GUIDE, 1999).

Os parâmetros fornecidos ao programa foram: algoritmo da análise de clusters pela média $k$ e o número de cluster desejado, que foi estabelecido em cinco, ou seja, cinco áreas sócio-economicamente homogêneas. Foi utilizado um terceiro banco de dados, contendo somente as 19 variáveis escolhidas após a análise de correlações. 


\section{Quadro 3 - Variáveis do Censo Populacional de 1991 selecionadas para a análise de clusters, Guarulhos - 2000}

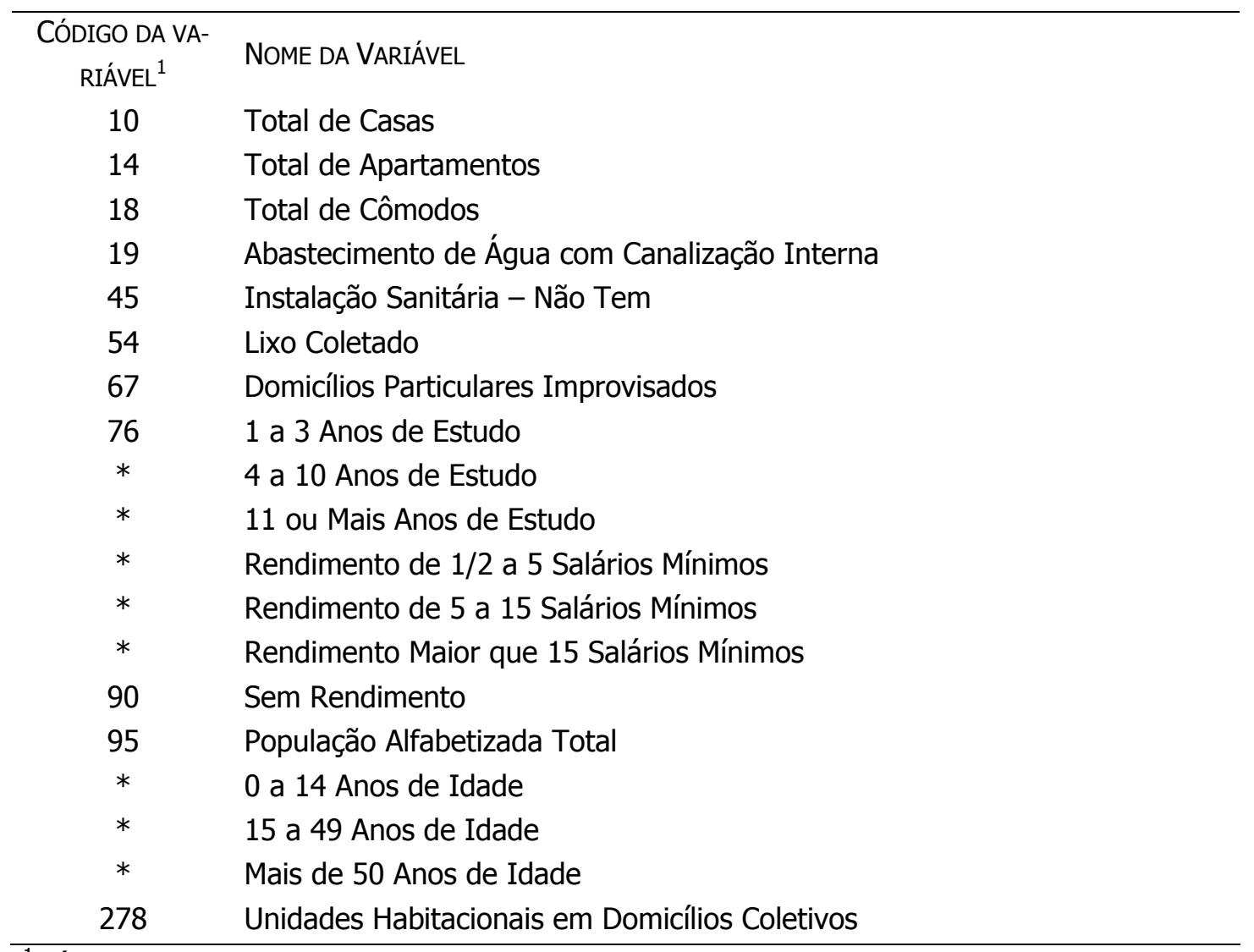

${ }^{1}$ Código do IBGE

Alguns setores censitários (35, 36, 37, 78, 79, 183, 198, 299, 308, 362, 380, 406, 407, 425, 434, 442, 447, 454, 458, 459, 466 e 475 no Distrito de Guarulhos; 105, 108, 129, 130, 131 e 139 no Distrito Jardim Presidente Dutra) não apresentavam população fixa e foram excluídos da análise. Desta forma, o banco de dados referia-se a 634 dos 662 setores censitários do Município de Guarulhos, em 1991.

Como resultado, o programa indicou o cluster (partição ou área sócioeconomicamente homogênea) a que cada setor censitário pertencia. 
Assim, a Área Homogênea 1 é constituída de 40 setores censitários, a Área Homogênea 2 é constituída de 188 setores censitários, a Área Homogênea 3 é constituída de 57 setores censitários, a Área Homogênea 4 é constituída de 322 setores censitários e a Área Homogênea 5 é constituída de 27 setores censitários, totalizando 634 setores censitários do Município de Guarulhos.

A lista com a identificação da área sócio-economicamente homogênea a que cada setor censitário pertence pode ser encontrada no Anexo 3.

Tendo obtido estas informações, foi possível construir o primeiro, de uma série de mapas temáticos, através do programa de computador ArcView GIS versão 3.1 (ESRI Inc., 1996), baseado no mapa de setores censitário, construído anteriormente. O Mapa 4 mostra a delimitação geográfica das áreas homogêneas, dentro do Município de Guarulhos, segundo os setores censitários constituintes.

Também foi possível observar, como resultado da análise de clusters, os setores típicos de cada área homogênea, ou seja, um setor médio (hipotético) de cada área homogênea (Tab. 1). 
Mapa 4 - Delimitação das áreas homogêneas, Município de GuaruIhos, Guarulhos - 2000

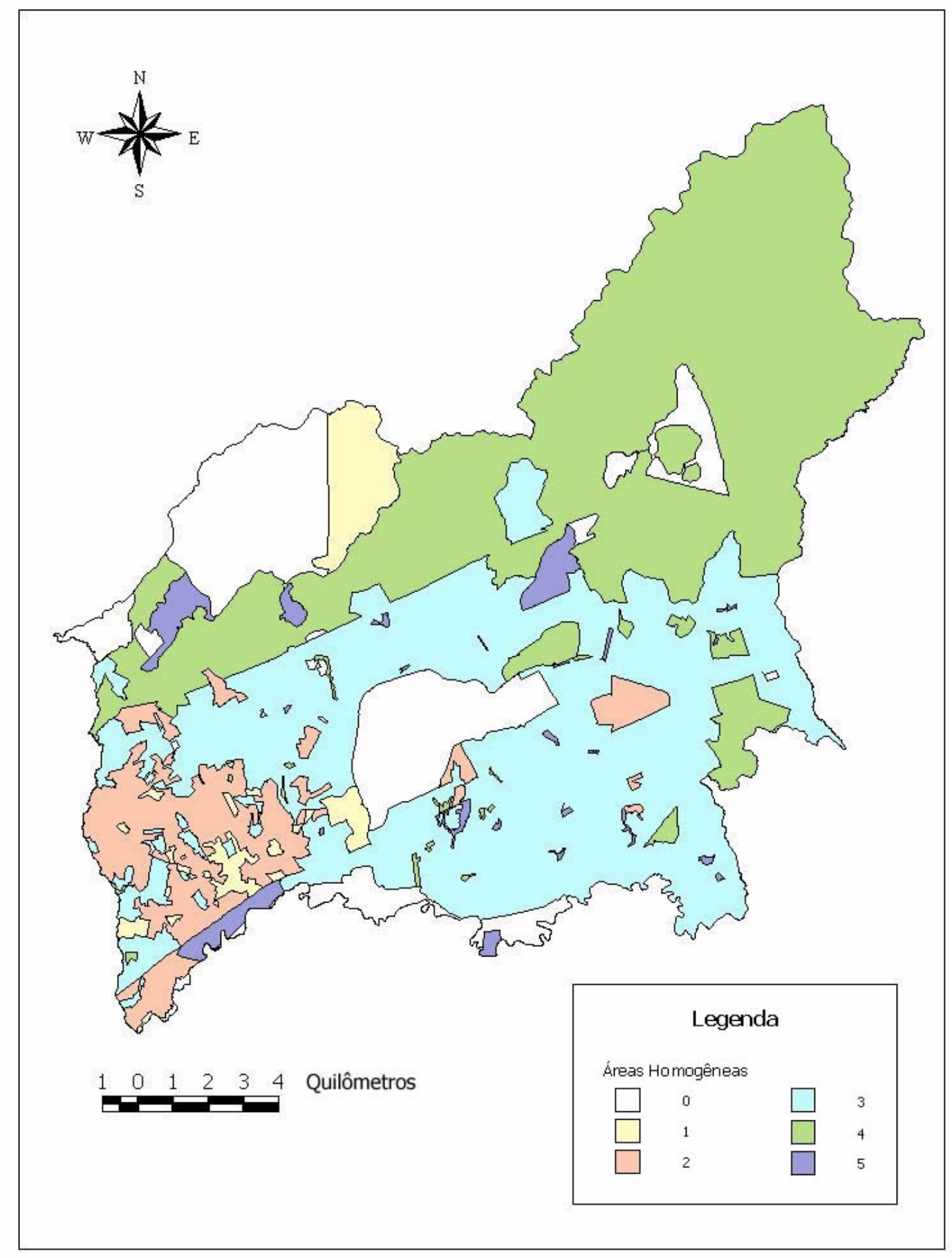


Tabela 1 - Setores censitários típicos, para cada área sócioeconomicamente homogênea, definidas pela análise de clusters, Guarulhos - 2000

\begin{tabular}{lrrrrr}
\hline ÁREA HOMOGÊNEA & 1 & \multicolumn{1}{c}{2} & \multicolumn{1}{c}{3} & \multicolumn{1}{c}{4} & \multicolumn{1}{c}{5} \\
\hline Casas & $27,40 \%$ & $91,90 \%$ & $98,28 \%$ & $99,65 \%$ & $98,14 \%$ \\
Apartamentos & $72,50 \%$ & $7,43 \%$ & $0,49 \%$ & $0,26 \%$ & $0,43 \%$ \\
Cômodos & $0,10 \%$ & $0,68 \%$ & $1,23 \%$ & $0,10 \%$ & $1,42 \%$ \\
Com Água Canalizada & $98,75 \%$ & $99,46 \%$ & $94,86 \%$ & $80,60 \%$ & $28,20 \%$ \\
Sem Instalação Sanitária & $0,13 \%$ & $0,22 \%$ & $1,76 \%$ & $8,59 \%$ & $20,89 \%$ \\
Com Coleta de Lixo & $97,01 \%$ & $99,43 \%$ & $93,58 \%$ & $12,00 \%$ & $46,84 \%$ \\
Domicílios Improvisados & $0,35 \%$ & $0,24 \%$ & $0,30 \%$ & $0,27 \%$ & $0,31 \%$ \\
0 - 14 Anos & $28,97 \%$ & $28,16 \%$ & $35,20 \%$ & $38,36 \%$ & $43,25 \%$ \\
15 - 49 Anos & $58,79 \%$ & $56,48 \%$ & $55,88 \%$ & $52,06 \%$ & $51,96 \%$ \\
50 ou Mais Anos & $12,24 \%$ & $15,35 \%$ & $8,92 \%$ & $9,58 \%$ & $4,79 \%$ \\
1 - 3 Anos de Estudo & $5,72 \%$ & $11,35 \%$ & $20,46 \%$ & $28,39 \%$ & $28,11 \%$ \\
4 - 10 Anos de Estudo & $36,20 \%$ & $52,93 \%$ & $56,72 \%$ & $39,21 \%$ & $43,34 \%$ \\
11 ou Mais Anos de Estudo & $54,81 \%$ & $28,07 \%$ & $7,19 \%$ & $3,32 \%$ & $1,40 \%$ \\
População Alfabetizada & $85,34 \%$ & $83,48 \%$ & $73,43 \%$ & $62,29 \%$ & $56,45 \%$ \\
Meio - 5 Salários Mínimos & $28,40 \%$ & $50,57 \%$ & $74,19 \%$ & $79,46 \%$ & $86,49 \%$ \\
5 - 15 Salários Mínimos & $46,95 \%$ & $34,16 \%$ & $16,36 \%$ & $10,83 \%$ & $3,48 \%$ \\
15 ou Mais Salários Mínimos & $17,75 \%$ & $7,90 \%$ & $1,10 \%$ & $1,49 \%$ & $0,21 \%$ \\
Sem Renda & $3,22 \%$ & $5,54 \%$ & $6,95 \%$ & $7,06 \%$ & $8,48 \%$ \\
Domicílios Coletivos & $3,82 \%$ & $1,06 \%$ & $2,38 \%$ & $3,65 \%$ & $0,87 \%$ \\
\hline
\end{tabular}

Não é possível afirmar qual a melhor ou qual a pior área sócioeconômica, porém é possível a comparação das variáveis, individualmente.

\subsection{Amostragem probabilística dos setores censitários}

Partindo da limitação operacional do número máximo de entrevistas a serem realizadas em 3000, foi realizada uma amostragem dos setores censitários em dois estágios. 
As premissas desta amostragem foram: (a) tamanho total da amostra fixo e (b) número de setores censitários (clusters) a ser amostrado a ser definido pela Equação 1.

As 3000 entrevistas foram divididas proporcionalmente ao tamanho da população humana, em cada uma das cinco áreas identificadas pela análise anterior, ou seja, foram realizadas cinco amostras.

O tamanho da amostra para cada área homogênea foi dependente da população humana (definida no Censo Populacional de 1991) presente nas mesmas. Contou-se a população humana contida em cada área homogênea, de acordo com os setores censitários constituintes das mesmas. Assim, a Área Homogênea 1, com uma população humana de 45637, em 1991, teve um tamanho de amostra fixado em 176 (5,87\% de 3000) domicílios. A Área Homogênea 2, com uma população de 231602, teve um tamanho de amostra fixado em 893 (29,77\% de 3000) domicílios. A Área Homogênea 3, com uma população de 406252, teve um tamanho de amostra fixado em 1566 (52,22\% de 3000) domicílios. A Área Homogênea 4, com uma população de 61804, teve um tamanho de amostra fixado em 238 (7,94\% de 3000) domicílios. A Área Homogênea 5, com uma população de 32733, teve um tamanho de amostra fixado em 126 (4,21\% de 3000) domicílios. O resumo da definição dos tamanhos das amostras é mostrado na Tabela 2. 
Tabela 2 - Definição do tamanho das amostras para cada área homogênea, segundo a população humana presente em 1991, Guarulhos - 2000

\begin{tabular}{crrr}
\hline ÁREA HOMOGÊNEA & $\begin{array}{c}\text { População HUMANA } \\
(1991)\end{array}$ & PORCENTAGEM & TAMANHO DA AMOSTRA \\
\hline 1 & 45637 & $5,87 \%$ & 176 \\
2 & 231602 & $29,77 \%$ & 893 \\
3 & 406252 & $52,22 \%$ & 1566 \\
4 & 61804 & $7,94 \%$ & 238 \\
5 & 32733 & $4,21 \%$ & 126 \\
\hline Total & 778028 & $100,00 \%$ & 3000 \\
\hline
\end{tabular}

De acordo com a Equação 1, foi estabelecido o número de setores censitários, em cada área homogênea, que deveriam ser submetidos à aplicação dos questionários domiciliares, considerando-se uma razão esperada ( $R_{\text {esp }}$ ) de 1,143 , precisão absoluta (d) de $7 \%$ e variância entre os setores censitários $\left(V_{c}\right)$ de 5\%. A Área Homogênea 1 teve 4 setores sorteados, a Área Homogênea 2 teve 3 setores sorteados, a Área Homogênea 3 teve 3 setores sorteados, a Área Homogênea 4 teve 4 setores sorteados e a Área Homogênea 5 teve 7 setores sorteados. Com base no tamanho da amostra fixado para cada área homogênea, determinou-se o número de domicílios a serem entrevistados em cada setor censitário sorteado (Tab. 3).

A partir da lista dos setores censitários constituintes de cada área homogênea, foram sorteados aleatoriamente, com a utilização do pacote estatístico SPSS versão 9.0 (SPSS Inc., 1999), os setores censitários que iriam ter seus domicílios entrevistados. 
Tabela 3 - Quadro-resumo do cálculo do número de setores censitários a ser sorteado em cada área homogênea, Guarulhos $-2000$

\begin{tabular}{lccccc}
\hline Área Homogênea & 1 & 2 & 3 & 4 & 5 \\
\hline Total de Setores & 40 & 188 & 322 & 57 & 27 \\
Setores Sorteados $(\mathrm{g})$ & 4,31 & 2,20 & 2,09 & 3,28 & 8,19 \\
Setores Sorteados $\left(\mathrm{g}_{\text {ajust }}\right)$ & 3,89 & 2,17 & 2,07 & 3,10 & 6,28 \\
Casas a serem Entrevistadas & 176 & 893 & 1566 & 238 & 126 \\
Casas Entrevistadas por Setor & 43,99 & 297,68 & 522,16 & 59,58 & 18,03 \\
\hline
\end{tabular}

A Área Homogênea 1 teve os setores censitários 20, 30, 109 e 274 (Distrito de Guarulhos) sorteados. A Área Homogênea 2 teve os setores 41, 123 e 241 (Distrito de Guarulhos) sorteados. A Área Homogênea 3 teve os setores 277 (Distrito de Guarulhos), 68 e 182 (Distrito Jardim Presidente Dutra) sorteados. A Área Homogênea 4 teve os setores 91 , 144, 162 e 187 (Distrito Jardim Presidente Dutra) sorteados. A Área Homogênea 5 teve os setores 310, 476 (Distrito de Guarulhos), 150, 177, 179, 185 e 190 (Distrito Jardim Presidente Dutra) sorteados.

A Área Homogênea 3, tendo os setores censitários 277 (Distrito de Guarulhos), 68 e 182 (Distrito Jardim Presidente Dutra) sorteados, alcançou uma somatória de, somente, 939 domićlios, ou seja, 627 a menos que o número definido para esta Área (1566). Assim foram sorteados mais dois setores censitários (16 e 114 do Distrito Jardim Presidente Dutra), até que a somatória de 1566 domicílios fosse alcançada.

O Mapa 5 mostra a localização espacial dos setores censitários sorteados, no mapa do Município de Guarulhos. 
Com a definição do número de domicílios a serem sorteados nos setores censitários sorteados, iniciou-se a aplicação dos questionários domiciliares. A seleção dos domicílios a serem entrevistados nos setores censitários sorteados foi realizada de maneira sistemática, ou seja, conhecendo-se o número de domicílios por setor e o número de domicílios a serem entrevistados, pôde-se determinar em que intervalo os domicílios seriam entrevistados.

As perguntas contidas neste questionário foram: (a) número de habitantes; (b) número de cães domiciliados (e respectivos gêneros) e (c) número de gatos domiciliados (e respectivos gêneros). 
Mapa 5 - Setores censitários sorteados para inquérito domiciliar, Guarulhos - 2000

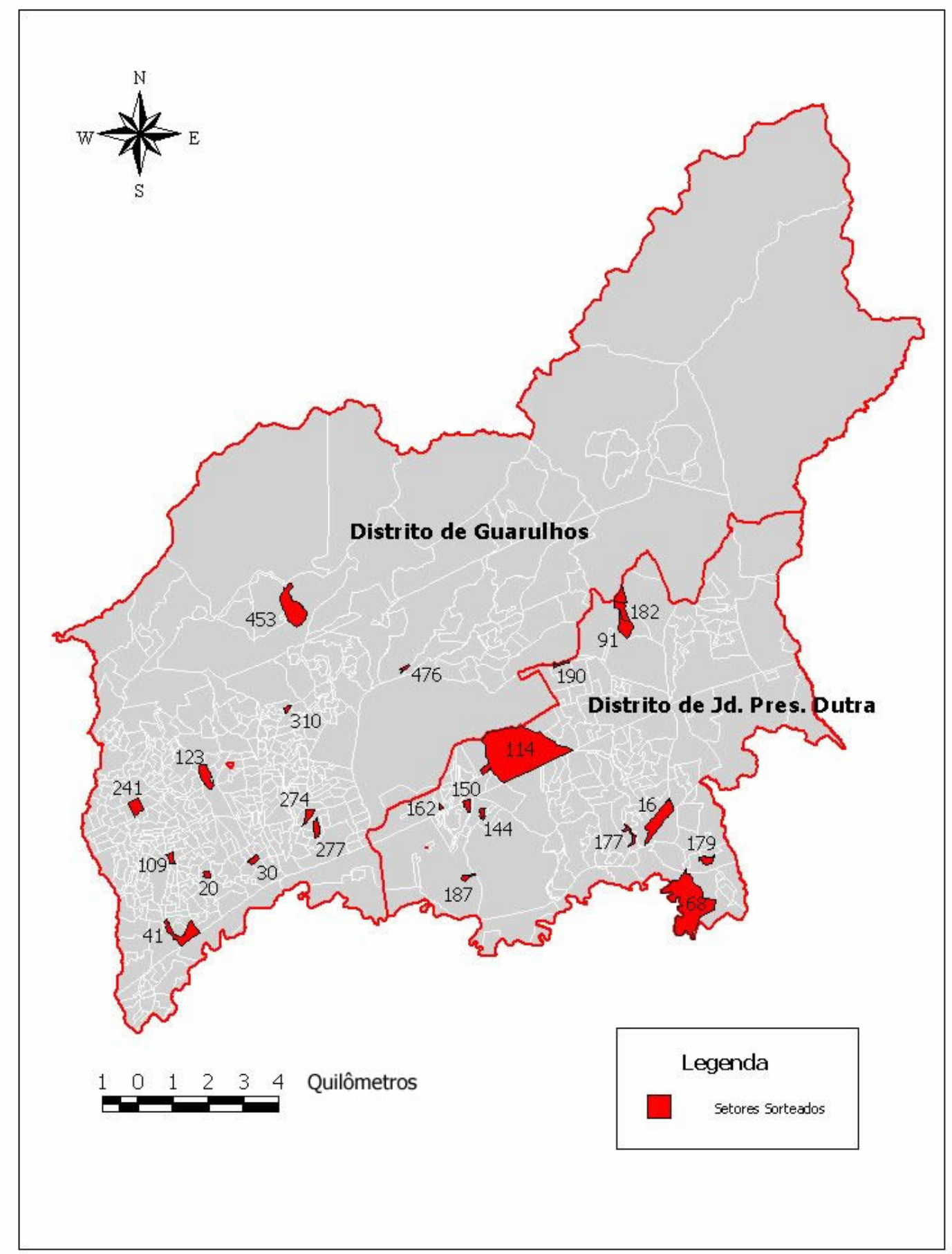




\subsection{Definição da razão entre a população humana e a popula- ção animal (canina e felina)}

A fase de aplicação dos questionários domiciliares contou com o apoio operacional da Divisão Técnica de Controle de Zoonoses da Prefeitura Municipal de Guarulhos.

O questionário domiciliar, aplicado em 2955 domicílios, possuía três questões: (a) número de habitantes; (b) número de cães domiciliados (e respectivos gêneros) e (c) número de gatos domiciliados (e respectivos gêneros).

A Tab. 4 mostra as somatórias dos números de pessoas, cães e gatos domiciliados por setor censitário submetido a inquérito domiciliar. 
Tabela 4 - Somatórias dos números de habitantes, cães e gatos por setor censitário amostrado, baseadas nos questionários domiciliares, Guarulhos - 2000

\begin{tabular}{|c|c|c|c|c|c|}
\hline $\begin{array}{c}\text { ÁREA } \\
\text { HOMOGÊNEA }\end{array}$ & $\begin{array}{c}\text { SETOR } \\
\text { CENSITÁRIO }^{1}\end{array}$ & HUMANOS & CÃES & GATOS & $\begin{array}{c}\text { DOMICÍLIOS } \\
\text { ENTREVISTADOS }\end{array}$ \\
\hline \multirow{4}{*}{1} & $20(5)$ & 156 & 32 & 21 & 44 \\
\hline & $30(5)$ & 229 & 27 & 13 & 44 \\
\hline & $109(5)$ & 181 & 41 & 7 & 44 \\
\hline & $274(5)$ & 235 & 59 & 10 & 44 \\
\hline \multirow{3}{*}{2} & $41(5)$ & 1095 & 216 & 71 & 298 \\
\hline & $123(5)$ & 1353 & 191 & 79 & 298 \\
\hline & $241(5)$ & 992 & 238 & 24 & 247 \\
\hline \multirow{5}{*}{3} & $68(10)$ & 1941 & 330 & 76 & 348 \\
\hline & $182(10)$ & 959 & 176 & 54 & 175 \\
\hline & $277(5)$ & 2056 & 419 & 142 & 416 \\
\hline & $16(10)$ & 1559 & 305 & 56 & 301 \\
\hline & $114(10)$ & 1609 & 329 & 42 & 327 \\
\hline \multirow{4}{*}{4} & $91(10)$ & 292 & 29 & 2 & 60 \\
\hline & $144(10)$ & 307 & 20 & 12 & 60 \\
\hline & $162(10)$ & 302 & 65 & 31 & 56 \\
\hline & $187(10)$ & 300 & 39 & 10 & 60 \\
\hline \multirow{7}{*}{5} & 150 (10) & 101 & 18 & 5 & 19 \\
\hline & 177 (10) & 120 & 25 & 9 & 19 \\
\hline & 179 (10) & 131 & 23 & 3 & 19 \\
\hline & $190(10)$ & 127 & 37 & 8 & 19 \\
\hline & $310(5)$ & 94 & 20 & 3 & 19 \\
\hline & $453(5)$ & 109 & 22 & 13 & 19 \\
\hline & $476(5)$ & 94 & 24 & 9 & 19 \\
\hline
\end{tabular}

${ }^{1}$ (5) Indica Distrito de Guarulhos e (10) Indica Distrito Jardim Presidente Dutra

Para cada setor censitário amostrado, foram calculados os valores médios dos habitantes, cães e gatos por domicílio e as incertezas ou os erros padrão associados (Tab. 5). 
Tabela 5 - Valores médios das populações humana, canina e felina e suas respectivas incertezas, por domicílio, nos setores censitários amostrados, Guarulhos - 2000

\begin{tabular}{|c|c|c|c|c|c|c|c|}
\hline $\begin{array}{c}\text { AिREA } \\
\text { HOMOGÊNEA }\end{array}$ & $\begin{array}{c}\text { SETOR } \\
\text { CENSITÁRIO }{ }^{1}\end{array}$ & $\begin{array}{c}\text { MÉdIA } \\
\text { HUMANOS }\end{array}$ & $\begin{array}{c}\text { ERRO } \\
\text { PADRÃO }\end{array}$ & $\begin{array}{l}\text { MÉDIA } \\
\text { CÃES }\end{array}$ & $\begin{array}{c}\text { ERRO } \\
\text { PADRÃO }\end{array}$ & $\begin{array}{l}\text { MÉDIA } \\
\text { GATOS }\end{array}$ & $\begin{array}{c}\text { ERRO } \\
\text { PADRÃO }\end{array}$ \\
\hline \multirow{4}{*}{1} & $20(5)$ & 3,54 & 0,19 & 0,71 & 0,15 & 0,48 & 0,26 \\
\hline & $30(5)$ & 5,20 & 0,54 & 0,61 & 0,14 & 0,30 & 0,14 \\
\hline & $109(5)$ & 4,11 & 0,19 & 0,93 & 0,17 & 0,16 & 0,10 \\
\hline & $274(5)$ & 5,34 & 0,63 & 1,34 & 0,21 & 0,205 & 0,077 \\
\hline \multirow{3}{*}{2} & $41(5)$ & 3,674 & 0,080 & 0,725 & 0,052 & 0,235 & 0,033 \\
\hline & $123(5)$ & 4,58 & 0,11 & 0,638 & 0,061 & 0,265 & 0,044 \\
\hline & $241(5)$ & 4,02 & 0,12 & 0,992 & 0,076 & 0,093 & 0,025 \\
\hline \multirow{5}{*}{3} & $16(10)$ & 5,26 & 0,18 & 1,003 & 0,065 & 0,183 & 0,059 \\
\hline & $68(10)$ & 5,52 & 0,15 & 0,948 & 0,050 & 0,218 & 0,037 \\
\hline & $114(10)$ & 4,92 & 0,14 & 1,00 & 0,13 & 0,128 & 0,029 \\
\hline & $182(10)$ & 5,42 & 0,19 & 1,006 & 0,070 & 0,320 & 0,064 \\
\hline & 277 (5) & 4,95 & 0,12 & 1,017 & 0,058 & 0,341 & 0,053 \\
\hline \multirow{4}{*}{4} & $91(10)$ & 4,87 & 0,32 & 0,98 & 0,14 & 0,167 & 0,059 \\
\hline & $144(10)$ & 5,12 & 0,40 & 0,333 & 0,088 & 0,20 & 0,11 \\
\hline & $162(10)$ & 5,39 & 0,36 & 1,16 & 0,13 & 0,55 & 0,13 \\
\hline & $187(10)$ & 5,13 & 0,26 & 0,67 & 0,10 & 0,167 & 0,059 \\
\hline \multirow{7}{*}{5} & 150 (10) & 5,32 & 0,38 & 0,95 & 0,20 & 0,26 & 0,13 \\
\hline & 177 (10) & 6,32 & 0,74 & 1,32 & 0,20 & 0,47 & 0,16 \\
\hline & 179 (10) & 6,90 & 0,77 & 1,21 & 0,29 & 0,16 & 0,12 \\
\hline & 190 (10) & 6,68 & 1,40 & 1,95 & 0,35 & 0,37 & 0,14 \\
\hline & $310(5)$ & 4,95 & 0,49 & 1,05 & 0,22 & 0,158 & 0,086 \\
\hline & $453(5)$ & 5,74 & 0,51 & 1,16 & 0,31 & 0,68 & 0,26 \\
\hline & $476(5)$ & 4,95 & 0,51 & 1,26 & 0,27 & 0,47 & 0,16 \\
\hline
\end{tabular}

${ }^{1}$ (5) Indica Distrito de Guarulhos e (10) Indica Distrito Jardim Presidente Dutra

Em seguida, foram calculadas as razões entre a população humana média e as populações animais (canina e felina) médias para cada setor censitário amostrado (Tab. 6). Nesta fase, as incertezas (erros padrão) das razões foram propagadas a partir dos erros das médias das populações humana e animal (canina e felina), segundo a Equação 3. 
Tabela 6 - Razões entre a população humana e animal (canina e felina) e suas respectivas incertezas, por setor censitário amostrado, Guarulhos - 2000

\begin{tabular}{|c|c|c|c|c|c|}
\hline $\begin{array}{c}\text { ÁREA } \\
\text { HOMOGÊNEA }\end{array}$ & $\begin{array}{c}\text { SETOR } \\
\text { CENSITÁRIO }^{1}\end{array}$ & $\begin{array}{l}\text { RAZÃO POPULAÇÃO } \\
\text { HUMANA:CANINA }\end{array}$ & ERRO PADRÃO & $\begin{array}{l}\text { RAZÃO POPULAÇÃO } \\
\text { HUMANA: FELINA }\end{array}$ & ERRO PADRÃO \\
\hline \multirow{4}{*}{1} & $20(5)$ & 5,03 & 1,29 & 7,43 & 3,99 \\
\hline & $30(5)$ & 8,48 & 4,64 & 17,62 & 8,55 \\
\hline & 109 (5) & 4,41 & 0,69 & 25,86 & 16,71 \\
\hline & $274(5)$ & 3,98 & 0,62 & 26,11 & 10,28 \\
\hline \multirow{3}{*}{2} & $41(5)$ & 5,07 & 0,15 & 15,64 & 2,24 \\
\hline & $123(5)$ & 7,18 & 0,50 & 17,28 & 2,90 \\
\hline & $241(5)$ & 4,05 & 0,11 & 43,13 & 11,78 \\
\hline \multirow{5}{*}{3} & $16(10)$ & 5,24 & 0,15 & 28,80 & 9,30 \\
\hline & $68(10)$ & 5,82 & 0,12 & 25,29 & 4,34 \\
\hline & $114(10)$ & 4,92 & 0,42 & 38,28 & 8,76 \\
\hline & $182(10)$ & 5,39 & 0,18 & 16,95 & 3,46 \\
\hline & $277(5)$ & 4,872 & 0,092 & 14,51 & 2,29 \\
\hline \multirow{4}{*}{4} & $91(10)$ & 4,95 & 0,57 & 29,20 & 10,52 \\
\hline & $144(10)$ & 15,35 & 17,81 & 25,58 & 14,01 \\
\hline & $162(10)$ & 4,64 & 0,39 & 9,74 & 2,33 \\
\hline & $187(10)$ & 7,70 & 1,56 & 30,80 & 11,02 \\
\hline \multirow{7}{*}{5} & $150(10)$ & 5,61 & 1,14 & 20,20 & 10,00 \\
\hline & $177(10)$ & 4,80 & 0,86 & 13,33 & 4,76 \\
\hline & 179 (10) & 5,69 & 2,29 & 43,67 & 32,19 \\
\hline & 190 (10) & 3,43 & 0,89 & 18,14 & 7,74 \\
\hline & $310(5)$ & 4,70 & 1,20 & 31,33 & 17,33 \\
\hline & $453(5)$ & 4,95 & 1,93 & 8,38 & 3,34 \\
\hline & $476(5)$ & 3,92 & 0,88 & 10,44 & 3,68 \\
\hline
\end{tabular}

${ }^{1}$ (5) Indica Distrito de Guarulhos e (10) Indica Distrito Jardim Presidente Dutra

O próximo passo foi o cálculo das razões entre as populações humana e animal (canina e felina), por área homogênea, ou seja um valor médio entre os setores censitários constituintes de cada área homogênea (Tab. 7). As incertezas (erros padrão) das razões, por área, foram propagadas a partir dos erros das razões entre as populações humana e animal (canina e felina), por setor censitário, segundo a Equação 4.

Tendo chegado à razão entre a população humana e a população canina por área homogênea, buscou-se verificar a existência de correlação das mesmas com o nível sócio-econômico. 
Tabela 7 - Razões entre a população humana e a população animal (canina e felina) e suas respectivas incertezas, por área sócio-economica-mente homogênea, Guarulhos - 2000

\begin{tabular}{|c|c|c|c|c|}
\hline $\begin{array}{c}\text { ÁREA } \\
\text { HOMOGÊNEA }\end{array}$ & $\begin{array}{l}\text { RAZÃO POPULAÇÃO } \\
\text { HUMANA:CANINA }\end{array}$ & ERRO PADRÃO & $\begin{array}{l}\text { RAZÃO POPULAÇÃOO } \\
\text { HUMANA: FELINA }\end{array}$ & ERRO PADRÃO \\
\hline 1 & 5,48 & 0,67 & 19,25 & 9,88 \\
\hline 2 & 5,43 & 0,29 & 25,35 & 5,64 \\
\hline 3 & 5,25 & 0,20 & 24,77 & 5,63 \\
\hline 4 & 8,16 & 1,13 & 23,83 & 9,47 \\
\hline 5 & 4,66 & 0,41 & 19,16 & 10,35 \\
\hline
\end{tabular}

Foi realizada uma análise de regressão linear, ajustada para incertezas diferentes, para verificar a existência de correlação entre o nível sócioeconômico com a razão entre a população humana e a população canina domiciliada (variável dependente), com base nos valores definidos por área homogênea. Verificou-se que a Área Homogênea 4 (correspondente à Zona Rural) apresentava um valor discrepante, e não foi incluída na análise.

A equação da reta de regressão foi: $y=5,90-0,23 \times\left(r^{2}=0,73\right)$ (Gráfico 2). A qualidade do ajuste foi verificada através do cálculo do $\chi_{\text {red }}^{2}$, obtendo-se o valor de 0,35 e, segundo BEVINGTON (1969), pode ser considerado adequado (para dois graus de liberdade), pois está compreendido entre 0,22 e 1,61. O intervalo de confiança do coeficiente angular da equação: [0,065; 0,53], compreende o valor 0 (zero), não sendo possível afirmar, com base nestes elementos, que existe correlação entre o nível sócio-econômico com a razão entre a população humana e a população canina domiciliada.

Portanto, foi possível utilizar uma razão única, para a Zona Urbana do Município de Guarulhos. Para Zona Rural, foi adotado o valor correspondente à razão da Área Homogênea 4. 


\section{Gráfico 2 - Representação da regressão linear baseada nas razões entre a população humana e população canina, por á- rea sócio-economicamente homogênea, Guarulhos - 2000}

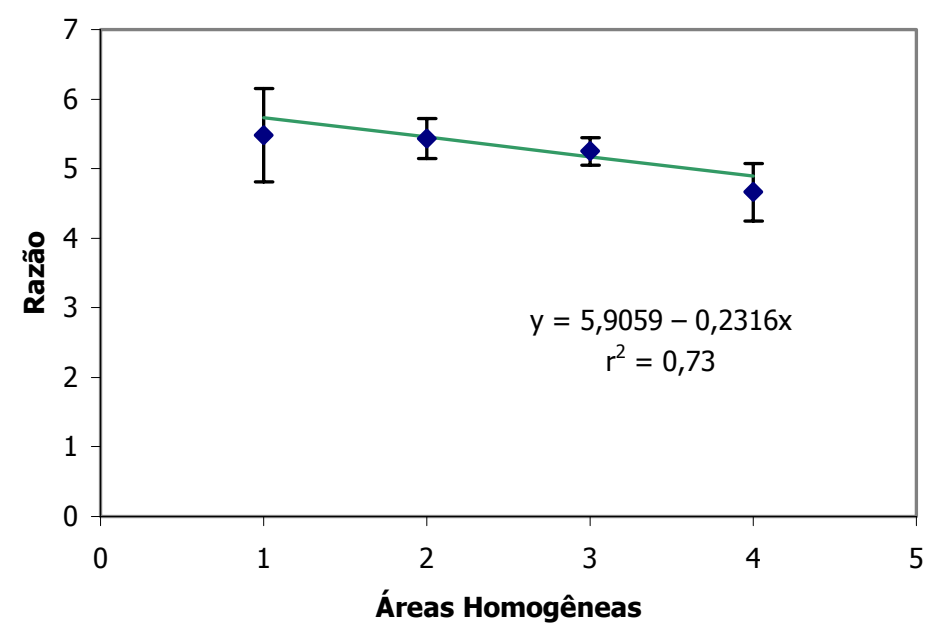

Para a obtenção das razões entre a população humana e a população animal (canina e felina) domiciliada para o Município de Guarulhos como um todo, as razões entre a população humana e a população animal (canina e felina), por área homogênea, foram multiplicadas por um ponderador, referente à população humana residente em cada área homogênea em relação à população total do Município, em 1991 (ou seja, 778028 habitantes).

Assim, Área Homogênea 1, com uma população humana de 45637, utilizou um ponderador com valor 0,059. A Área Homogênea 2 (população humana de 231602), utilizou um ponderador de 0,30. A Área Homogênea 3 (população humana de 406252), utilizou um ponderador de 0,52. A Área Homogênea 4 (população humana de 61804), utilizou um ponderador de 0,079. A Área Homogênea 5 (população humana de 32733), utilizou um ponderador de 0,042. 
Dessa forma, a razão entre a população humana e a população canina domiciliada no Município de Guarulhos foi estimada em 5,52 (com erro padrão associado de 0,33).

Utilizando os mesmos ponderadores, estimou-se a razão entre a população humana e a população canina domiciliada na Zona Urbana do Município de Guarulhos em 5,30 (com erro padrão associado de 0,27). Na Zona Rural, esta razão foi estimada em 8,16 (com erro padrão associado de 1,13).

A razão entre a população humana e a população felina domiciliada no Município de Guarulhos foi estimada em 24,31 (com incerteza associada de 6,39).

\subsection{Construção do mapa de densidade populacional canina}

Foi construído um novo mapa temático mostrando a estimativa da densidade populacional canina domiciliada (Mapa 6) no Município de Guarulhos, para o ano de 1991, a partir da razão entre a população humana e a população canina definida para a Zona Urbana $(5,30)$ e para a Zona Rural $(8,16)$ do Município de Guarulhos. O mapa de densidade populacional felina não foi construído. 
Foi definido o tamanho da população canina domiciliada em cada setor censitário dividindo-se a população humana de cada setor censitário, no ano de 1991, pela razão entre a população humana e canina, definida para o Município de Guarulhos. A densidade populacional canina por setor censitário foi obtida dividindo-se a população animal, definida anteriormente, pela área de cada setor. Esta fase foi realizada através do programa de computador ArcView GIS versão 3.1 (ESRI Inc., 1996).

Não foram utilizados os dados de população humana do ano 2000 , por setor censitário, pois estes só estarão disponíveis no ano 2003 (IBGE, 2001). Somente foram divulgados resultados preliminares do Censo de 2000, referente ao total da população humana no Município de Guarulhos no ano 2000, totalizando 1071299 habitantes (IBGE, 2001). 
Mapa 6 - Densidade populacional canina no ano de 1991, Guarulhos - 2000

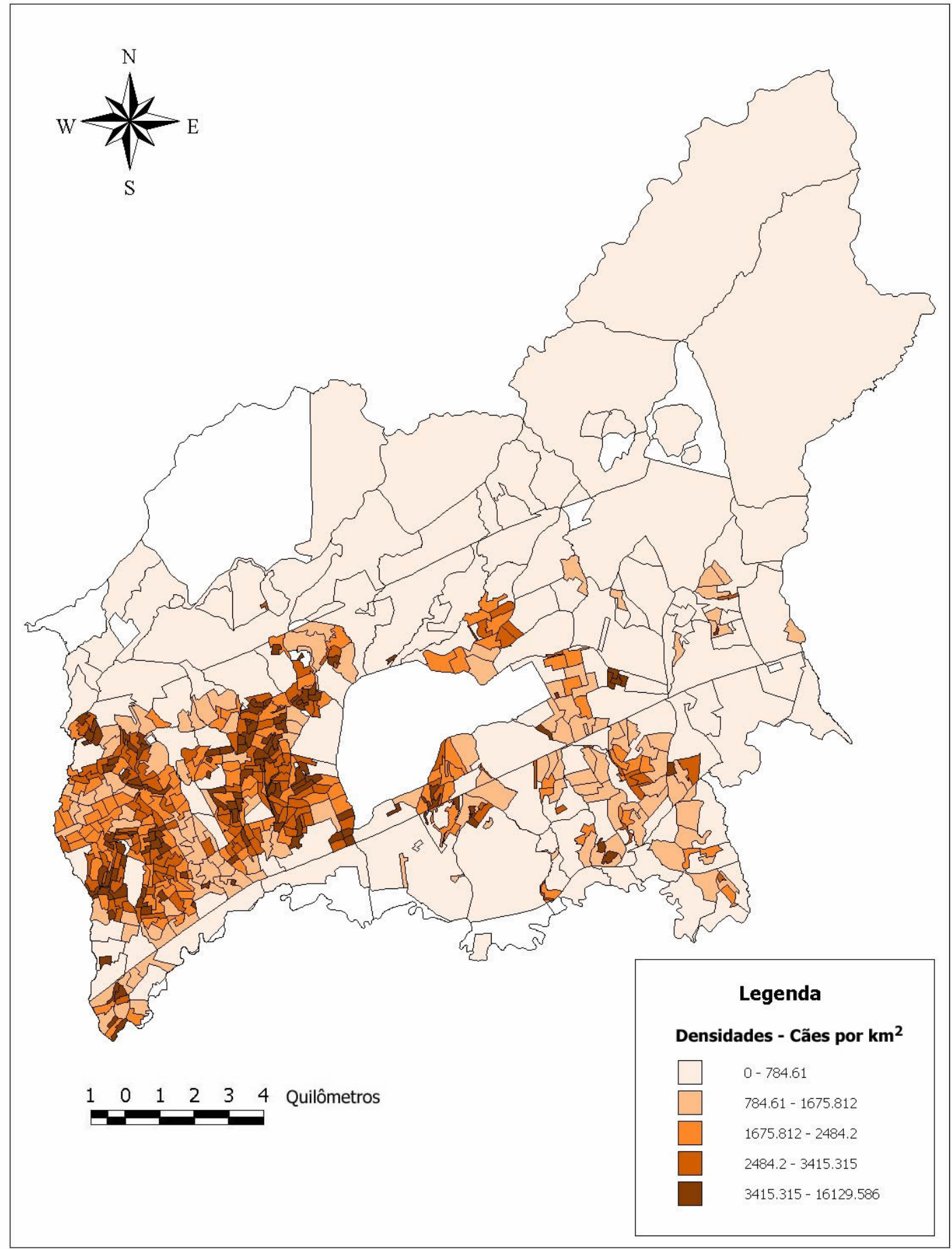




\subsection{Localização espacial dos postos de vacinação e definição das suas áreas de influência}

Com base em uma lista dos endereços dos 160 postos de vacinação, fornecida pela Divisão Técnica de Controle de Zoonoses da Prefeitura Municipal de Guarulhos, foram levantadas as localizações geográficas de cada posto, com o auxílio de um aparelho de posicionamento global por satélite (GPS). As coordenadas de cada posto foram plotadas no mapa georreferenciado do Município de Guarulhos (Mapa 7).

A determinação das áreas de influência dos postos de vacinação foi dependente da definição da distância média de deslocamento dos proprietários até um posto de vacinação. Esta distância, baseada nos resultados da aplicação do segundo questionário, direcionado a uma amostra dos proprietários que levaram seus animais aos postos de vacinação, durante a Campanha de Vacinação Anti-rábica, no ano 2000. Os endereços dos proprietários foram localizados nos mapas georreferenciados e, as distâncias entre as residências dos proprietários até o posto de vacinação correspondente foram medidas, possibilitando calcular a distância média de deslocamento, para cada posto de vacinação.

Estas distâncias, específicas para cada posto de vacinação, foram plotadas no mapa georreferenciado, na forma de um raio (buffer), originando então as áreas de influência dos postos de vacinação (Mapa 8). 
Mapa 7 - Localização dos postos da Campanha de Vacinação Antirábica, Guarulhos - 2000

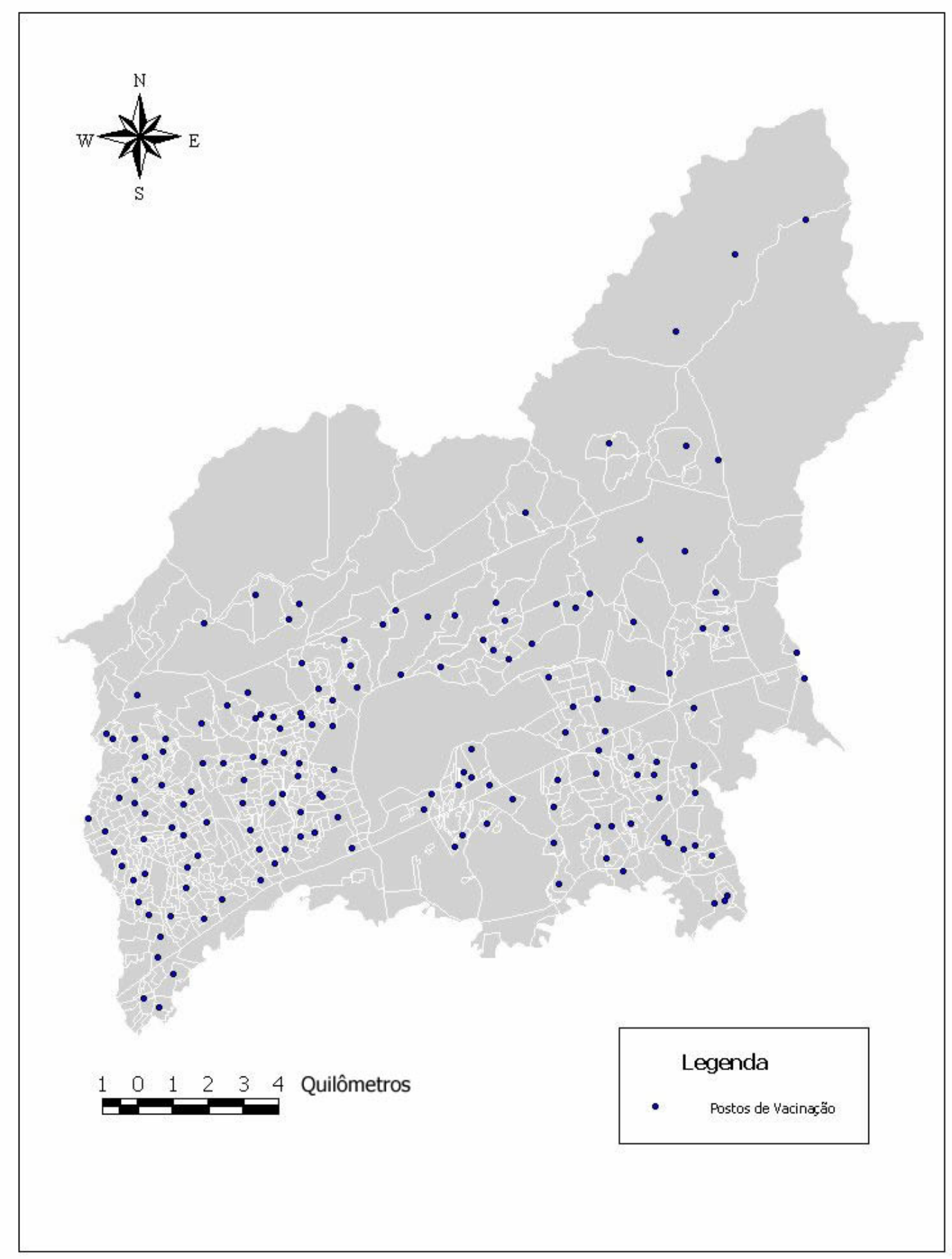


Mapa 8 - Mapa das áreas de influência dos postos da Campanha de Vacinação Anti-rábica, Guarulhos - 2000

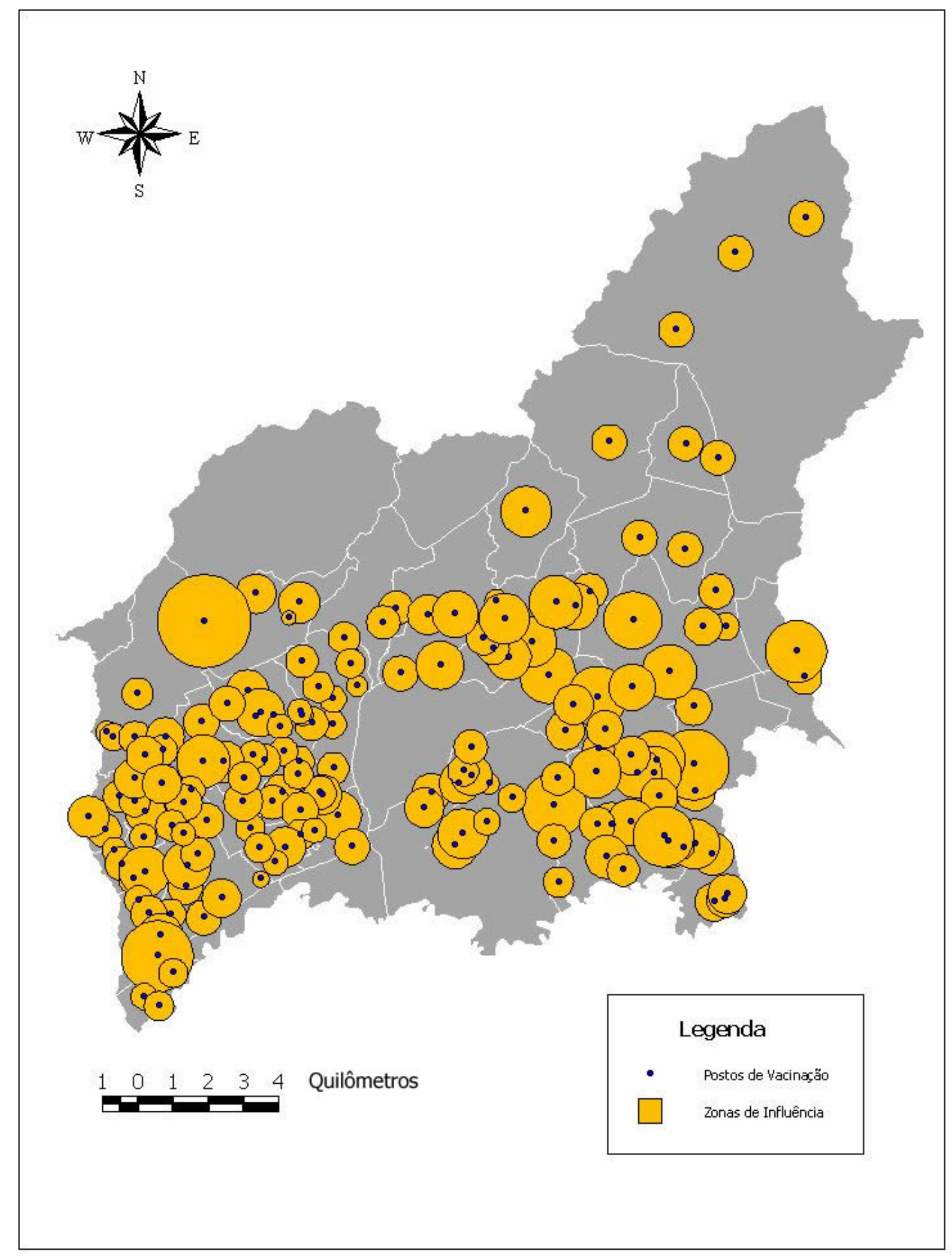


O Anexo 4 contém a lista com o endereço dos 160 postos de vacinação, suas localizações geográficas e as distâncias médias de deslocamento dos proprietários até cada posto de vacinação.

\subsection{Determinação da cobertura vacinal da Campanha de Vaci- nação Anti-rábica no Município de Guarulhos, no ano 2000}

Baseado nos resultados preliminares do Censo de 2000 do IBGE, referentes ao total da população humana do Município de Guarulhos, ou seja, 1071299 habitantes, foi estimada a população canina, no mesmo ano, com base na razão entre a população humana e a população canina calculada anteriormente.

Dividindo-se o total da população humana do Município no ano 2000 (1071299 habitantes) pela razão entre a população humana e a população canina $(5,52)$, estimou-se a população canina domiciliada em 193886 animais. A população felina domiciliada foi estimada da mesma forma, dividindo-se o total da população humana do Município no ano 2000 (1071299 habitantes) pela razão entre a população humana e a população felina $(24,31)$, em 44070 animais.

Dessa forma, pôde-se comparar o total de animais efetivamente vacinados no ano 2000, com a estimativa da população animal domiciliada no mesmo ano, de modo a estimar-se a cobertura vacinal da Campanha. 
A população canina efetivamente vacinada durante a Campanha de Vacinação do ano 2000 , foi 119758 . Este valor representa $61,77 \%$ da população canina domiciliada estimada para o ano 2000.

A população felina efetivamente vacinada durante a Campanha de Vacinação do ano 2000 , foi 16887 . Este valor representa $38,31 \%$ da população felina domiciliada estimada para o ano 2000.

Paralelamente, buscou-se verificar a cobertura espacial dos postos de vacinação, sobrepondo-se o mapa da mancha constituída pelas 'áreas de influência' dos postos de vacinação ao mapa de densidade populacional canina (Mapa 9). 
Mapa 9 - Sobreposição da mancha constituída pelas áreas de influência dos postos da Campanha de Vacinação Anti-rábica ao mapa de densidade populacional canina, Guarulhos 2000

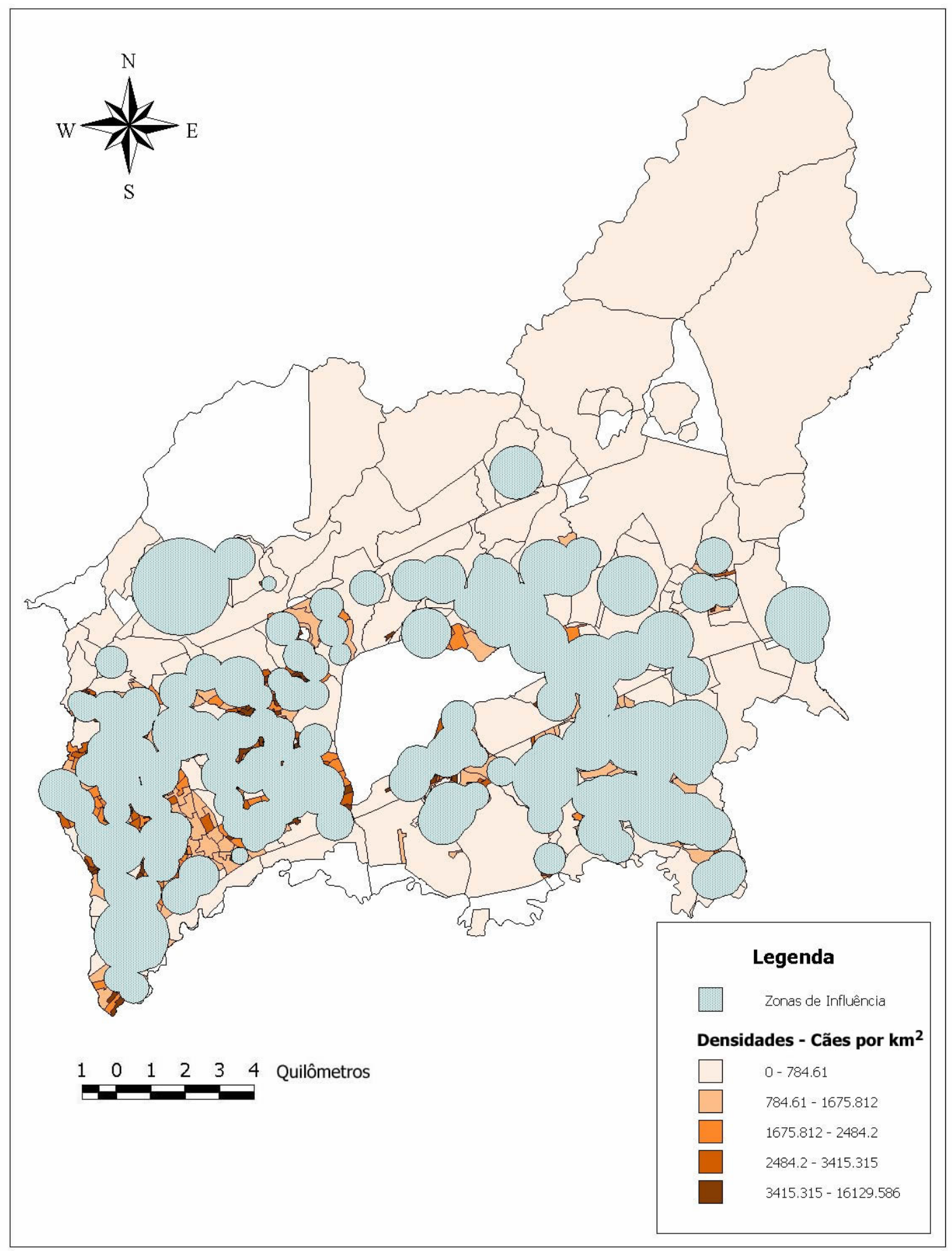




\subsection{Determinação da razão entre os gêneros na população a- nimal (canina e felina) domiciliada}

Durante a fase de aplicação de questionários domiciliares, foi perguntado o gênero dos animais presentes nos domicílios.

A somatória dos cães do sexo masculino e do sexo feminino permitiu definir uma razão entre gêneros. Esta razão foi estabelecida em 1,70, ou seja 1,70 machos para cada fêmea.

A somatória dos gatos do sexo masculino e do sexo feminino permitiu definir uma razão entre gêneros. Esta razão foi estabelecida em 1,44, ou seja 1,44 machos para cada fêmea.

Esta informação é relevante no planejamento de medidas de controle populacional, em especial a castração. A definição das metas e prioridades destes programas depende da estimativa do impacto das ações na população-alvo. 


\section{DISCUSSÃO}

Desde 1973, com o início do Programa de Controle da Raiva, os centros de controle de zoonoses do Estado de São Paulo, fazem uso de uma proporção entre a população humana e a população canina de $1: 10$, ou seja, um cão para dez pessoas, o que gerou, em diversos municípios, vacinações em valores superiores a $100 \%$ da população canina estimada, segundo a relação entre a população humana e canina inicialmente proposta. Na década de 1990, o Instituto Pasteur de São Paulo propôs uma nova proporção, de 1:7, (INSTITUTO PASTEUR, 1999). Entretanto, essa nova proporção foi arbitrariamente estabelecida, carecendo de verificação experimental.

O desconhecimento do tamanho real da população canina compromete o planejamento e a avaliação do programa de controle da raiva, uma vez que não se pode determinar a cobertura vacinal, avaliar o impacto da captura e estabelecer metas para o programa.

Para conhecer o tamanho da população canina, alguns municípios adotaram a estratégia de realização de censo animal e outros optaram pela realização de amostragens, a custos comparativamente mais baixos, tornando viável a sua aplicação a grandes centros urbanos.

A realização da amostragem é um processo caro e trabalhoso, dificultando a sua realização periódica pelas prefeituras municipais, nesse sentido há a necessidade de se utilizar um indicador baseado em uma variável que seja freqüentemente atualizada e de fácil obtenção, assim propôs-se o recál- 
culo da razão entre população humana e canina, considerando-se a realidade brasileira e refinando-se a estimativa oficial de 1:7.

O recálculo realizado no Município de Guarulhos procurou verificar ainda, a existência de correlação entre o indicador e condições sócioeconômicas da população de modo a estabelecer se haveria necessidade de utilização de diferentes indicadores para diferentes condições sócioeconômicas.

Esse cálculo permitiu observar que é possível utilizar índice único para estimativa da população animal em Zonas Urbanas, independente do nível sócio-econômico. Em Guarulhos, este índice foi estabelecido em 5,30 para a Zona Urbana. Entretanto, para a Zona Rural, este índice foi estabelecido em 8,16 demonstrando diferença significativa em relação à Zona Urbana.

Para a totalidade do Município de Guarulhos observou-se uma razão média entre a população humana e canina igual a 5,52.

Essa razão permitiu estimar as populações canina no ano 2000 em 193886. Esse valor provoca uma queda elevada da cobertura vacinal canina, que passa de 83,68\% (PREFEITURA MUNICIPAL DE GUARULHOS, 2000) (considerando-se a razão 1:7 na estimativa do tamanho da população canina) para $61,77 \%$. Esta nova cobertura parece mais próxima da realidade dadas as características limitadas de divulgação das campanhas de vacinação animal. 
O tamanho da população felina domiciliada foi estimado em 44070 animais de modo que a cobertura vacinal em 2000 para essa população foi estimada em $38,31 \%$.

Esse valor reduzido pode ser explicado pela dificuldade de levar o animal ao posto, de contenção para a vacinação e ao acesso que esse animais normalmente têm à rua. A baixa cobertura vacinal dessa população associada ao contato que esses animais têm com animais não domiciliados e ao hábito de caçar animais, muitos dos quais silvestres, evidencia a importância que esses animais podem ter na reintrodução da raiva em municípios que já controlaram a doença, principalmente quando se considera que a população não domiciliada é bastante grande. Nesse sentido, cumpre destacar que Guarulhos estava sem casos de raiva em cães e gatos desde 1983, e em 1992 houve a notificação de um gato positivo para a raiva, originário de Zona Rural (PREFEITURA MUNICIPAL DE GUARULHOS, 2000).

As entrevistas permitiram ainda estabelecer a razão entre os gêneros para a população canina domiciliada, em 1,70, ou seja 1,70 machos para cada fêmea. A razão entre os gêneros da população felina domiciliada, em 1,44, ou seja 1,44 machos para cada fêmea.

Esses valores foram obtidos com a finalidade de descrever as populações canina e felina quanto à sua composição por sexo além de fornecer um parâmetro importante para avaliar o impacto da esterilização como medida de controle populacional. 
Analisando a distribuição espacial dos postos de vacinação, como mostra o Mapa 7, observa-se que existem postos próximos uns dos outros e, como mostra o Mapa 8, há sobreposição das áreas de influência dos postos, em algumas regiões do município.

A realocação dos postos de vacinação pode ser considerada, porém após a análise do impacto desta medida, em termos de segurança dos proprietários e dos animais atendidos, uma vez que muitos dos postos próximos estão separados por grandes avenidas de modo que, para minimizar o risco de acidentes a prefeitura opta pela sua manutenção. Além disso, deve ser considerado o custo-benefício e a disponibilidade infraestrutura logística para mudança. A DTCZ têm optado por localizar os postos próximos a escolas de modo que os funcionários possam se utilizar da infraestrutura oferecida, isto é, água, sanitários, etc.

Seria conveniente que estudos futuros permitissem a incorporação das populações não domiciliadas.

A possibilidade de analisar espacial e temporalmente as ações de saúde possibilitam estabelecer e avaliar com mais racionalidade as medidas de controle de doenças animais e humanas. 


\section{CONCLUSÕES}

- A razão entre a população humana e a população canina foi estimada em 5,52 (com erro padrão associado de 0,33 ) e a razão entre a população humana e a população felina foi estimada em 24,31 (com erro padrão associado de 6,39).

- Não houve diferença estatística entre as razões entre a população animal (canina e felina) e a população humana entre as quatro categorias sócio-econômicas pertencentes à Zona Urbana. Porém, houve diferença significativa entre estas e a categoria correspondente à Zona Rural. Assim, pode-se adotar uma razão única para áreas urbanas, independentes do nível sócioeconômico. Para o Município de Guarulhos, foi estabelecida a razão 5,30 para a Zona Urbana e 8,16 para a Zona Rural.

- A população canina domiciliada do Município de Guarulhos foi estimada em 193886, no ano 2000.

- A proporção entre os gêneros na população canina domiciliada foi estimada em 1,70, ou seja, 1,70 macho para cada fêmea.

- A proporção entre os gêneros na população felina domiciliada foi estimada em 1,44, ou seja, 1,44 macho para cada fêmea.

- A cobertura vacinal da Campanha de Vacinação Anti-rábica do ano 2000 foi estimada em $61,77 \%$ da população canina e $38,31 \%$ da população felina. 
- A cobertura espacial dos postos de vacinação é adequada ao Município de Guarulhos, pois atende às áreas com maior densidade populacional animal. 


\section{REFERÊNCIAS}

ACHA, P. N.; SZYFRES, B. Zoonosis y enfermidades transmissibles comunes al hombre y los animales. Washington: Organización Panamericana de la Salud, 1986. p. 502-526 (Publicación científica, 503).

ArcView version 3.1. Redlands : ESRI Inc., 1996. 1 CD-Rom.

BENENSON, A. S. (Ed.) El control de las enfermidades transmissibles em el hombre. Washington: Organización Panamericana de la Salud, 1986. p. 379-389 (Publicación científica, 507).

BEVINGTON, P. R. Data reduction and error analysis for the physical sciences. New York: McGraw-Hill, 1969. 336 p.

CHATFIELD, C.; CILLINS, A. J. Introduction to multivariate analysis. London: Chapman \& Hall, 1980. 246 p.

COCHRAN, W. G. Sampling techniques. 3. ed. New York: John Wiley \& Sons, 1977. $428 \mathrm{p}$.

DEMERS, M. N. Fundamentals of geographic information systems. New York: John Wiley \& Sons, 1997.

FANG, Z. F. Rabies and rabies research: past, present and future. Vaccine, v. 15, p. 20-24, 1997.

FENNER, F.; BACHMANN, P. A.; GIBBS, E. P. J.; MURPHY, F. A.; STUDDERT, M. J.; WHITE, D. O. Veterinary virology. 2. ed. New York: Academic Press, 1993. $660 \mathrm{p}$.

FOREMAN, E. K. Survey sampling techniques. New York: Marcel Dekker, 1991. $497 \mathrm{p}$.

FUNDAÇÃO NACIONAL DE SAÚDE. Boletim eletrônico epidemiológico. Brasília, 2001- . Disponível em: <http://www.funasa.gov.br/pub/boletim_eletronico_epi/ boletim_eletronico_epi0101.pdf>. Acesso em: 12 mar. 2001.

GREGG, M. B. Field epidemiology. New York: Oxford University, 1996. 275 p. 
INSTITUTO BRASILEIRO DE GEOGRAFIA E ESTATÍSTICA. Censo populacional de 1991. Rio de Janeiro: IBGE, 1991 (disquete).

INSTITUTO BRASILEIRO DE GEOGRAFIA E ESTATÍSTICA. Contagem populacional de 1996. Rio de Janeiro: IBGE, 1996. 1 CD-Rom.

INSTITUTO BRASILEIRO DE GEOGRAFIA E ESTATÍSTICA. Cidades@. Rio de Janeiro, 1991- . Disponível em: < http://www1.ibge.gov.br/cidadesat/index2.htm>. Acesso em: 20 mai. 2001.

INSTITUTO PASTEUR (São Paulo). Raiva. São Paulo: Instituto Pasteur, 1999. (Comunicação Pessoal).

LEECH, F. B.; SELLERS, K. C. Statistical epidemiology in veterinary science. New York: Macmillan Publishing, 1979. 158 p.

PREFEITURA MUNICIPAL DE GUARULHOS. Raiva. Guarulhos: Prefeitura Municipal de Guarulhos, 2000. (Comunicação Pessoal).

SCHNEIDER, M. C.; ALMEIDA, G. A.; SOUZA, L. M.; MORAES, N. B.; DIAZ, R. C. Rabies control in Brazil from 1980 to 1990. Revista Saúde Pública, v. 30, n. 2, p. 196-203, 1996.

SILVA, N. N. Amostragem probabilística. São Paulo: Edusp, 1998. 120 p.

SPOSATI, A. O. Mapa de exclusão-inclusão social na cidade de São Paulo. São Paulo : Educ, 1996. 126 p.

SPPS INC. Spss base 9.0 user's guide. Chicago: SPSS Inc., 1999. 740p.

SPSS base 9.0. Chicago: SPSS Inc., 1999. 1 CD-Rom.

THRUSFIELD, M. Veterinary epidemiology. 2. ed. Cambridge: Blackwell Science, 1995. $479 \mathrm{p}$.

WORLD HEALTH ORGANIZATION. Guidelines for dog population management. Geneva: WHO, 1990. $116 \mathrm{p}$. 


\section{ANEXO 1 - VARIÁVEIS DO CENSO POPULACIONAL DE 1991}

DESCRIÇÃO DO REGISTRO - LAYOUT

VARI NOME

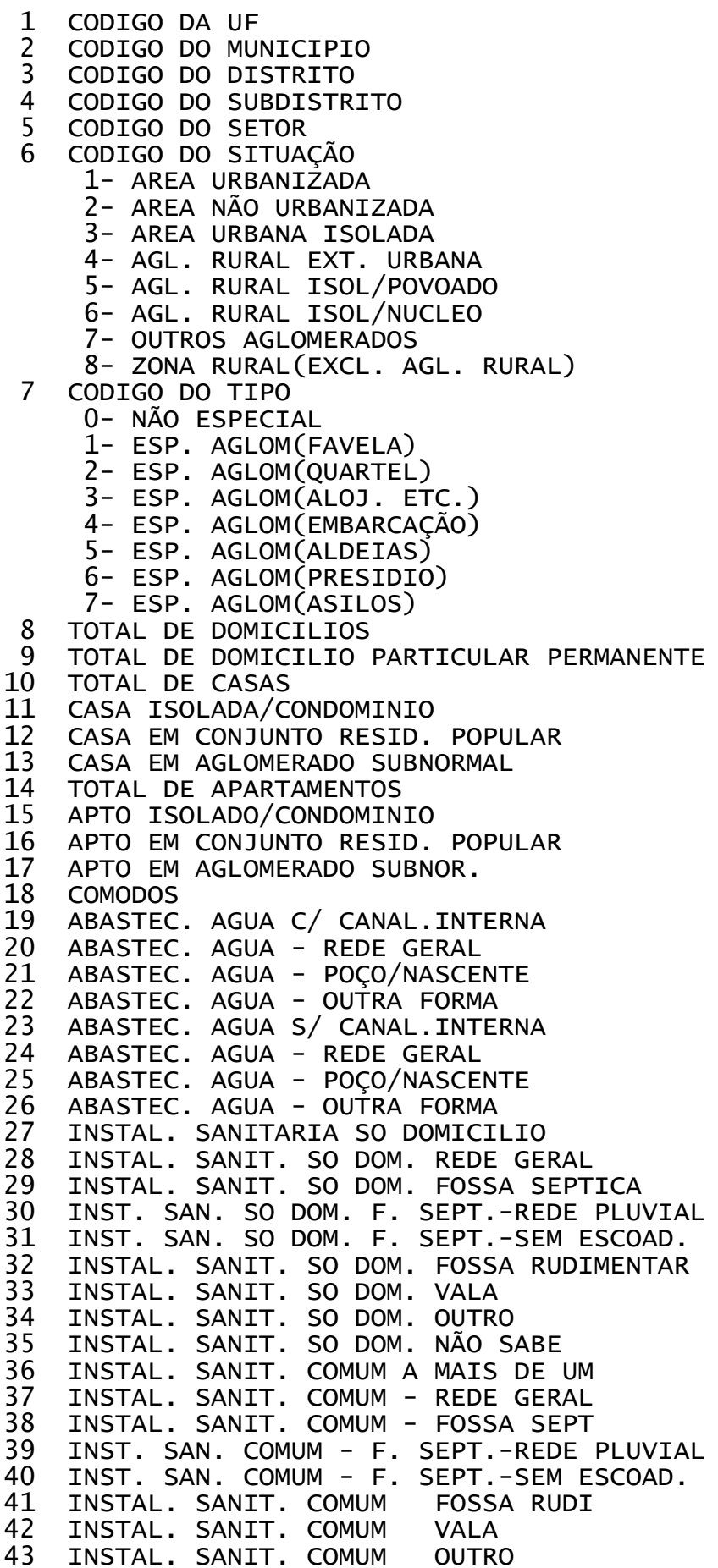


INSTAL. SANIT. COMUM NÃO SABE

INSTALAÇÃOO SANITARIA NÃO TEM

CONDICÃO DE OCUPAÇ̃̃O - PROPRIO

COND OCUP PROPRIO - A CONTR E O TERRENO

COND OCUP PROPRIO - SO A CONTRUÇÃO

CONDIĈ̃̃ DE OCUPAÇÃO - ALUGADO

CONDIÇÃO DE OCUPAÇÃO - CEDIDO

COND OCUP - CEDIDO POR EMPREGADOR

COND OCUP - CEDIDO POR PARTICULAR

CONDIÇÃO DE OCUPAÇÃO - OUTRA

LIXO COLETADO

LIXO COLETADO - DIRETAMENTE

LIXO COLETADO - INDIRETAMENTE

LIXO QUEIMADO

LIXO ENTERRADO

LIXO JOGADO EM

LIXO JOGADO EM TERRENO BALDIO

LIXO JOGADO EM RIO, LAGO OU MAR

LIXO OUTRO DESTINO

N. MEDIO DE COMODOS POR DOMICILIO

N. MEDIO DE DORMIT. POR DOMICILIO

N. MEDIO DE BANHEIROS P/DOMICILIO

N. MEDIO DE PESSOAS POR DOMICILIO

DOMICILIOS PARTIC. IMPROVISADOS

MORADORES EM DOMI PART PERM - TOTAL

HOMENS EM DOMIC. PARTIC. PERMAN.

MULHERES EM DOMIC. PART. PERMAN.

MORADORES EM DOMIC. PART. IMPROV.

HOMENS EM DOMIC. PARTIC. IMPROV.

MULHERES EM DOMIC. PART. IMPROV.

TOTAL DE CHEFES EM DOMIC. PART. PERM

S/ INSTRUÇÃO OU MENOS DE 1 ANO

1 A 3 ANOS DE ESTUDO

4 A 7 ANOS DE ESTUDO

8 A 10 ANOS DE ESTUDO

11 A 14 ANOS DE ESTUDO

15 OU MAIS ANOS DE ESTUDO

RENDIMENTO ATE 1/2 SALARIO MINIMO

MAIS DE $1 / 2$ A 1 SALARIO MINIMO

MAIS DE 1 A 2 SALARIOS MINIMOS

MAIS DE 2 A 3 SALARIOS MINIMOS

MAIS DE 3 A 5 SALARIOS MINIMOS

MAIS DE 5 A 10 SALARIOS MINIMOS

MAIS DE 10 A 15 SALARIOS MINIMOS

MAIS DE 15 A 20 SALARIOS MINIMOS

MAIS DE 20 SALARIOS MINIMOS

SEM RENDIMENTO

SEM DECLARAÇÃO

RENDA MEDIA NOMINAL DOS CHEFES

RENDA MED. NOM. UNID. HAB.EM DOM COL

POPULAÇÃO TOTAL

POPULAÇÃO AFABETIZADAS TOTAL

TOTAL DE 0 A 4 ANOS

TOTAL ALFABETIZADAS DE 0 A 4 ANOS

TOTAL DE 5 A 9 ANOS

TOTAL ALFABETIZADAS DE 5 A 9 ANOS

100 TOTAL DE 10 A 14 ANOS

101 TOTAL ALFABET. DE 10 A 14 ANOS

102 TOTAL DE 15 A 19 ANOS

103 TOTAL ALFABET. DE 15 A 19 ANOS

104 TOTAL DE 20 A 24 ANOS

105 TOTAL ALFABET. DE 20 A 24 ANOS

106 TOTAL DE 25 A 29 ANOS

107 TOTAL ALFABET. DE 25 A 29 ANOS

108 TOTAL DE 30 A 34 ANOS

109 TOTAL ALFABET. DE 30 A 34 ANOS

110 TOTAL DE 35 A 39 ANOS

111 TOTAL ALFABET. DE 35 A 39 ANOS

112 TOTAL DE 40 A 44 ANOS

113 TOTAL ALFABET. DE 40 A 44 ANOS

114 TOTAL DE 45 A 49 ANOS

115 TOTAL ALFABET. DE 45 A 49 ANOS

116 TOTAL DE 50 A 54 ANOS

117 TOTAL ALFABET. DE 50 A 54 ANOS 
118 TOTAL DE 55 A 59 ANOS

119 TOTAL ALFABET. DE 55 A 59 ANOS

120 TOTAL DE 60 A 64 ANOS

121 TOTAL ALFABET. DE 60 A 64 ANOS

122 TOTAL DE 65 A 69 ANOS

123 TOTAL ALFABET. DE 65 A 69 ANOS

124 TOTAL DE 70 A 74 ANOS

125 TOTAL ALFABET. DE 70 A 74 ANOS

126 TOTAL DE 75 A 79 ANOS

127 TOTAL ALFABET. DE 75 A 79 ANOS

128 TOTAL DE 80 ANOS E MAIS

129 TOTAL ALFABET. DE 80 ANOS E MAIS

130 POPULAÇão RESIDENTE HOMENS - TOTAL

131 POPULAÇãO REDIDENTE HOMENS ALFABETIZADOS

132 HOMENS DE 0 A 4 ANOS

133 HOMENS ALFABET. DE $0 \mathrm{~A} 4$ ANOS

134 HOMENS DE 5 A 9 ANOS

135 HOMENS ALFABET. DE 5 A 9 ANOS

136 HOMENS DE 10 A 14 ANOS

137 HOMENS ALFABET. DE 10 A 14 ANOS

138 HOMENS DE 15 A 19 ANOS

139 HOMENS ALFABET. DE 15 A 19 ANOS

140 HOMENS DE 20 A 24 ANOS

141 HOMENS ALFABET. DE 20 A 24 ANOS

142 HOMENS DE 25 A 29 ANOS

143 HOMENS ALFABET. DE 25 A 29 ANOS

144 HOMENS DE 30 A 34 ANOS

145 HOMENS ALFABET. DE 30 A 34 ANOS

146 HOMENS DE 35 A 39 ANOS

147 HOMENS ALFABET. DE 35 A 39 ANOS

148 HOMENS DE 40 A 44 ANOS

149 HOMENS ALFABET. DE 40 A 44 ANOS

150 HOMENS DE 45 A 49 ANOS

151 HOMENS ALFABET. DE 45 A 49 ANOS

152 HOMENS DE 50 A 54 ANOS

153 HOMENS ALFABET. DE 50 A 54 ANOS

154 HOMENS DE 55 A 59 ANOS

155 HOMENS ALFABET. DE 55 A 59 ANOS

156 HOMENS DE 60 A 64 ANOS

157 HOMENS ALFABET. DE 60 A 64 ANOS

158 HOMENS DE 65 A 69 ANOS

159 HOMENS ALFABET. DE 65 A 69 ANOS

160 HOMENS DE 70 A 74 ANOS

161 HOMENS ALFABET. DE 70 A 74 ANOS

162 HOMENS DE 75 A 79 ANOS

163 HOMENS ALFABET. DE 75 A 79 ANOS

164 HOMENS DE 80 ANOS E MAIS

165 HOMENS ALFABET. DE 80 ANOS E MAIS

166 POPULAÇÃO RESIDENTE MULHER - TOTAL

167 POPULAÇÃO RESIDENTE MULHER-ALFABETIZADA

168 MULHERES DE $0 \mathrm{~A} 4$ ANOS

169 MULHERES ALFABET. DE 0 A 4 ANOS

170 MULHERES DE 5 A 9 ANOS

171 MULHERES ALFABET. DE 5 A 9 ANOS

172 MULHERES DE 10 A 14 ANOS

173 MULHERES ALFABET. DE 10 A 14 ANOS

174 MULHERES DE 15 A 19 ANOS

175 MULHERES ALFABET. DE 15 A 19 ANOS

176 MULHERES DE 20 A 24 ANOS

177 MULHERES ALFABET. DE 20 A 24 ANOS

178 MULHERES DE 25 A 29 ANOS

179 MULHERES ALFABET. DE 25 A 29 ANOS

180 MULHERES DE 30 A 34 ANOS

181 MULHERES ALFABET. DE 30 A 34 ANOS

182 MULHERES DE 35 A 39 ANOS

183 MULHERES ALFABET. DE 35 A 39 ANOS

184 MULHERES DE 40 A 44 ANOS

185 MULHERES ALFABET. DE 40 A 44 ANOS

186 MULHERES DE 45 A 49 ANOS

187 MULHERES ALFABET. DE 45 A 49 ANOS

188 MULHERES DE 50 A 54 ANOS

189 MULHERES ALFABET. DE 50 A 54 ANOS

190 MULHERES DE 55 A 59 ANOS

191 MULHERES ALFABET. DE 55 A 59 ANOS 
192 MULHERES DE 60 A 64 ANOS

193 MULHERES ALFABET. DE 60 A 64 ANOS

194 MULHERES DE 65 A 69 ANOS

195 MULHERES ALFABET. DE 65 A 69 ANOS

196 MULHERES DE 70 A 74 ANOS

197 MULHERES ALFABET. DE 70 A 74 ANOS

198 MULHERES DE 75 A 79 ANOS

199 MULHERES ALFABET. DE 75 A 79 ANOS

200 MULHERES DE 80 ANOS E MAIS

201 MULHERES ALFAB. DE 80 ANOS E MAIS

202 POPULAÇÃO NO DOMICILIO TOTAL

203 POPULAÇÃO NO DOMIC ALFABETIZADA TOTAL

204 TOTAL DE CHEFES

205 TOTAL DE CHEFES ALFABETIZADOS

206 TOTAL DE CONJUGES

207 TOTAL DE CONJUGES ALFABETIZADAS

208 TOTAL DE FILHOS

209 TOTAL DE FILHOS ALFABETIZADOS

210 TOTAL DE AGREGADOS

211 TOTAL DE AGREGADOS ALFABETIZADOS

212 TOTAL DE OUTROS PARENTES

213 TOTAL DE OUTROS PARENTES ALFAB.

214 TOTAL DE PENSIONISTAS

215 TOTAL DE PENSIONISTAS ALFABETIZ.

216 TOTAL DE EMPREGADOS DOMESTICOS

217 TOTAL DE EMPREG. DOMESTICOS ALFAB

218 TOTAL DE PARENTE DO EMPREGADO DOM.

219 TOTAL PARENTE EMP DOMESTICO ALFAB

220 TOTAL DE HOMENS NO DOMICILIO

221 TOTAL DE HOMENS NO DOMIC. ALFABETIZADOS

222 HOMEM CHEFE

223 HOMEM CHEFE ALFABETIZADO

224 HOMEM CONJUGE

225 HOMEM CONJUGE ALFABETIZADO

226 HOMEM FILHO

227 HOMEM FILHO ALFABETIZADO

228 HOMEM AGREGADOS

229 HOMEM AGREGADOS ALFABETIZADOS

230 HOMEM OUTROS PARENTES

231 HOMEM OUTROS PARENTES ALFABETIZADOS

232 HOMEM PENSIONISTA

233 HOMEM PENSIONISTA ALFABETIZADO

234 HOMEM EMPREGADO DOMESTICO

235 HOMEM EMPREG. DOMESTICOS ALFAB

236 HOMEM PARENTE DO EMPREGADO DOM.

237 HOMEM PARENTE EMP DOMESTICO ALFAB

238 TOTAL DE MULHERES NO DOMICILIO

239 TOTAL DE MULHERES NO DOMIC.ALFABETIZADAS

240 MULHER CHEFE

241 MULHER CHEFE ALFABETIZADA

242 MULHER CONJUGE

243 MULHER CONJUGE ALFABETIZADA

244 MULHER FILHA

245 MULHER FILHA ALFABETIZADA

246 MULHER AGREGADA

247 MULHER AGREGADA ALFABETIZADA

248 MULHER OUTROS PARENTES

249 MULHER OUTROS PARENTES ALFABET.

250 MULHER PENSIONISTA

251 MULHER PENSIONISTA ALFABETIZADA

252 MULHER EMPREGADA DOMESTICA

253 MULHER EMPREG. DOMESTICA ALFAB

254 MULHER PARENTE DO EMPREGADO DOM.

255 MULHER PARENT EMP DOMESTICO ALFAB

256 N. DE DOMICILIOS

257 N. DE DOMIC. COM 1 MORADOR

258 N. DE DOMIC. COM 2 MORADORES

259 N. DE DOMIC. COM 3 MORADORES

$260 \mathrm{~N}$. DE DOMIC. COM 4 MORADORES

261 N. DE DOMIC. COM 5 MORADORES

262 N. DE DOMIC. COM 6 MORADORES

263 N. DE DOMIC. COM 7 MORADORES

264 N. DE DOMIC. COM 8 MORADORES

$265 \mathrm{~N}$. DE DOMIC. COM 9 MORADORES 
266 N. DE DOM. COM $10 \mathrm{E}+$ MORADORES

267 N. DE DOMIC. PARTICULARES

268 N. DE DOMIC. PART. COM 1 MORADOR

269 N. DE DOM. PART. COM 2 MORADORES

270 N. DE DOM. PART. COM 3 MORADORES

271 N. DE DOM. PART. COM 4 MORADORES

272 N. DE DOM. PART. COM 5 MORADORES

273 N. DE DOM. PART. COM 6 MORADORES

274 N. DE DOM. PART. COM 7 MORADORES

275 N. DE DOM. PART. COM 8 MORADORES

276 N. DE DOM. PART. COM 9 MORADORES

277 N. DE DOM. PART. C/ $10 \mathrm{E}+$ + MORAD.

278 N. DE UNIDAD. HAB. EM DOMIC. COLETIVOS

279 N. UNID. HAB. COLET. C/ 1 MORADOR

280 N. UNID. HAB. COL. C/ 2 MORADORES

281 N. UNID. HAB. COL. C/ 3 MORADORES

282 N. UNID. HAB. COL. C/ 4 MORADORES

283 N. UNID. HAB. COL. C/ 5 MORADORES

284 N. UNID. HAB. COL. C/ 6 MORADORES

285 N. UNID. HAB. COL. C/ 7 MORADORES

286 N. UNID. HAB. COL. C/ 8 MORADORES

287 N. UNID. HAB. COL. C/ 9 MORADORES

288 N. UNID. HAB. COL.C/ $10 \mathrm{E}+$ MORAD.

289 NOME DO MUNICIPIO

290 NOME DO DISTRITO

291 NOME DO SUBDISTRITO

$292 *$ (FIM DE REGISTRO)

* salario min. $(9 / 91)=\mathrm{cr} \$ 36.161,60$ 
ANEXO 2 - MATRIZ DE CORRELAÇÃO DE 38 VARIÁVEIS SELECIONADAS

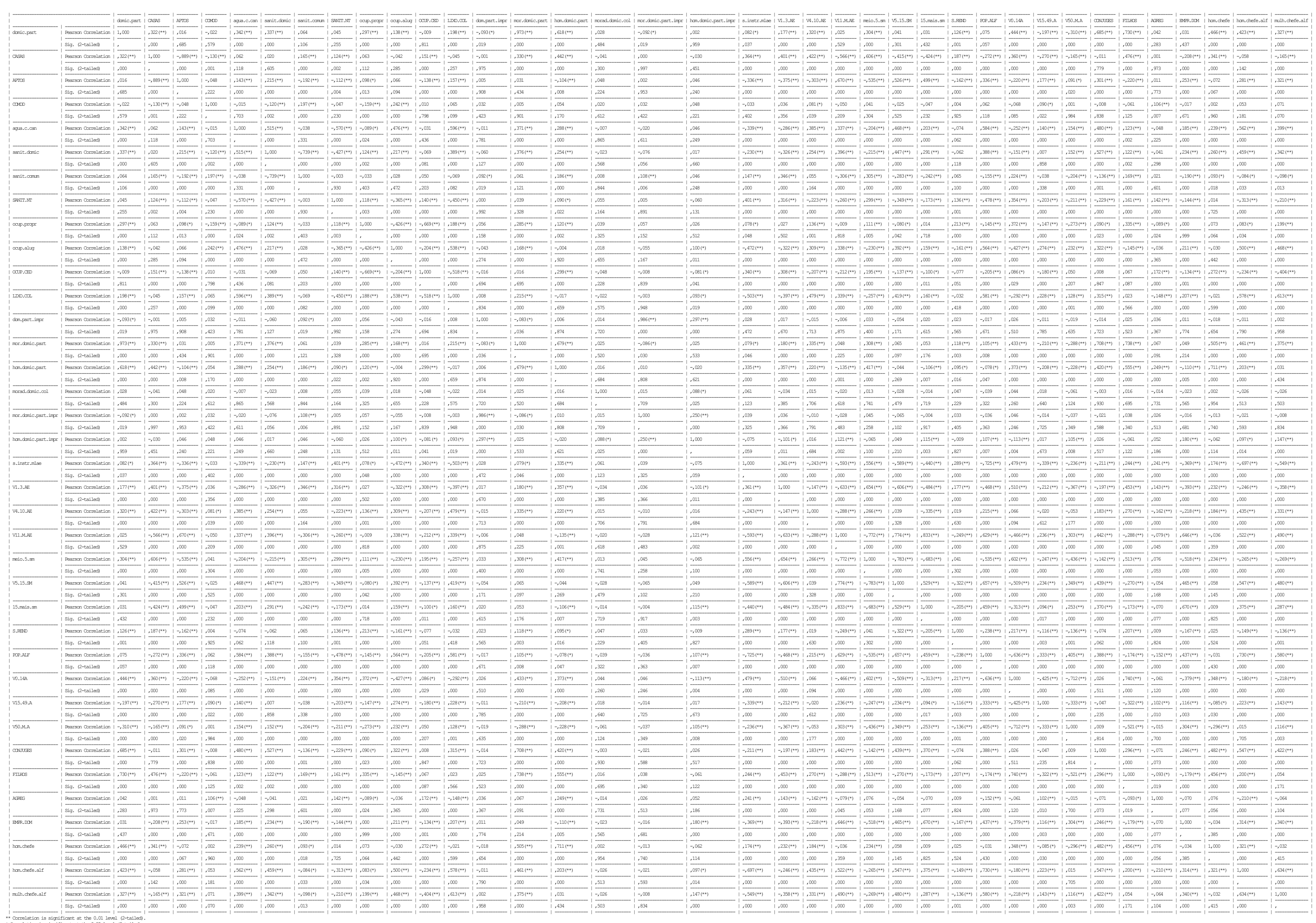




\section{ANEXO 3 - ÁREA SÓCIO-ECONÔMICA A QUE CADA SETOR CENSI- TÁRIO PERTENCE}

\begin{tabular}{|c|c|c|c|c|c|c|c|c|}
\hline SETOR & DISTR. & CLUSTER & SETOR & DISTR. & CLUSTER & SETOR & DISTR. & CLUSTER \\
\hline 1 & 5 & 1 & 31 & 5 & 2 & 62 & 10 & 3 \\
\hline 1 & 10 & 3 & 31 & 10 & 3 & 63 & 5 & 1 \\
\hline 2 & 5 & 1 & 32 & 5 & 2 & 63 & 10 & 3 \\
\hline 2 & 10 & 3 & 32 & 10 & 3 & 64 & 5 & 2 \\
\hline 3 & 5 & 2 & 33 & 5 & 1 & 64 & 10 & 3 \\
\hline 3 & 10 & 2 & 33 & 10 & 3 & 65 & 5 & 3 \\
\hline 4 & 5 & 1 & 34 & 5 & 3 & 65 & 10 & 3 \\
\hline 4 & 10 & 3 & 34 & 10 & 4 & 66 & 5 & 2 \\
\hline 5 & 5 & 1 & 35 & 10 & 3 & 66 & 10 & 3 \\
\hline 5 & 10 & 3 & 36 & 10 & 3 & 67 & 5 & 2 \\
\hline 6 & 5 & 2 & 37 & 10 & 3 & 67 & 10 & 3 \\
\hline 6 & 10 & 3 & 38 & 5 & 2 & 68 & 5 & 2 \\
\hline 7 & 5 & 1 & 38 & 10 & 3 & 68 & 10 & 3 \\
\hline 7 & 10 & 3 & 39 & 5 & 2 & 69 & 5 & 2 \\
\hline 8 & 5 & 3 & 39 & 10 & 3 & 69 & 10 & 3 \\
\hline 8 & 10 & 2 & 40 & 5 & 3 & 70 & 5 & 3 \\
\hline 9 & 5 & 1 & 40 & 10 & 3 & 70 & 10 & 3 \\
\hline 9 & 10 & 3 & 41 & 5 & 2 & 71 & 5 & 2 \\
\hline 10 & 5 & 2 & 41 & 10 & 3 & 71 & 10 & 3 \\
\hline 10 & 10 & 3 & 42 & 5 & 2 & 72 & 5 & 2 \\
\hline 11 & 5 & 2 & 42 & 10 & 3 & 72 & 10 & 3 \\
\hline 11 & 10 & 3 & 43 & 5 & 1 & 73 & 5 & 2 \\
\hline 12 & 5 & 0 & 43 & 10 & 3 & 73 & 10 & 3 \\
\hline 12 & 10 & 3 & 44 & 5 & 2 & 74 & 5 & 2 \\
\hline 13 & 5 & 1 & 44 & 10 & 3 & 74 & 10 & 3 \\
\hline 13 & 10 & 3 & 45 & 5 & 2 & 75 & 5 & 1 \\
\hline 14 & 5 & 5 & 45 & 10 & 3 & 75 & 10 & 3 \\
\hline 14 & 10 & 3 & 46 & 5 & 3 & 76 & 5 & 2 \\
\hline 15 & 5 & 2 & 46 & 10 & 3 & 76 & 10 & 3 \\
\hline 15 & 10 & 3 & 47 & 5 & 2 & 77 & 5 & 2 \\
\hline 16 & 5 & 2 & 47 & 10 & 3 & 77 & 10 & 3 \\
\hline 16 & 10 & 3 & 48 & 5 & 2 & 78 & 10 & 3 \\
\hline 17 & 5 & 1 & 48 & 10 & 2 & 79 & 10 & 3 \\
\hline 17 & 10 & 3 & 49 & 5 & 2 & 80 & 5 & 2 \\
\hline 18 & 5 & 2 & 49 & 10 & 2 & 80 & 10 & 3 \\
\hline 18 & 10 & 3 & 50 & 5 & 2 & 81 & 5 & 2 \\
\hline 19 & 5 & 2 & 50 & 10 & 2 & 81 & 10 & 3 \\
\hline 19 & 10 & 3 & 51 & 5 & 2 & 82 & 5 & 2 \\
\hline 20 & 5 & 1 & 51 & 10 & 2 & 82 & 10 & 3 \\
\hline 20 & 10 & 3 & 52 & 5 & 2 & 83 & 5 & 1 \\
\hline 21 & 5 & 2 & 52 & 10 & 2 & 83 & 10 & 3 \\
\hline 21 & 10 & 3 & 53 & 5 & 2 & 84 & 5 & 2 \\
\hline 22 & 5 & 3 & 53 & 10 & 2 & 84 & 10 & 3 \\
\hline 22 & 10 & 3 & 54 & 5 & 1 & 85 & 5 & 2 \\
\hline 23 & 5 & 2 & 54 & 10 & 3 & 85 & 10 & 5 \\
\hline 23 & 10 & 3 & 55 & 5 & 2 & 86 & 5 & 2 \\
\hline 24 & 5 & 2 & 55 & 10 & 3 & 86 & 10 & 3 \\
\hline 24 & 10 & 3 & 56 & 5 & 3 & 87 & 5 & 3 \\
\hline 25 & 5 & 2 & 56 & 10 & 3 & 87 & 10 & 3 \\
\hline 25 & 10 & 3 & 57 & 5 & 3 & 88 & 5 & 2 \\
\hline 26 & 5 & 2 & 57 & 10 & 3 & 88 & 10 & 3 \\
\hline 26 & 10 & 3 & 58 & 5 & 2 & 89 & 5 & 2 \\
\hline 27 & 5 & 1 & 58 & 10 & 3 & 89 & 10 & 3 \\
\hline 27 & 10 & 3 & 59 & 5 & 2 & 90 & 5 & 2 \\
\hline 28 & 5 & 1 & 59 & 10 & 4 & 90 & 10 & 3 \\
\hline 28 & 10 & 3 & 60 & 5 & 2 & 91 & 5 & 3 \\
\hline 29 & 5 & 2 & 60 & 10 & 3 & 91 & 10 & 4 \\
\hline 29 & 10 & 3 & 61 & 5 & 2 & 92 & 5 & 2 \\
\hline 30 & 5 & 1 & 61 & 10 & 3 & 92 & 10 & 3 \\
\hline 30 & 10 & 3 & 62 & 5 & 2 & 93 & 5 & 3 \\
\hline
\end{tabular}




\begin{tabular}{|c|c|c|c|c|c|c|c|c|}
\hline SETOR & DISTR. & CLUSTER & SETOR & DISTR. & CLUSTER & SETOR & DISTR. & CLUSTER \\
\hline 93 & 10 & 3 & 127 & 5 & 4 & 162 & 5 & 3 \\
\hline 94 & 5 & 3 & 127 & 10 & 3 & 162 & 10 & 4 \\
\hline 94 & 10 & 4 & 128 & 5 & 3 & 163 & 5 & 3 \\
\hline 95 & 5 & 4 & 128 & 10 & 3 & 163 & 10 & 3 \\
\hline 95 & 10 & 3 & 129 & 5 & 1 & 164 & 5 & 3 \\
\hline 96 & 5 & 2 & 130 & 5 & 2 & 164 & 10 & 3 \\
\hline 96 & 10 & 3 & 131 & 5 & 3 & 165 & 5 & 3 \\
\hline 97 & 5 & 2 & 132 & 5 & 2 & 165 & 10 & 4 \\
\hline 97 & 10 & 3 & 132 & 10 & 3 & 166 & 5 & 3 \\
\hline 98 & 5 & 2 & 133 & 5 & 2 & 166 & 10 & 2 \\
\hline 98 & 10 & 3 & 133 & 10 & 3 & 167 & 5 & 3 \\
\hline 99 & 5 & 2 & 134 & 5 & 3 & 167 & 10 & 2 \\
\hline 99 & 10 & 4 & 134 & 10 & 3 & 168 & 5 & 2 \\
\hline 100 & 5 & 2 & 135 & 5 & 2 & 168 & 10 & 4 \\
\hline 100 & 10 & 5 & 135 & 10 & 3 & 169 & 5 & 2 \\
\hline 101 & 5 & 2 & 136 & 5 & 2 & 169 & 10 & 4 \\
\hline 101 & 10 & 4 & 136 & 10 & 3 & 170 & 5 & 2 \\
\hline 102 & 5 & 2 & 137 & 5 & 2 & 170 & 10 & 4 \\
\hline 102 & 10 & 3 & 137 & 10 & 4 & 171 & 5 & 2 \\
\hline 103 & 5 & 2 & 138 & 5 & 1 & 171 & 10 & 4 \\
\hline 103 & 10 & 3 & 138 & 10 & 3 & 172 & 5 & 2 \\
\hline 104 & 5 & 2 & 139 & 5 & 1 & 172 & 10 & 4 \\
\hline 104 & 10 & 3 & 140 & 5 & 2 & 173 & 5 & 2 \\
\hline 105 & 5 & 3 & 140 & 10 & 3 & 173 & 10 & 4 \\
\hline 105 & 10 & 0 & 141 & 5 & 2 & 174 & 5 & 2 \\
\hline 106 & 5 & 2 & 141 & 10 & 4 & 174 & 10 & 5 \\
\hline 106 & 10 & 3 & 142 & 5 & 3 & 175 & 5 & 2 \\
\hline 107 & 5 & 1 & 142 & 10 & 3 & 175 & 10 & 3 \\
\hline 107 & 10 & 3 & 143 & 5 & 1 & 176 & 5 & 3 \\
\hline 108 & 5 & 2 & 143 & 10 & 3 & 176 & 10 & 3 \\
\hline 109 & 5 & 1 & 144 & 5 & 2 & 177 & 5 & 2 \\
\hline 109 & 10 & 3 & 144 & 10 & 4 & 177 & 10 & 5 \\
\hline 110 & 5 & 1 & 145 & 5 & 3 & 178 & 5 & 3 \\
\hline 110 & 10 & 3 & 145 & 10 & 4 & 178 & 10 & 5 \\
\hline 111 & 5 & 2 & 146 & 5 & 2 & 179 & 5 & 3 \\
\hline 111 & 10 & 3 & 146 & 10 & 3 & 179 & 10 & 5 \\
\hline 112 & 5 & 2 & 147 & 5 & 3 & 180 & 5 & 2 \\
\hline 112 & 10 & 5 & 147 & 10 & 2 & 180 & 10 & 5 \\
\hline 113 & 5 & 2 & 148 & 5 & 3 & 181 & 5 & 2 \\
\hline 113 & 10 & 3 & 148 & 10 & 2 & 181 & 10 & 5 \\
\hline 114 & 5 & 2 & 149 & 5 & 3 & 182 & 5 & 2 \\
\hline 114 & 10 & 3 & 149 & 10 & 3 & 182 & 10 & 3 \\
\hline 115 & 5 & 2 & 150 & 5 & 2 & 183 & 10 & 3 \\
\hline 115 & 10 & 3 & 150 & 10 & 5 & 184 & 5 & 2 \\
\hline 116 & 5 & 2 & 151 & 5 & 3 & 184 & 10 & 5 \\
\hline 116 & 10 & 3 & 151 & 10 & 5 & 185 & 5 & 2 \\
\hline 117 & 5 & 3 & 152 & 5 & 2 & 185 & 10 & 5 \\
\hline 117 & 10 & 3 & 152 & 10 & 5 & 186 & 5 & 2 \\
\hline 118 & 5 & 2 & 153 & 5 & 2 & 186 & 10 & 4 \\
\hline 118 & 10 & 3 & 153 & 10 & 2 & 187 & 5 & 2 \\
\hline 119 & 5 & 2 & 154 & 5 & 2 & 187 & 10 & 4 \\
\hline 119 & 10 & 3 & 154 & 10 & 3 & 188 & 5 & 2 \\
\hline 120 & 5 & 2 & 155 & 5 & 2 & 188 & 10 & 5 \\
\hline 120 & 10 & 3 & 155 & 10 & 3 & 189 & 5 & 2 \\
\hline 121 & 5 & 2 & 156 & 5 & 3 & 189 & 10 & 5 \\
\hline 121 & 10 & 3 & 156 & 10 & 3 & 190 & 5 & 2 \\
\hline 122 & 5 & 2 & 157 & 5 & 3 & 190 & 10 & 5 \\
\hline 122 & 10 & 4 & 157 & 10 & 3 & 191 & 5 & 2 \\
\hline 123 & 5 & 2 & 158 & 5 & 3 & 192 & 5 & 1 \\
\hline 123 & 10 & 3 & 158 & 10 & 3 & 193 & 5 & 2 \\
\hline 124 & 5 & 2 & 159 & 5 & 3 & 194 & 5 & 3 \\
\hline 124 & 10 & 3 & 159 & 10 & 2 & 195 & 5 & 3 \\
\hline 125 & 5 & 2 & 160 & 5 & 3 & 196 & 5 & 2 \\
\hline 125 & 10 & 3 & 160 & 10 & 3 & 197 & 5 & 3 \\
\hline 126 & 5 & 2 & 161 & 5 & 2 & 198 & 5 & 0 \\
\hline 126 & 10 & 3 & 161 & 10 & 4 & 199 & 5 & 3 \\
\hline
\end{tabular}




\begin{tabular}{|c|c|c|c|c|c|c|c|c|}
\hline SETOR & DISTR. & CLUSTER & SETOR & DISTR. & CLUSTER & SETOR & DISTR. & CLUSTER \\
\hline 200 & 5 & 3 & 266 & 5 & 3 & 334 & 5 & 2 \\
\hline 201 & 5 & 3 & 267 & 5 & 2 & 335 & 5 & 2 \\
\hline 202 & 5 & 3 & 268 & 5 & 2 & 336 & 5 & 2 \\
\hline 203 & 5 & 3 & 269 & 5 & 3 & 337 & 5 & 2 \\
\hline 204 & 5 & 3 & 270 & 5 & 3 & 338 & 5 & 2 \\
\hline 205 & 5 & 3 & 271 & 5 & 3 & 339 & 5 & 2 \\
\hline 206 & 5 & 3 & 272 & 5 & 3 & 340 & 5 & 2 \\
\hline 207 & 5 & 3 & 273 & 5 & 2 & 341 & 5 & 3 \\
\hline 208 & 5 & 3 & 274 & 5 & 1 & 342 & 5 & 3 \\
\hline 209 & 5 & 3 & 275 & 5 & 3 & 343 & 5 & 3 \\
\hline 210 & 5 & 3 & 276 & 5 & 3 & 344 & 5 & 2 \\
\hline 211 & 5 & 3 & 277 & 5 & 3 & 345 & 5 & 3 \\
\hline 212 & 5 & 3 & 278 & 5 & 3 & 346 & 5 & 3 \\
\hline 213 & 5 & 3 & 279 & 5 & 3 & 347 & 5 & 3 \\
\hline 214 & 5 & 3 & 280 & 5 & 1 & 348 & 5 & 3 \\
\hline 215 & 5 & 4 & 281 & 5 & 1 & 349 & 5 & 3 \\
\hline 216 & 5 & 3 & 282 & 5 & 1 & 350 & 5 & 3 \\
\hline 217 & 5 & 3 & 283 & 5 & 2 & 351 & 5 & 3 \\
\hline 218 & 5 & 3 & 284 & 5 & 4 & 352 & 5 & 3 \\
\hline 219 & 5 & 4 & 285 & 5 & 2 & 353 & 5 & 2 \\
\hline 220 & 5 & 3 & 286 & 5 & 2 & 354 & 5 & 4 \\
\hline 221 & 5 & 3 & 287 & 5 & 2 & 355 & 5 & 3 \\
\hline 222 & 5 & 3 & 288 & 5 & 2 & 356 & 5 & 3 \\
\hline 223 & 5 & 2 & 289 & 5 & 2 & 357 & 5 & 3 \\
\hline 224 & 5 & 1 & 290 & 5 & 2 & 358 & 5 & 3 \\
\hline 225 & 5 & 2 & 291 & 5 & 2 & 359 & 5 & 3 \\
\hline 226 & 5 & 3 & 292 & 5 & 2 & 360 & 5 & 3 \\
\hline 227 & 5 & 3 & 293 & 5 & 2 & 361 & 5 & 3 \\
\hline 228 & 5 & 5 & 294 & 5 & 2 & 362 & 5 & 0 \\
\hline 229 & 5 & 3 & 295 & 5 & 2 & 363 & 5 & 2 \\
\hline 230 & 5 & 3 & 296 & 5 & 2 & 364 & 5 & 3 \\
\hline 231 & 5 & 3 & 297 & 5 & 2 & 365 & 5 & 3 \\
\hline 232 & 5 & 2 & 298 & 5 & 3 & 366 & 5 & 3 \\
\hline 233 & 5 & 2 & 300 & 5 & 2 & 369 & 5 & 3 \\
\hline 234 & 5 & 2 & 301 & 5 & 3 & 370 & 5 & 3 \\
\hline 235 & 5 & 2 & 302 & 5 & 3 & 371 & 5 & 3 \\
\hline 236 & 5 & 2 & 303 & 5 & 3 & 372 & 5 & 3 \\
\hline 237 & 5 & 2 & 304 & 5 & 3 & 373 & 5 & 1 \\
\hline 238 & 5 & 1 & 305 & 5 & 3 & 374 & 5 & 1 \\
\hline 239 & 5 & 2 & 306 & 5 & 3 & 375 & 5 & 1 \\
\hline 240 & 5 & 2 & 307 & 5 & 3 & 376 & 5 & 1 \\
\hline 241 & 5 & 2 & 309 & 5 & 3 & 377 & 5 & 1 \\
\hline 242 & 5 & 2 & 310 & 5 & 5 & 378 & 5 & 1 \\
\hline 243 & 5 & 2 & 311 & 5 & 3 & 379 & 5 & 1 \\
\hline 244 & 5 & 3 & 312 & 5 & 3 & 380 & 5 & 0 \\
\hline 245 & 5 & 2 & 313 & 5 & 3 & 381 & 5 & 3 \\
\hline 246 & 5 & 2 & 314 & 5 & 3 & 382 & 5 & 3 \\
\hline 247 & 5 & 2 & 315 & 5 & 3 & 383 & 5 & 3 \\
\hline 248 & 5 & 3 & 316 & 5 & 3 & 384 & 5 & 3 \\
\hline 249 & 5 & 3 & 317 & 5 & 2 & 385 & 5 & 4 \\
\hline 250 & 5 & 2 & 318 & 5 & 3 & 386 & 5 & 3 \\
\hline 251 & 5 & 3 & 319 & 5 & 2 & 387 & 5 & 3 \\
\hline 252 & 5 & 2 & 320 & 5 & 3 & 388 & 5 & 3 \\
\hline 253 & 5 & 3 & 321 & 5 & 3 & 389 & 5 & 3 \\
\hline 254 & 5 & 3 & 322 & 5 & 2 & 390 & 5 & 3 \\
\hline 255 & 5 & 3 & 323 & 5 & 3 & 391 & 5 & 3 \\
\hline 256 & 5 & 3 & 324 & 5 & 2 & 392 & 5 & 4 \\
\hline 257 & 5 & 3 & 325 & 5 & 3 & 393 & 5 & 3 \\
\hline 258 & 5 & 3 & 326 & 5 & 3 & 394 & 5 & 3 \\
\hline 259 & 5 & 3 & 327 & 5 & 2 & 395 & 5 & 3 \\
\hline 260 & 5 & 3 & 328 & 5 & 3 & 396 & 5 & 3 \\
\hline 261 & 5 & 3 & 329 & 5 & 3 & 397 & 5 & 3 \\
\hline 262 & 5 & 3 & 330 & 5 & 2 & 398 & 5 & 3 \\
\hline 263 & 5 & 3 & 331 & 5 & 2 & 399 & 5 & 3 \\
\hline 264 & 5 & 3 & 332 & 5 & 2 & 400 & 5 & 3 \\
\hline 265 & 5 & 3 & 333 & 5 & 3 & 401 & 5 & 3 \\
\hline
\end{tabular}




\begin{tabular}{|c|c|c|c|c|c|c|c|c|}
\hline SETOR & DISTR. & CLUSTER & SETOR & DISTR. & CLUSTER & SETOR & DISTR. & CLUSTER \\
\hline 402 & 5 & 4 & 424 & 5 & 3 & 450 & 5 & 3 \\
\hline 403 & 5 & 4 & 426 & 5 & 5 & 451 & 5 & 3 \\
\hline 404 & 5 & 4 & 427 & 5 & 4 & 452 & 5 & 5 \\
\hline 405 & 5 & 4 & 428 & 5 & 4 & 453 & 5 & 5 \\
\hline 406 & 5 & 0 & 429 & 5 & 4 & 455 & 5 & 1 \\
\hline 407 & 5 & 0 & 430 & 5 & 4 & 456 & 5 & 3 \\
\hline 408 & 5 & 4 & 431 & 5 & 4 & 457 & 5 & 3 \\
\hline 409 & 5 & 4 & 432 & 5 & 3 & 460 & 5 & 3 \\
\hline 410 & 5 & 3 & 433 & 5 & 3 & 461 & 5 & 3 \\
\hline 411 & 5 & 4 & 435 & 5 & 5 & 462 & 5 & 3 \\
\hline 412 & 5 & 4 & 436 & 5 & 3 & 463 & 5 & 3 \\
\hline 413 & 5 & 4 & 437 & 5 & 3 & 464 & 5 & 3 \\
\hline 414 & 5 & 4 & 438 & 5 & 3 & 465 & 5 & 3 \\
\hline 415 & 5 & 4 & 439 & 5 & 3 & 467 & 5 & 3 \\
\hline 416 & 5 & 5 & 440 & 5 & 3 & 468 & 5 & 3 \\
\hline 417 & 5 & 4 & 441 & 5 & 3 & 469 & 5 & 4 \\
\hline 418 & 5 & 4 & 443 & 5 & 3 & 471 & 5 & 4 \\
\hline 419 & 5 & 4 & 444 & 5 & 3 & 472 & 5 & 4 \\
\hline 420 & 5 & 4 & 445 & 5 & 3 & 473 & 5 & 4 \\
\hline 421 & 5 & 4 & 446 & 5 & 4 & 474 & 5 & 5 \\
\hline 422 & 5 & 4 & 448 & 5 & 3 & 475 & 5 & 0 \\
\hline 423 & 5 & 4 & 449 & 5 & 3 & 476 & 5 & 5 \\
\hline
\end{tabular}

Distrito 5: Distrito de Guarulhos

Distrito 10: Distrito de Jardim Presidente Dutra 
ANEXO 4 - LISTA DE ENDEREÇOS DOS POSTOS DE VACINAÇÃO

\begin{tabular}{|c|c|c|c|c|c|}
\hline Posto & Endereço & Bairro & $\begin{array}{l}\text { Cães Vaci- } \\
\text { nados }\end{array}$ & $\begin{array}{l}\text { Gatos Vaci- } \\
\text { nados }\end{array}$ & $\begin{array}{l}\begin{array}{l}\text { Raio } \\
(\mathrm{m})\end{array} \\
\end{array}$ \\
\hline EMEI CERQUEIRA CÉSAR & Av. Domingos Fanganiello, 251 & Ponte Grande & 423 & 54 & 420 \\
\hline EE MAL CARLOS MACHADO BITTENCOURT & R. Madalena Rampanelli, 39 & Ponte Grande & 639 & 90 & 373 \\
\hline EE(A) ANA MARIA CAVALLARI & R. Sd. Antônio Patrocínio Fernandes, 212 & Ponte Grande & 180 & 19 & 413 \\
\hline EE ROTARY & Av. Sen. Adolf Schindling, 361 & Itapegica & 140 & 31 & 1019 \\
\hline EE ÉRICO VERÍSSIMO & R. Portuguesa, 500 & Vila Endres & 228 & 26 & 632 \\
\hline EMEI DA EMÍLIA & R. João Lopret, 150 & Vila São João & 370 & 49 & 510 \\
\hline EE CORONEL ARY GOMES & R. Alegre, $s / n$ & Vila São Rafael & 788 & 109 & 414 \\
\hline EE JOÃO CRISPINIANO SOARES & R. Francisco Antunes, 35 & Vila Augusta & 516 & 52 & 439 \\
\hline EE PROF JOSÉ SCARAMELLI & R. das Palmeiras, 440 & $\begin{array}{l}\text { Vila Paulista } \\
\text { Jd. Sta. Francis- }\end{array}$ & 374 & 72 & 490 \\
\hline EE PROF PAULO NOGUEIRA & R. Bartolomeu de Gusmão, 2 & ca & 258 & 38 & 554 \\
\hline CENTRO EDUCACIONAL DO SESI & R. Felipe C. de Vasconcelos, $s / n$ & V. Sorocabana & 96 & 6 & 500 \\
\hline EMEI PE JOÃo ÁLVARES & R. Estilac Leal, 235 & Macedo & 26 & 4 & 234 \\
\hline EE PROF ÊNIO CHIESA & R. Mariano Manzoni, 11 & V. Silveira & 646 & 92 & 344 \\
\hline EE CLARICE LISPECTOR & R. Meiguel Biondi, 566 & Torres Tibagi & 798 & 167 & 447 \\
\hline EE VER WALDEMAR FREIRE VERAS & R. Dr. Brandão Veras, 14 & Vila Tijuco & 275 & 40 & 478 \\
\hline EE ANITA SARACENI & Av. Emílio Ribas, 998 & Vila Paulista & 468 & 68 & 676 \\
\hline EMEI OLAVO BILAC & R. Jacob, 447 & Jd. Tranquilidade & 762 & 70 & 720 \\
\hline EE PROFA IZABEL F DOS SANTOS (D BELINHA) & R. Ciriaco, 27 & Jd. Tranquilidade & 476 & 102 & 404 \\
\hline EMEI SIQUEIRA BUENO & Pça. Nossa Senhora Aparecida, 33 & Jd. Vila Galvão & 795 & 96 & 487 \\
\hline EE PROF FABIO FANUCCHI & Av. Faustino Ramalho, s/n & Jd. Vila Galvão & 391 & 66 & 352 \\
\hline EE EMÍLIA ANNA ANTÔNIO & R. Moras, $s / n$ & Pq. Sto. Antônio & 555 & 78 & 381 \\
\hline CAMPO DO SANTA CRUZ & & Cabuçu & 0 & 0 & 0 \\
\hline EE PEDREIRA FIRPAVI & Estr. da Barrocada, 7200 & $\begin{array}{l}\text { Cabuçu } \\
\text { Jd. Rosa de }\end{array}$ & 0 & 0 & 0 \\
\hline EE JUVENAL RAMOS BARBOSA & R. Marcos A. Liotta, s/n & $\begin{array}{l}\text { França } \\
\text { Jd. Rosa de }\end{array}$ & 655 & 53 & 558 \\
\hline EE WANDA MASCAGNI DE SÁ & R. Olga M. Liotta, 63 & França & 315 & 36 & 528 \\
\hline EE JOSÉ ROBERTO FRIEBOLIN & R. Bahia, s/n & Vila Rosália & 824 & 95 & 574 \\
\hline EMEI PE MANUEL DE PAIVA & Av. Francisco Conde, 600 & Vila Rosália & 317 & 46 & 440 \\
\hline EE(A) LAR DA IRMÃ CELESTE & Av. Timóteo Penteado, 3035 & Torres Tibagi & 152 & 18 & 583 \\
\hline EE JOSÉ ALVES DE CERQUEIRA CÉSAR & Av. São Luiz, 451 & Vila Rosália & 163 & 16 & 463 \\
\hline EE DONA BRASÍLIA CASTANHO DE OLIVEIRA & R. Anésio, $s / n$ & $\begin{array}{l}\text { Picanço } \\
\text { Flor da Monta- }\end{array}$ & 414 & 100 & 527 \\
\hline EMEI GABRIEL JOSÉ ANTÔNIO & R. Edson de Souza, 85 & & 688 & 119 & 403 \\
\hline EE PROFA JOCILA P GUIMARÃES & R. Maria Elisa da Nóbrega, 100 & Vila Galvão & 466 & 25 & 485 \\
\hline EMEI MOREIRA MATOS & Av. Vitorino Freire, 201 & Vila Galvão & 583 & 47 & 588 \\
\hline EMEI TIA NASTÁCIA & R. Vila Lobos, s/n & Paraventi & 577 & 56 & 413 \\
\hline EE PROFA ALICE CHUERI & R. Antônio de Camargo, s/n & V. São Jorge & 377 & 65 & 427 \\
\hline EE PROF FRANCISCA BATISTA TRINDADE & R. Paulo José Bazzani, 268 & Macedo & 118 & 5 & 359 \\
\hline EE JD STA CLARA / JD ROSSI & Trav. José Rossi, 40 & Jd. Rossi & 98 & 14 & 452 \\
\hline EE VER ANTÔNIO DE RÉ & R. da Penha 123 & Macedo & 421 & 52 & 585 \\
\hline EE PROF SILVÉRIO BERTONI & R. São Geraldo, 303 & Jd. Sta. Cecilia & 932 & 140 & 588 \\
\hline EE FIORAVANTE IERVOLINO & R. Juracy de Camargo, 60 & Vila Industrial & 639 & 94 & 550 \\
\hline EMEI JOÃO CRISPINIANO SOARES & Av. Bom Clima, 175 & Bom Clima & 700 & 56 & 486 \\
\hline EE DEP CANTÍDIO SAMPAIO & R. Guaratuba, 14 & Vila Flórida & 671 & 148 & 534 \\
\hline EE PROFA FRANCISCA DE ASSIS F NOVAK & Av. Santa Bárbara, s/n & Jd. Sta. Bárbara & 609 & 100 & 354 \\
\hline EMEI ASSIS FERREIRA & R. José Manoel M. da Cunha, 81 & V. Fátima & 491 & 113 & 431 \\
\hline EE VALDIVINO DE CASTRO PEREIRA & Av. Tiradentes, 153 & V. Flórida & 620 & 83 & 524 \\
\hline EE FRANCISCO ANTUNES FILHO & Av. Monteiro Lobato, s/n & CECAP & 160 & 45 & 508 \\
\hline EE LEOPOLDO GENTIL JÚNIOR & R. Cristóbal Cláudio Elillo, 1 & CECAP & 202 & 41 & 695 \\
\hline EMEI PROFA DALVA MARINA R MINGOSSI & R. Aporé, 133-B & V. Barros & 503 & 40 & 574 \\
\hline EE PROF ROBERTO ALVES DOS SANTOS & R. Carlos Korkischiko, 80 & V. Barros & 855 & 135 & 468 \\
\hline EMEI JD IPANEMA & R. Maria Lúcia, 87 & Jd. Ipanema & 378 & 66 & 451 \\
\hline EE PROF JOAQUIM GARCIA SALVADOR & R. Catulo da P. Cearense, 242 & Jd. América & 744 & 65 & 421 \\
\hline EE PROFA ODETE F PINTO DA SILVA & R. Chibatta, 126 & Jd. Bela Vista & 807 & 144 & 452 \\
\hline EMEI CASIMIRO DE ABREU & R. Itaguaí, 42 & $\begin{array}{l}\text { Jd. Moreira } \\
\text { Pq. Continental }\end{array}$ & 856 & 145 & 437 \\
\hline EMEI DOLORES GILABEL HERNANDES POMPEO & R. Carlos Rodrigues, $\mathrm{s} / \mathrm{n}$ & II & 540 & 77 & 545 \\
\hline EE JOSÉ MARUN ATALLA & R. $36, \mathrm{~s} / \mathrm{n}$ & Pq. Continental & 802 & 91 & 466 \\
\hline
\end{tabular}




\begin{tabular}{|c|c|c|c|c|c|}
\hline Posto & Endereço & Bairro & $\begin{array}{l}\text { Cães Vaci- } \\
\text { nados }\end{array}$ & $\begin{array}{l}\text { Gatos Vaci- } \\
\text { nados }\end{array}$ & $\begin{array}{l}\text { Raio } \\
(\mathrm{m})\end{array}$ \\
\hline EMEI ANTÔNIO GONÇALVES DIAS & R. Augusta dos Santos Augusto, 47 & Jd. Palmira & 963 & 117 & 386 \\
\hline EE PROFA GENOEFA D'AQUINO PACCITI & R. Augusto Barbosa, 100 & Jd. Palmira & 531 & 74 & 319 \\
\hline EMEI SELMA COLALLILO MARQUES & Av. Salgado Filho, 3295 & V. Rio de Janeiro & 531 & 66 & 751 \\
\hline EMEI VER SVAA EVANS & Av. Benjamin Harris Hannicult, 2632 & V. Rio de Janeiro & 588 & 69 & 512 \\
\hline EE PEDRO ROBERTO VAGHI & R. Falcão Dourado, s/n & Jd. Adriana & 631 & 50 & 507 \\
\hline EE FRANCISCO MILTON ANDRADE & R. 115,30 & Cambará & 619 & 83 & 441 \\
\hline EE MARIA HELENA FARIA LIMA E CUNHA & Estr. do Cabuçu, 8000 & Cabuçu & 765 & 118 & 1326 \\
\hline EE BOM PASTOR & R. Palmira Rossi, 110 & Recr. S. Jorge & 1494 & 212 & 563 \\
\hline EMEI DO RECREIO SÃO JORGE & R. Itororós, $\mathrm{s} / \mathrm{n}$ & Recr. S. Jorge & 492 & 87 & 203 \\
\hline CLUBE DAS MÃES NOVO RECREIO & R. Paulo Canarinho, 65 & $\begin{array}{l}\text { N. Recreio } \\
\text { Pq. Continental }\end{array}$ & 321 & 69 & 0 \\
\hline CENTRO EDUCACIONAL DO SESI & R. Benedito Caetano da Cruz, 560 & VI & 427 & 77 & 0 \\
\hline EE HILDA PRATES GALLO & Av. Brig. Faria Lima, 3700 & Morros & 604 & 65 & 691 \\
\hline EMEI DR JOSÉ MAURÍCIO DE OLIVEIRA & R. dos Orixás, 10-B & Morros & 558 & 74 & 385 \\
\hline SAB DO JD ELISABETE & R. Serra Negra, 312 & Jd. Elisabeth & 723 & 107 & 324 \\
\hline EE VALDERICE T DA MOTA C MARCHINI & Av. Anibal Martins, $\mathrm{s} / \mathrm{n}$ & Jd. Sta. Emília & 972 & 185 & 361 \\
\hline EE PREF WALDOMIRO POMPEO & R. Carilau Cerri, 60 & Jd. Divinolândia & 720 & 116 & 401 \\
\hline EE PASTOR AMARO JOSÉ DOS SANTOS & R. Sarutaia, 90 & Jd. S. Paulo & 543 & 53 & 406 \\
\hline EE PROFA BENEDITA DE OLIVEIRA ALE & R. S. João Del Rey, 141 & Jd. Jovaia & 861 & 108 & 458 \\
\hline EE PROF JOSÉ SYLVIO CIMINO & Al. Amélia Martins, s/n & Jd. Sta. Emília & 615 & 89 & 346 \\
\hline EMEI PEDRINHO E NARIZINHO & R. Água Vermelha, 71-A & Jd. Sta. Emília & 434 & 70 & 311 \\
\hline EMEI LINO FERREIRA DE OLIVEIRA & R. Maria Luisa Perico, $\mathrm{s} / \mathrm{n}$ & Jd. Acácio & 739 & 112 & 466 \\
\hline EE PADRE ANTÔNIO VELASCO DE ARAGÃO & R. Fraiburgo, 100 & Jd. Belvedere & 866 & 148 & 421 \\
\hline EE MARIA CÉLIA FALCÃO RODRIGUES & R. Aracy Valente, $s / n$ & Pq. Mikail & 1250 & 230 & 453 \\
\hline ASSOC PRÓ-MORADIA NOSSO TETO & R. S. Sebastião da Boa Vista, 1053 & Jd. Sta. Lídia & 533 & 121 & 300 \\
\hline EE MARIA ANGÉLICA SOAVE & R. Coronel Pacheco, s/n & Jd. Nova Taboão & 457 & 54 & 477 \\
\hline EMEI AMADOR BUENO & R. Maria Elisa, 10 & Taboão & 522 & 75 & 402 \\
\hline EE FLÁVIO XAVIER ARANTES & & & 866 & 133 & 377 \\
\hline EE PROF MILTON CERNACH & Av. Cesário Lange, s/n & Jd. Paraíso & 1060 & 151 & 446 \\
\hline EE VICTOR CIVITA & R. Regiano, $s / n$ & Cid. Jd. Cumbica & 449 & 70 & 561 \\
\hline EE COM JOÃO RIBEIRO DE BARROS & R. Juazeiro do Norte, $s / n$ & Cumbica & 432 & 62 & 547 \\
\hline EE ALEXANDRE LOPES OLIVEIRA & Pça. do Vaticano, s/n & $\begin{array}{l}\text { Jd. das Nações } \\
\text { Conj. P. de }\end{array}$ & 462 & 60 & 478 \\
\hline EMEI VISCONDE DE SABUGOSA & R. Pte. Branca, 20 & Barros & 350 & 68 & 438 \\
\hline EE BRIG DO AR ROBERTO H DA COSTA & R. Aceburgo, 544 & Cid. Soimco & 496 & 105 & 583 \\
\hline EE CIDADE SOIMCO II & Av. Plínio F. Gonçalves, s/n & Cumbica & 892 & 158 & 579 \\
\hline EE PROFA LAURA DA P DE CASTRO MENDES & R. Imaculada, $\mathrm{s} / \mathrm{n}$ & Jd. S. Manoel & 299 & 45 & 300 \\
\hline EE PROF ALBERTO BACAN & R. Jaguaribe, 20 & Jd. N. Cumbica & 789 & 200 & 715 \\
\hline EE JOÃO DE ALMEIDA BARBOSA & Av. Nova Cumbica, s/n & Jd. N. Cumbica & 294 & 77 & 658 \\
\hline EE MARIO NAKATA & R. Eurachio Maurício, $s / n$ & Cid. Tupinambá & 997 & 164 & 858 \\
\hline EE CONJ RES BAIRRO DOS PIMENTAS II & Av. Marginal Sul, s/n & Pimentas & 616 & 157 & 284 \\
\hline EE ANNA LAMBERG ZEGLIO & Av. Marginal Sul, s/n & Pimentas & 736 & 180 & 707 \\
\hline EE PROFA ALAYDE MARIA VICENTE & R. Ida Righi, 100 & Jd. M. Alice & 746 & 124 & 599 \\
\hline EMEI IONE GONÇALVES OLIVEIRA DE CONTI & Estr. do Sacramento, 777 & Cid. Tupinambá & 649 & 97 & 738 \\
\hline EE ORLANDO MINELLA & R. Candelária, s/n & Jd. Jaci & 919 & 149 & 554 \\
\hline EMEI JD GUARACY & Av. 2 e $3, s / n$ & Jd. Guaracy & 491 & 84 & 508 \\
\hline EE CID AUGUSTO GUELLI & R. Braga, 100 & V. Any & 725 & 116 & 543 \\
\hline EE(A) REP DA VENEZUELA & R. Boca da Mata, $s / n$ & Jd. Arapongas & 515 & 112 & 482 \\
\hline PÁTIO DA REGIONAL & Av. Venturosa, 150 & Jd. Cumbica & 874 & 160 & 902 \\
\hline EE PROF JOÃO CAVALHEIRO SALEM & R. Porto Velho, 125 & Jd. Cumbica & 945 & 193 & 474 \\
\hline EE PROFA MARIA LEDA FERNANDES BRIGO & R. Wambesi, s/n & Jd. Ottawa & 431 & 64 & 401 \\
\hline EE HUGO DE AGUIAR & Av. José Miguel Ackia, 150 & V. Paraíso & 1507 & 173 & 723 \\
\hline EMEI CASSIANO RICARDO & R. Itatira, $s / n$ & Jd. Uirapuru & 859 & 154 & 381 \\
\hline EE OSWALDO SAMPAIO ALVES & R. Ouricuri, 16 & Jd. M. Dirce & 560 & 52 & 457 \\
\hline EMEI ZILDA FURINI FANGANIELO & R. Aracaju, $s / n$ & Jd. Leblon & 956 & 135 & 615 \\
\hline EE PROF LICINIO CARPINELLI & Av. Centenário, s/n & Jd. Centenário & 889 & 133 & 500 \\
\hline EE PROF PASCOAL MAIMONI & R. Telha, 100 & Jd. Angélica & 738 & 163 & 668 \\
\hline EE PEDRO MORCELI & R. João Carlos Zanaroll, s/n & Jd. Angélica & 1154 & 164 & 516 \\
\hline EE PASTOR JOÃO NUNES & Av. Centenário, s/n & Jd. Centenário & 620 & 92 & 635 \\
\hline EMEI GRACIRA M TRAMA & R. Ivinhema, 1 & Jd. Sto. Afonso & 393 & 80 & 433 \\
\hline EE GUILHERMINO RODRIGUES DE LIMA & R. do Grupo, s/n & Pimentas & 649 & 92 & 465 \\
\hline EMEI NELSON ANDRADE & R. Berillo, 6 & Pq. Alvorada & 1159 & 206 & 545 \\
\hline EMEI MANUEL BANDEIRA & R. Jutaí, 138 & Pq. Alvorada & 768 & 138 & 708 \\
\hline
\end{tabular}




\begin{tabular}{|c|c|c|c|c|c|}
\hline Posto & Endereço & Bairro & $\begin{array}{l}\text { Cães Vaci- } \\
\text { nados }\end{array}$ & $\begin{array}{l}\text { Gatos Vaci- } \\
\text { nados }\end{array}$ & $\begin{array}{l}\text { Raio } \\
(\mathrm{m})\end{array}$ \\
\hline EE PROF ANTÔNIO VIANA DE SOUZA & R. Jupira, 132 & Pq. Jurema & 832 & 86 & 769 \\
\hline EE MARIA AP FELIX PORTO & R. Japão, $s / n$ & Pq. das Nações & 735 & 85 & 831 \\
\hline EE DEP MAURÍ́CIO GOULART & R. Itacarambi, 8 & V. Dinamarca & 615 & 68 & 524 \\
\hline EMEI DR VICENTE FERREIRA SILVEIRA & R. $5-B, s / n$ & Jd. N. Cidade & 801 & 153 & 999 \\
\hline EE THEREZINHA CLOSA EULETÉRIO & R. Charles Muller Cooper, 35 & Pq. M. Helena & 1439 & 231 & 561 \\
\hline EE PROF ARTHUR MARRET & R. Itutinga, $s / n$ & Bonsucesso & 1045 & 153 & 535 \\
\hline EE HÉLIO POLESEL & R. Cordeiros, 20 & Bonsucesso & 904 & 191 & 391 \\
\hline EMEI JOCYMARA DE FALCHI JORGE & R. Flor da Serra/Av. Serra Mantiqueira & V. Carmela & 1242 & 181 & 500 \\
\hline EE CHIYO YAMAMOTO & Av. Yamamoto, $s / n$ & Sadokim & 541 & 103 & 874 \\
\hline EMEI INÊS RIZZATO RODRIGUES & R. Pe. Marcos, 371 & Cid. Aracilia & 625 & 83 & 488 \\
\hline EE PROF ESTEVAN DIAS TAVARES & R. Dr. Arthur M. Siqueira, 121 & Bonsucesso & 604 & 77 & 779 \\
\hline EMEI AMÉLIA DUARTE DA SILVA & R. Maria Quitéria J. Medeiros, s/n & Ponte Alta & 2320 & 367 & 820 \\
\hline EE PROF CYRO BARREIROS & Av. Aracati, 4 & Jd. Lenise & 1229 & 172 & 720 \\
\hline EMEI CIDADE SOBERANA & R. Taubaté, lote 6 & Cid. Soberana & 1948 & 277 & 758 \\
\hline EE PROFA ILIA ZILDA INNOCENTI BLANCO & Estr. Velha de Itaberaba, 2600 & Lavras & 620 & 123 & 663 \\
\hline EE(A) PROFA MARIA AP R MAGALHÃES & Estr. Velha de Itaberaba, 145 & Lavras & 847 & 178 & 505 \\
\hline EMEI GIOVANI ANGELINI & R. Ivan Edmundo Scaramelli, 100 & Jd. Bonança & 623 & 98 & 331 \\
\hline EMEI JD FORTALEZA & R. Roberto Magalhães, 32 & $\begin{array}{l}\text { Jd. Fortaleza } \\
\text { Jd. Sta. Teresi- }\end{array}$ & 1181 & 173 & 724 \\
\hline EE DEP JOSÉ STORÓPOLI & Estr. de Itaberaba, $\mathrm{s} / \mathrm{n}$ & & 746 & 113 & 709 \\
\hline EMEI DONA BENTA & R. Taipú, $s / n$ & Jd. S. João & 908 & 145 & 481 \\
\hline EE CAP AVIADOR SANDI MIYAKE & Av. Juarez Távora, 171 & Jd. S. João & 768 & 88 & 455 \\
\hline EE PASTOR E VER ANTÔNIO GROTKOWSKY & Estr. de Itaberaba, 115 & Jd. N. Portugal & 1139 & 213 & 640 \\
\hline EMEI BRIG HAROLDO VELOSO & R. Ester, s/n & Jd. Maringá & 1068 & 92 & 684 \\
\hline EE PROF MAURÍCIO NAZAR & R. João Dias, s/n & Pq. S. Dumont & 1510 & 231 & 657 \\
\hline EMEI JD MUNIRA & R. 8,6 & Jd. Munira & 760 & 107 & 565 \\
\hline EMEIF JD PRIMAVERA & R. Asteróide, 27 & Pq. Primavera & 847 & 146 & 475 \\
\hline ALAN KARDEC & R. Ipacaetá, 12 & Jd. Pres. Dutra & 1131 & 137 & 807 \\
\hline EE PROFA ZILDA ROMERO P M DA SILVA & R. Mancarini, 1750 & Jd. Pres. Dutra & 1677 & 202 & 565 \\
\hline EE CACILDA CAÇAPAVA DE OLIVEIRA & R. Amélia Rodrigues, s/n & Jd. Pres. Dutra & 1047 & 156 & 856 \\
\hline EE PE BRUNO RICCO & Av. Rio Real, 379 & Jd. Pres. Dutra & 1183 & 211 & 546 \\
\hline EE PREF ANTÔNIO PATRICI & R. 7,350 & Inocoop & 891 & 96 & 660 \\
\hline EMEI WILSON PEREIRA DA SILVA & Av. São Paulo, s/n & Jd. M. Dirce & 613 & 74 & 527 \\
\hline EE MATO DAS COBRAS & Estr. Albino Martelo, 2500 & M. das Cobras & 30 & 6 & 500 \\
\hline EMEIEF PQ RESID BAMBI & R. 5,14 & Pq. Res. Bambi & 487 & 68 & 500 \\
\hline EE PQ ORQUIDIANA & Faz. Itaberaba & Água Azul & 157 & 4 & 500 \\
\hline EE (R) DR. JOSE LEME LOPES & R. Acapulco, s/n & Água Azul & 283 & 22 & 500 \\
\hline EE ITABERABA & Faz. Itaberaba & Água Azul & 35 & 7 & 500 \\
\hline EE DO BAIRRO TOME GONCALVES & Vasconcelândia & Vasconcelândia & 19 & 4 & 500 \\
\hline EE (R) SERAPHINA R MARTELO & Estr. Nazaré, Km 36 & Capelinha & 79 & 9 & 500 \\
\hline IGREJA DA TAPERA GRANDE & Tapera Grande & Tapera Grande & 151 & 21 & 500 \\
\hline R NOVA UNIAO & Vila União & V. União & 337 & 41 & 500 \\
\hline R EXISTENTE & Favela & Jd. Eucalipto & 227 & 71 & 500 \\
\hline DTCZ & & & 1556 & 238 & 500 \\
\hline
\end{tabular}

